Aus der Klinik für Psychosomatische Medizin und Psychotherapie

(Prof. Dr. med. C. Herrmann-Lingen)

der Medizinischen Fakultät der Universität Göttingen

\title{
Assoziationen zwischen der Einnahme oraler Kontrazeptiva und hämatologischen Parametern bei weiblichen Jugendlichen
}

\author{
INAUGURAL-DISSERTATION \\ zur Erlangung des Doktorgrades \\ für Zahnheilkunde \\ der Medizinischen Fakultät der \\ Georg-August-Universität zu Göttingen
}

vorgelegt von

Sabina Klara Lewandowski

aus

Freiburg im Breisgau

Göttingen 2020 
Dekan:

Betreuungsausschuss

Betreuer/in

Ko-Betreuer/in:

\section{Prüfungskommission}

Referent/in

Ko-Referent/in:

Drittreferent/in:
Prof. Dr. med. W. Brück

Prof. Dr. rer. nat. Dr. med. Dr. phil. T. Meyer

Prof. Dr. med. N. Miosge

Prof. Dr. Thomas Meyer

PD Dr. Julie Schanz

Prof. Dr. Rainer Mausberg

Datum der mündlichen Prüfung: 05.10.2020 
Hiermit erkläre ich, die Dissertation mit dem Titel "Assoziationen zwischen der Einnahme oraler Kontrazeptiva und hämatologischen Parametern bei weiblichen Jugendlichen" eigenständig angefertigt und keine anderen als die von mir angegebenen Quellen und Hilfsmittel verwendet zu haben.

Göttingen, den

(Unterschrift) 


\section{Inhalt}

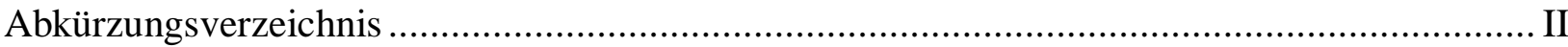

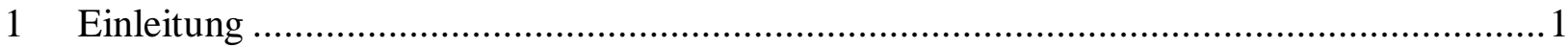

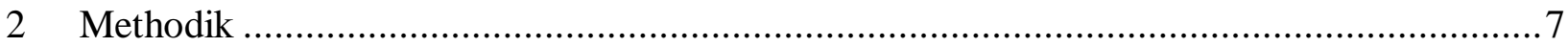

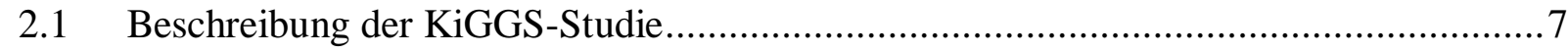

2.2 Bestimmung sozioökonomischer Parameter .......................................................

2.3 Bestimmung der Körpermaße......................................................................... 10

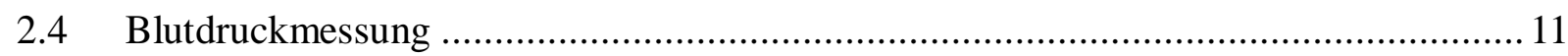

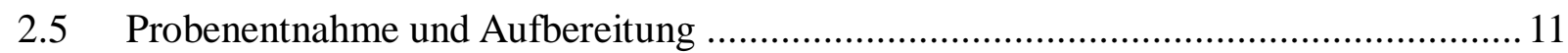

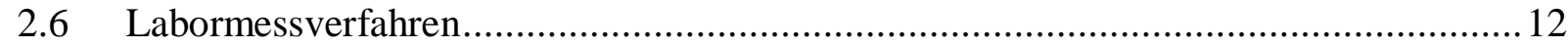

2.7 Bestimmung der Lebensqualität und der psychosozialen Stärken und

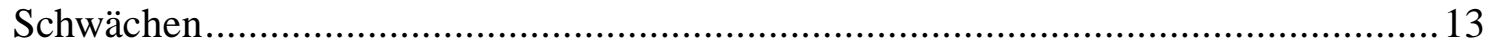

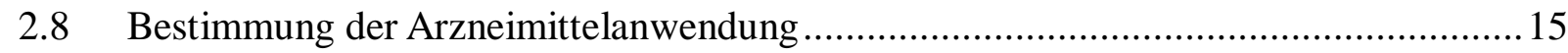

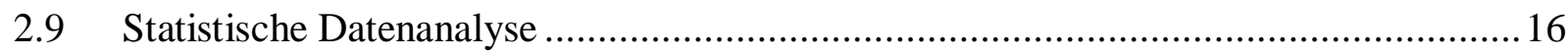

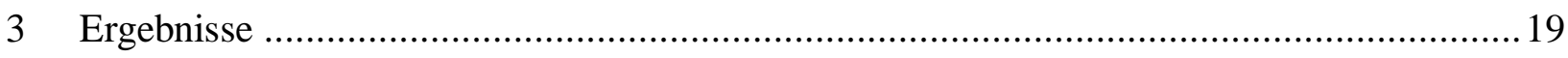

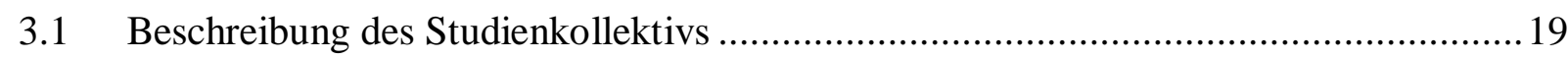

3.2 Prävalenz der Einnahme von Kontrazeptiva mit zunehmendem Lebensalter ................ 19

3.3 Vergleich der Anwenderinnen und Nichtanwenderinnen von Kontrazeptiva hinsichtlich klinisch-chemischer Parameter.

3.4 Unterschiede hinsichtlich der Anwendung oraler Kontrazeptiva innerhalb der

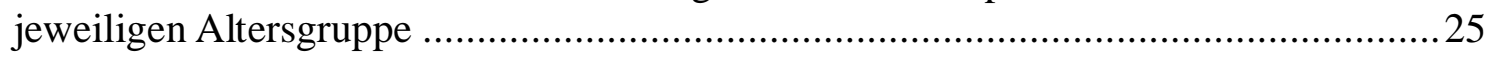

3.5 Bestimmung der Lebensqualität bei Anwenderinnen von Kontrazeptiva.....................28

3.6 Korrelation zwischen 25(OH)-Vitamin D und hämatologischen Parametern unter der Einnahme von Kontrazeptiva .............................................................. 30

3.7 Hämatologische Parameter als Prädiktoren für die Einnahme oraler

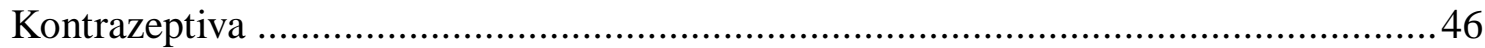

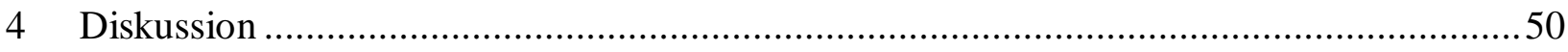

4.1 Signifikante Unterschiede hämatologischer Parameter bei Anwenderinnen gegenüber Nichtanwenderinnen von Kontrazeptiva ....................................... 50

4.2 Vergleich der Beobachtungen mit anderen Studien ...............................................52

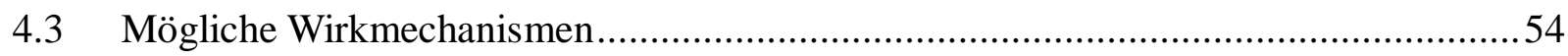

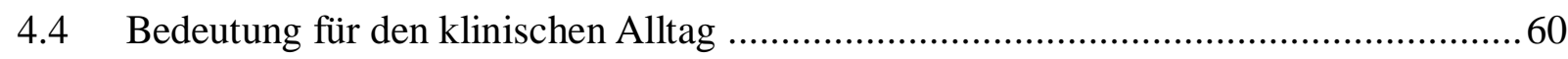

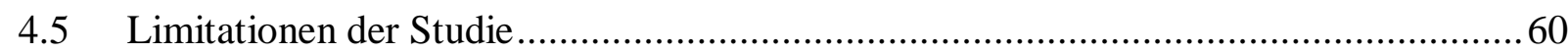

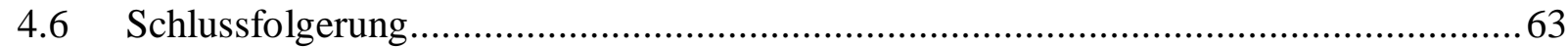

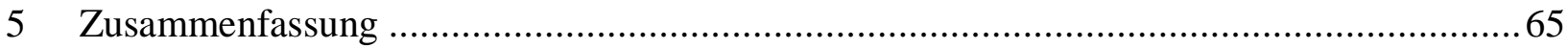

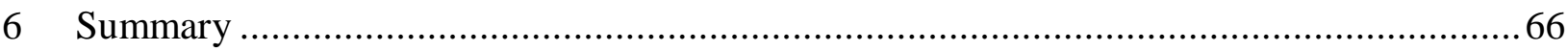

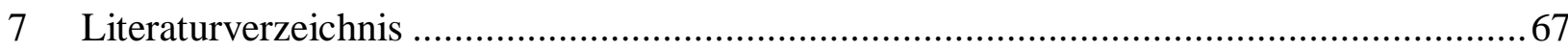




\section{Abkürzungsverzeichnis}

25(OH)D

AF-3

AR

ASC

ATC

Bcl-xL

BGS98

BMI

BMSC

$\mathrm{BZgA}$

Cas

CAPI

cGMP

CHOD

CLIA

CPG

c-Src

DGGG

DGKL

E2

ECLIA

EDC

EDTA

EGFR

Epo

EpoR

ER

ERK

ER- $\alpha$

$\mathrm{FSH}$

$\mathrm{GnRH}$
25-Hydroxy-Vitamin-D

activation function 3

Androgenrezeptor

Fettstammzellen

anatomisch-therapeutisch-chemisch

B-cell lymphoma-extra large

Bundesgesundheitssurvey 1998

Body Mass Index

Knochenmarkstammzellen

Bundeszentrale für gesundheitliche Aufklärung

Crk-associated substrate

computergestütztes Interview

zyklisches Guanosinmonophosphat

Cholesterinoxidase

Lumineszenz-Immunoassay

Plasma-Cholinphosphoglyceride

Tyrosinkinase

Deutsche Gesellschaft für Gynäkologie und Geburtshilfe

Deutsche Vereinte Gesellschaft für klinische Chemie und

Laboratoriumsmedizin

17- $\beta$-Estradiol

Elektrochemilumineszenz-Immunoassay

Estrogen-Dendrimer-Konjugat

Ethylendiamintetraessigsäure

epidermaler Wachstumsfaktor

Erythropoetin

Erythropoetinrezeptor

Estrogenrezeptor

Extracellular-signal-regulated-kinase

Estrogen- $\alpha$-Rezeptor

follikelstimulierendes Hormon

gonadotropin-releasing hormone 


\begin{tabular}{|c|c|}
\hline GPCR & G-Protein-gekoppelter Rezeptor \\
\hline GPER & Orphan-G-Protein-gekoppelter Rezeptor \\
\hline GPO & Glycerol-3-Phosphat-Oxidase \\
\hline GR & Glukokortikoidrezeptor \\
\hline Grb2 & growth factor receptor-bound 2 \\
\hline $\mathrm{Hb}$ & Hämoglobin \\
\hline HDL & bigh-density lipoprotein \\
\hline Hkt & Hämatokrit \\
\hline ICD & International Classification of Diseases \\
\hline ID & inhibierende Domäne \\
\hline IFCC & International Federation for Clinical Chemistry \\
\hline IGF & insulin-like growth factor \\
\hline KiGGS & Kinder- und Jugendgesundheitssurvey \\
\hline KINDL-R & Kinder-Lebensqualitätsfragebogen \\
\hline LCP & langkettige, mehrfach ungesättigte Fettsäuren \\
\hline LDL & low-density lipoprotein \\
\hline $\mathrm{LH}$ & luteinisierendes Hormon \\
\hline MAPK & mitogen-activated protein kinase \\
\hline MA-SCF & membranassoziierter Stammzellfaktor \\
\hline MC1P1 & modulatory calcineurin-interacting protein \\
\hline $\mathrm{MCH}$ & mittleres korpuskuläres Hämoglobin \\
\hline $\mathrm{MCHC}$ & mittlere korpuskuläre Hämoglobinkonzentration \\
\hline $\mathrm{MCV}$ & mittleres korpuskuläres Erythrozytenvolumen \\
\hline MEK & MAPK/ERK-Kinase \\
\hline MR-SCF & membranbegrenzter Stammzellfaktor \\
\hline MTA & medizinisch-technische Assistenz \\
\hline $\mathrm{NO}$ & Stickstoffmonooxid \\
\hline PAP-Methode & Phenol/Aminophenzazon/Peroxidase-Methode \\
\hline PI3K & Phosphoinositid-3-Kinase \\
\hline PR & Progesteronrezeptor \\
\hline Raf12 & Serin/Threonin-Kinase 12 \\
\hline Ras & rat sarcoma \\
\hline $\mathrm{RBC}$ & Erythrozytenanzahl \\
\hline RKI & Robert Koch-Institut \\
\hline RSK & ribosomale Proteinkinase \\
\hline
\end{tabular}


Strength and Difficulties Quentionnaire

Shc

SH containing

SMRT

silencing mediator for retinoid or thyroid-hormone receptor

SNAP

S-Nitroso-N-Acetylpenicillinamin

SOS

son of seventess

SPSS

Statistical Package for the Social Sciences

$\mathrm{SRC}$

steroid receptor coactivator

S-SCF

löslicher Stammzellfaktor

Stat5

Signaltransduktor und Aktivator der Transkription 5

TEG

Thromboelastographie

VDR

Vitamin D-Rezeptor

WHO

World Health Organization

WHI

Women's Health Initiative

ZUMA

Zentrum für Umfragen, Methoden und Analysen 


\section{Einleitung}

\section{Einleitung}

Orale hormonelle Kontrazeptiva, welche umgangssprachlich als "die Pille" bezeichnet werden, sind ein beliebtes Verhütungsmittel für ungewollte Schwangerschaften. In Deutschland verwenden nach Angaben der Deutschen Gesellschaft für Gynäkologie und Geburtshilfe (DGGG 2004) mehr als ein Drittel (38,5\%) der Frauen im reproduktionsfähigen Alter zwischen 14 und 44 orale Kontrazeptiva, was einer Anzahl von 6,6 Millionen Frauen entspricht. Im jugendlichen Alter von 14 bis 19 Jahren sind 1,5 Millionen, also 55\% der Mädchen, Anwenderinnen von oraler Kontrazeption (DGGG 2004). Orale Kontrazeptiva enthalten Hormone, welche in die Ovulation eingreifen. Die Follikelreifung und Ovulation werden bekanntermaßen über neuroendokrine Signalwege von Hypothalamus, Hypophyse und Ovar gesteuert. Die in Kontrazeptiva enthaltenen Hormone greifen zum einen in die Freisetzung des gonadotropin-releasing hormone $(\mathrm{GnRH})$ aus dem Hypothalamus ein. Zum anderen hemmen Kontrazeptiva die Sekretion von follikelstimulierendem Hormon (FSH) und luteinisierendem Hormon (LH) aus dem Hypophysenvorderlappen. Im Ovar hemmen diese Arzneimittel direkt die Steroidsynthese und Follikelreifung. Die in Kombinationspräparaten gleichzeitig vorkommenden Hormone Ethinylestradiol und Gestagen verhindern den LH-Peak, welcher physiologisch in der Mitte des Zyklus auftritt und die Ovulation auslöst (Kuhl und Taubert 1996). Ethinylestradiol selbst kann die Ovulation hemmen; allerdings wäre hierfür eine höhere Dosis als $50 \mu \mathrm{g}$ notwendig. In den Kombinationspräparaten sind niedrigere Dosierungen von Ethinylestradiol möglich, da hierbei die Gestagene für die ovulationshemmende Wirkung verantwortlich sind.

Das in den Kombinationspräparaten niedriger dosierte Estrogen bewirkt eine allgemeine Zykluskontrolle und verhindert Zwischenblutungen. Das Gestagen bewirkt unter anderem auch eine Verdickung des Zervixschleims, was den Spermien den Zugang zum Uterus erschwert. Des Weiteren hemmen Kontrazeptiva den Transport der Eizelle im Eileiter. Die estrogeninduzierte Proliferation des Endometriums wird durch das Gestagen gehemmt, sodass es früher zum Einsetzen der Sekretionsphase im Zyklus kommt. Sollte es trotz Einnahme des Kontrazeptiva-Präparats zur Ovulation und Fertilisation der Eizelle gekommen sein, würde die früher eintretende Sekretionsphase die Nidation des Embryos verhindern. Diese vielschichtigen Mechanismen machen Kontrazeptiva zu einem zuverlässigen und häufig verwendeten Verhütungsmittel (Kuhl und Taubert 1996; Keck und Tempfer 2003). Progesteron ist ein essentieller Regulator der menschlichen Reproduktion der Frau und übt vor allem einen Einfluss auf die weiblichen Geschlechtsorgane aus, wie dem Uterus, den Ovarien und der weiblichen Brustdrüse. Zudem spielt das Hormon Progesteron eine Rolle 


\section{Einleitung}

in weiteren Geweben, wie unter anderem dem kardiovaskulären System, dem Knochenstoffwechsel und dem zentralen Nervensystem (Graham und Clarke 1997; Graham und Clarke 2002; Li et al. 2004; Mote et al. 2007). Der Einfluss von Progesteron wird über den Progesteronrezeptor (PR) vermittelt, welcher mit Co-Regulatoren der Transkription interagiert (Lonard und O'Malley 2007; Lonard et al. 2007). Die Aktivierung des Progesteronrezeptors bewirkt bekanntermaßen eine Veränderung der Genexpression. Für den Progesteronrezeptor gibt es zwei Isoformen, die von dem gleichen Gen transkribiert werden. Die beiden Isoformen gleichen sich in ihrer Aminosäurensequenz und unterscheiden sich an ihrer Promotor-Bindestelle (Gronemeyer 1991; Gronemeyer et al. 1991; Kastner et al. 1990). Somit ist PR-A um 164 Aminosäuren am N-Terminus kürzer als PR-B (Kastner et al. 1990). In weiteren Untersuchungen wurde im PR-Gen eine dritte Promotor-Region identifiziert. Diese befindet sich im Bereich der Aminosäureposition 595. Die dritte Isoform PR-C übt keinen Einfluss auf die Transkription der Zelle aus, scheint aber ebenso wie PR-A und PRB Hormonliganden zu binden (Wei et al. 1990; Wei et al. 1996). Neuere Untersuchungen zeigen allerdings, dass PR-C nicht in vivo gebildet wird und keine Rolle in physiologischen Signalwegen spielt (Samalecos und Gellersen 2008).

Möglicherweise trägt die Activation Function 3 (AF-3)-Domäne der PR-B-Sequenz, welche nicht in der kürzeren PR-A-Sequenz vorkommt, zu der wesentlichen Wirkung von PR-B bei. Die AF-3-Domäne der PR-B-Sequenz unterdrückt die inhibierende Domäne (ID), welche jeweils in den PR-A- und PR-B-Molekülen vorkommt (Abdel-Hafiz et al. 2002; Tung et al. 2006). Weitere Studien lassen vermuten, dass beide Rezeptoren ihre Konformation innerhalb der Zelle ändern können (Bain et al. 2000; Bain et al. 2001) und dass die unterschiedlichen Effekte dadurch resultieren, dass PR-A mit anderen Co-Regulatoren agiert als die PR-BIsoform (Tetel et al. 1999). Diese Vermutung wird dadurch bestätigt, dass PR-A in anderen Studien eine höhere Affinität in Anwesenheit von PR-Antagonisten zu dem Co-Repressor silencing mediator for retinoid or thyroid-hormone receptors (SMRT) zeigte als PR-B. Hingegen interagierte PR-B affiner im Sinne einer agonistischen Bindung an die Co-Aktivatoren steroid receptor coactivator (SRC)-1 und SRC-2 als die PR-A-Isoform (Giangrande et al. 2000; Heneghan et al. 2007; Molenda-Figueira et al. 2008).

Um die unterschiedlichen Funktionen der Rezeptoren besser verstehen zu können, wurde deren Dimerisierung betrachtet. PR-A und PR-B können Homodimere und Heterodimere bilden, sodass drei Kombinationen möglich sind. In menschlichen Zellen findet gleichermaßen eine Expression von PR-A und PR-B statt (Mote et al. 1999; Mote et al. 2002; Mote et al. 2007). Die Expression gleicher Mengen von beiden Rezeptoren lässt vermuten, dass beim Menschen die heterodimere Form dominiert. 


\section{Einleitung}

Obwohl PR-A und PR-B gleichermaßen exprimiert werden, gibt es zyklische Unterschiede der Verteilung im Brustdrüsengewebe und im Endometrium. Während der sekretorischen Phase des Menstruationszyklus liegt vermehrt Progesteron vor und es findet eine verminderte PR-Expression in den Zellen statt. Hierbei wird die Expression von PR-A gehemmt, was zu dem Zeitpunkt der sekretorischen Phase zu einem vorübergehenden Vorherrschen von PR-B führt (Mote et al. 1999). Untersuchungen an Mäusen zeigen, dass PR-B vorwiegend an der Entwicklung der weiblichen Brust beteiligt ist (Mulac-Jericevic et al. 2003). PR-A liegt primär während der Entwicklung des Uterus sowie der Reproduktion vor (MulacJericevic et al. 2000). Allgemein ist die PR-Expression in unterschiedlichen Geweben zu finden, wie Uterus, Brustdrüsengewebe, Gehirn, Pankreas, Knochen, Ovarien und Hoden sowie dem unteren Urinaltrakt (Bland 2000; Graham und Clarke 1997; Graham und Clarke 2002; Han et al. 2009; Ozawa 2005; Tincello et al. 2009).

Die ubiquitäre Expression des Progesteronrezeptors in den genannten unterschiedlichen Geweben lässt weitreichende physiologische Effekte von Progesteron in unterschiedlichen Organsystemen vermuten. PR-A reguliert eine Vielzahl von nuklearen Rezeptoren, welche durch Glukokortikoide, Mineralokortikoide, Androgene und Estrogene stimuliert werden können (McDonnell und Goldman 1994; Tung et al. 1993; Vegeto et al. 1993; Wen et al. 1994). Durch Transfektionsexperimente mit Expression von markierten Rezeptoren konnte gezeigt werden, dass diese Zellkernaggregate bilden, sobald sie mit einem Liganden in Verbindung treten. Zu den positiv getesteten Rezeptoren gehören der Estrogen- $\alpha$-Rezeptor (ER- $\alpha$; Htun et al. 1999), der Androgenrezeptor (AR; Tyagi et al. 2000), der Glukokortikoidrezeptor (GR; van Steensel et al. 1995) sowie der Mineralokortikoidrezeptor (MR; Fejes-Toth et al. 1998; Htun et al. 1996; Htun et al. 1999; Tyagi et al. 2000). Zusätzlich zu den bereits diskutierten ligandenaktivierten Transkriptionseffekten kann das Hormon über einen sekundären Messenger Signalwege aktivieren (Lange et al. 1998; Leonhardt et al. 2003; Nilsen und Brinton 2002; Nilsen und Brinton 2003). Die ligandenunabhängige Aktivierung des Progesteronrezeptors kann zelltypspezifisch und promotorspezifisch erfolgen, was auf einen durch das Zytoplasma vermittelten oder auch membrangenerierten Signalweg schlieBen lässt (Daniel et al. 2007; Jacobsen et al. 2005).

Ein weiteres Hormon, Estrogen, reguliert ebenfalls den weiblichen Zyklus. Estrogen kann an den zwei bekannten Estrogenrezeptoren ER- $\alpha$ und ER- $\beta$, binden und darüber einen Einfluss auf die Genexpression ausüben. Infolge der ligandengesteuerten ER-Aktivierung binden Co-Aktivatoren und Co-Repressoren an die DNA und nehmen somit Einfluss auf die Transkription (Murphy und Steenbergen 2014). Es wird vermutet, dass einige Gene ein Estrogen-Response-Element besitzen. Des Weiteren können unterschiedliche Signalwege 


\section{Einleitung}

über den Estrogenrezeptor aktiviert werden, welche die Genexpression verändern können. Eine Bindung von ER- $\alpha$ an der Plasmamembran führt zu einer Aktivierung des PI3-KinaseSignals. Es wurde gezeigt, dass Estrogen an den Orphan-G-Protein-gekoppelten Rezeptor (GPR30, auch bekannt als GPER) bindet, was zu der Aktivierung von Signalwegen wie dem PI3-Kinase-Signalweg und dem Extracellular-signal-regulated-kinases (ERK)-Signalweg führt (Deschamps et al. 2009; Murphy und Steenbergen 2014; Revankar et al. 2005). Durch die plasmamembranvermittelte Aktivierung von Signalwegen oder auch die Aktivierung von ERunabhängigen Signalen kann es zu einer veränderten Genexpression kommen. ER kann zum einen ligandenunabhängig durch Phosphorylierung aktiviert werden, zum anderen durch die Veränderung der Zusammensetzung an Co-Aktivatoren und an Co-Repressoren. Estrogen reguliert nicht nur die Expression von mRNA, sondern auch von miRNA. ER- $\alpha$ bewirkt eine Hochregulierung von miR-203, welches an der Gefäßproliferation beteiligt ist (Zhao et al. 2012). Durch den veränderten Proteinspiegel wird letztendlich die Zellfunktion beeinflusst. Es wurde die Expression einer Reihe von Genen unter Estrogeneinfluss untersucht und eine Veränderung der folgenden Proteine festgestellt, PGC-1 $\alpha$ (Hsieh et al. 2005), Connexin 43 (Cx43; Yu et al. 1994; Chung et al. 2004), Adeninnukleotid-Translokator (Too et al. 1999), Hitzeschockproteine (Voss et al. 2003) und ein Inhibitor von Calcineurin modulatory calcineurin-interacting protein (MC1P1; Pedram et al. 2008). Weitere Untersuchungen zeigen, dass ER- $\alpha$ und ER- $\beta$ die Genexpression in entgegengesetzter Richtung beeinflussen. So kann ER$\alpha$ eine hemmende Wirkung haben, während ER- $\beta$ die entsprechende Genexpression aktiviert (Barros et al. 2006; Lindberg et al. 2003; Tsutsumi et al. 2008). Beispielsweise bewirkt ER- $\alpha$ im Muskel eine Erhöhung des GLUT4-Spiegels, während ER- $\beta$ die Expression von GLUT4 unterdrückt (Barros et al. 2006). Schlussfolgernd kann Estrogen in Abhängigkeit des relativen Anteils von ER- $\alpha$ und ER- $\beta$ die Genexpression differenziert beeinflussen.

Diese unterschiedliche Genregulation von ER- $\alpha$ und ER- $\beta$ lässt sich auf die Unterschiede der Bindung der Co-Aktivatoren und Co-Repressoren an beiden Rezeptoren zurückführen. Estrogen wirkt in Abhängigkeit von Co-Faktoren regulierend, beispielsweise erhöht es den Progesteronrezeptorgehalt bei Frauen, während Estrogen bei Männern eine Senkung des Progesteronrezeptoranteils bewirkt (Kararigas et al. 2012). In Untersuchungen zeigten weibliche Probandinnen höhere Phosphorylierungsgrade von pyruvat debydrogenase und alphaketoglutarat dehydrogenase als Männer. Die erhöhte Phosphorylierung bei Frauen lässt auf eine estrogenabhängige Aktivierung des PI3-Kinase-Signalwegs schließen (Yan et al. 2004). Zusammengefasst kann Estrogen über seine intrazellulären Rezeptoren ER- $\alpha$ und ER- $\beta$ oder über die Aktivierung von Signalwegen (Deschamps et al. 2009; Simoncini et al. 2000) zu einer veränderten Genexpression führen. 


\section{Einleitung}

Studienergebnisse zeigen, dass Frauen vor der Menopause im Vergleich zu Männern seltener an kardiovaskulären Erkrankungen leiden, während die Häufigkeit der kardiovaskulären Erkrankungen bei Frauen nach der Menopause ansteigt. Es wird vermutet, dass Estrogen für die Stoffwechselunterschiede zwischen Männern und Frauen mit verantwortlich ist. Es konnte im PET-Versuch festgestellt werden, dass Frauen im Vergleich zu Männern einen erhöhten Fettsäuremetabolismus aufweisen (Lyons et al. 2013). Außerdem konnten nach Einschränkung der Kalorienzufuhr Unterschiede im Triglyceridspiegel von Frauen und Männern festgestellt werden (Yan et al. 2004). Estrogen zeigt eine zelltypabhängig unterschiedliche Wirkung. In der Skelettmuskulatur bewirkt Estrogen eine Zunahme der von Insulin stimulierten Glukoseaufnahme (Gorres et al. 2011) und in der Herzmuskulatur fördert ER- $\alpha$ ebenfalls die Glukoseaufnahme (Arias-Loza et al. 2012). Die Women's Health Initiative (WHI) stellte fest, dass eine Hormonersatztherapie zu einer Verbesserung der Insulinsensitivität bei Frauen führt (Margolis et al. 2004). In der Plasmamembran lokalisierte Estrogenrezeptoren sind wichtig für die Kardioprotektion. In vaskulären Zellen bietet der ER- $\alpha$ einen gewissen Schutz vor Verletzungen (Pare et al. 2002), während der ER- $\beta$ die Vasodilatation reguliert (Zhu et al. 2002).

Bei der Behandlung eines Langendorff-perfundierten Herzens mit einem GPR30-Agonisten G-1 kam es zu einer Verringerung des Ischämie/Reperfusions-Schadens (Bopassa et al. 2010; Deschamps et al. 2009). Unter Verwendung eines Estrogen-Dendrimer-Konjugates (EDC), welches eine nukleare Aktivität ausschließt und nur zytoplasmatisch lokalisiert ist, konnte ebenso die estrogeninduzierte Reduktion von Gefäßverletzungen nachgewiesen werden (Chambliss et al. 2010). Die Wirkung von Estrogen ist abhängig von dem Anteil der jeweiligen Rezeptoren ER- $\alpha$ und ER- $\beta$ sowie der zelltyp-spezifischen Expression von CoRepressoren und Co-Aktivatoren. Vermutlich wird die Antwort der Zelle auf Estrogen ebenso durch den GRP30-Spiegel beeinflusst. Die exprimierte Menge an Estrogenrezeptoren und der beteiligten Co-Regulatoren kann sich mit dem Auftreten von Erkrankungen und bei zunehmendem Alter in beiden Geschlechtern ändern.

Das Ziel dieser Arbeit war es, anhand der Daten aus dem Kinder- und Jugendgesundheitssurvey (KiGGS) zu untersuchen, welchen Einfluss die Einnahme oraler Kontrazeptiva bei jugendlichen Mädchen im Alter von 13 bis 17 Jahren auf klinisch-chemische Blutserumparameter hat. Mit der Einnahme von oralen Kontrazeptiva werden Sexualhormone in pharmakologisch relevanten Mengen aufgenommen und somit wird intentional in den Menstruationszyklus interveniert. Aus der Literatur ist bereits ein Einfluss der Sexualhormone auf unterschiedliche Gewebearten beschrieben worden. Damit ergibt sich die Frage, welche klinisch messbaren Parameter durch die hormonale Empfängnisverhütung signifikant ver- 


\section{Einleitung}

ändert werden. Mit der Einnahme von Kontrazeptiva soll laut früheren epidemiologischen Studien das Risiko von kardiovaskulären Erkrankungen ansteigen. Bei den Anwenderinnen oraler Kontrazeptiva konnte ein erhöhtes Risiko für das Auftreten von venösen Thromboembolien, ischämischen und hämorrhagischen Schlaganfällen und Myokardinfarkten festgestellt werden, doch existieren hierzu auch widersprüchliche Studiendaten (Bloemenkamp et al. 1995; Croft und Hannaford 1989; Petitti et al. 1996; WHO 1995a, WHO 1995b; WHO 1996a; WHO 1996b; WHO 1997).

Die Frage, ob ein Zusammenhang zwischen hämatologischen Parametern und der Einnahme oraler hormoneller Verhütungsmittel besteht, könnte also klinisch relevant sein. Sexualhormone binden, wie erwähnt an spezifische Rezeptoren im Zytosol und üben ihren Einfluss auf die Transkription über die Bindung an Promotoren im Zellkern aus (Murphy und Steenbergen 2014; Scarpin et al. 2009). Verschiedene Faktoren wie Co-Aktivatoren und CoRepressoren spielen dabei eine Rolle und lösen indirekte Signalwege aus (Murphy und Steenbergen 2014). Nicht im Einzelnen geklärt ist, ob Sexualhormone über einen indirekten Signalweg wie dem ERK-Signalweg oder über nicht homologe Trankriptionsfaktoren, wie beispielweise dem Signaltransduktor und Aktivator der Transkription 5 (Stat5), einen Einfluss auf die Proliferation von Zellen ausüben. Können täglich eingenommene Kontrazeptiva möglicherweise die Proliferation von Proerythroblasten oder Erythroblasten modulieren und somit die Erythropoese beeinflussen und wenn ja, über welche Mechanismen nehmen sie Einfluss auf die Hämatopoese? Diese interessanten Fragen sind noch weitgehend unbeantwortet und harren bislang weitgehend einer experimentellen Untersuchung. In dieser Arbeit soll deshalb hypothesengenerierend mithilfe eines epidemiologischen Ansatzes unter Verwendung von Daten aus der KiGGS-Studie nach Assoziationen zwischen der Anwendung von Kontrazeptiva und hämatologischen Parametern bei jugendlichen Anwenderinnen gefahndet werden. Dabei wird der soziodemographische Hintergrund der Probandinnen in die Analyse miteinbezogen. 


\section{Methodik}

\subsection{Beschreibung der KiGGS-Studie}

Der Kinder- und Jugendsurvey (KiGGS-Studie) ist eine für Deutschland repräsentative nationale Studie, welche von Mai 2003 bis Mai 2007 vom Robert Koch-Institut (RKI) erhoben wurde. In der bundesweiten Studie wurde die Gesundheit von Kindern und Jugendlichen im Alter von 0 bis 17 Jahren untersucht. Ziel dieser Studie war es, die für Deutschland bevölkerungsrepräsentativen Daten von den Kindern und Jugendlichen in den Altersgruppen 0 bis $17 \mathrm{zu}$ erheben (Kamtsiuris et al. 2007). Das Bundesministerium für Bildung und Forschung sowie das Bundesministerium für Gesundheit unterstützten die Studie mit finanziellen Mitteln. Zudem finanzierte sich ein Teil der Studie aus einem Eigenanteil des RKIs (Kurth 2007).

Aus insgesamt 167 Städten und Gemeinden wurden die Daten von 17.641 Kindern und Jugendlichen erhoben (Hölling et al. 2012). Um die Auswahl der Probanden und deren Wohnorte kümmerte sich das Zentrum für Umfragen, Methoden und Analysen (ZUMA) in Mannheim. Die finale Auswahl wurde mithilfe der Klassifikation nach der BIK Aschpurwis und Behrens GmbH für Regionen getroffen (Hölling et al. 2007).

Um das Ziel einer bevölkerungsrepräsentativen Studie zu erfüllen, wurde zunächst eine Teilnehmerzahl von ca. 1000 Mädchen und Jungen für jede Altersklasse von 0 bis 17 Jahren angestrebt (Kurt 2007). Die Studie hatte einen hohen Stichprobenumfang. Um diesem erstrebten Wert der Teilnehmerzahl von insgesamt ca. 18.000 nahe zu kommen, fand die Studie in Städten und Gemeinden unterschiedlicher Größe statt. Dort wurden 26.899 Kinder und Jugendliche zur Teilnahme eingeladen, wobei die Teilnehmerquote bei 66,6\% lag und somit einen Datensatz von 8656 Mädchen und 8985 Jungen ergab (Kamtsiuris et al. 2007). Es wurden ebenfalls die Nichtteilnehmer erfasst, um die Repräsentativität der Studie durch die Vergleichbarkeit von Teilnehmern und Nichtteilnehmern zu beurteilen. Dies erfolgte mithilfe eines kurzen Fragebogens, welcher sowohl gesundheitsbezogene als auch soziodemographische Merkmale erfasste. Zudem erlaubte die Einteilung in die drei Regionen Ost- und Westdeutschland sowie Berlin einen für die Region repräsentativen Vergleich (Kamtsiuris et al. 2007a).

Die KiGGS-Studie wurde in einem modularen Studiendesign gestaltet. Bereits beim Bundesgesundheitssurvey 1998 (BGS98) erwies sich das modulare Studiendesign als gut geeignet, sodass die KiGGS-Studie ebenfalls in Module aufgebaut wurde (Kurth 2007). Die Gestaltung in Modulen brachte einige Vorteile. Zum einen ergaben sich finanzielle Vorteile und 


\section{Methodik}

zum anderen auch Vorteile in der organisatorischen Gestaltung. Die Module waren in ein Umweltmodul, das Motorik-Modul, ein Modul der psychischen Gesundheit, ein Jod-Monitoring-Modul, das Ernährungsmodul und das länderspezifische Modul Schleswig-Holstein eingeteilt (Kurth 2007).

Um die Altersgruppen 0 bis $17 \mathrm{zu}$ untersuchen, wurden gesundheitsbezogene Fragebögen eingesetzt. Hierfür wurden sowohl Eltern als auch Kinder befragt. In den Altersgruppen 0 bis 2 Jahre, 3 bis 6 Jahre, 7 bis 10 Jahre wurden nur die Eltern befragt. In den Altersgruppen 11 bis 13 Jahre kam ein Kinderfragebogen hinzu und bei den 14- bis 17- Jährigen ein Jugendfragebogen. Bei den 11- bis 17-Jährigen wurden die Fragebögen ebenfalls von den Eltern sowie den Studienteilnehmern ausgefüllt. Inhalt der selbstauszufüllenden Fragebögen waren die Themen „seelische Gesundheit und Probleme“, „soziale Gesundheit und Lebensbedingungen“, „körperliche Gesundheit und die medizinische Versorgung“ (Hölling et al. 2012). Die Kinder und Jugendlichen wurden zudem ärztlich untersucht. Dies beinhaltete eine ärztliche Befragung sowie eine umfassende körperliche Untersuchung, darüber hinaus wurden verschiedene Laborparameter erfasst (Hölling et al. 2007). Die ärztlichen Interviews erfolgten mithilfe von computergestützten, standardisierten Fragebögen zu speziellen Krankheiten, der Medikamenteneinnahme der letzten sieben Tage und dem aktuellen Impfstatus. Objektive Messdaten zum Gesundheitszustand der Kinder und Jugendlichen ergaben sich auch aus den Ergebnissen der körperlichen Untersuchung (Hölling et al. 2007).

Ein Team aus fünf Mitarbeitern führte diese Datenerhebung in jedem Studienzentrum aus. Das Team setzte sich zusammen aus einem leitenden pädiatrischen Arzt, einem Zentrumsinterviewer, einem Umweltinterviewer, einer Kinderkrankenschwester und einem medizinisch-technischem Assistenten (MTA), welche jeweils für ihren eigenen fachspezifischen Aufgabenbereich zuständig waren. Der Zentrumsinterviewer begrüßte die Probanden mit ihren Erziehungsberechtigten und klärte diese auf. Der pädiatrische Arzt führte die ärztlichen Aufgaben einschließlich der körperlichen Untersuchung durch. Die Kinderkrankenschwester untersuchte die Kinder anthropometrisch, während die MTA die Laborproben erhob und die anschließende Auswertung dieser Proben vornahm. Zuletzt führte der Umweltinterviewer die für ihn fachspezifischen, umweltbezogenen Unter-suchungen durch (Hölling et al. 2007). Diese bundesweit repräsentative Querschnittsstudie wurde durch ein sehr umfangreiches Qualitätsmanagement gesichert. Um die Durchführ-barkeit der Studie zu prüfen, überwachte das Bremer Institut für Prävention und Sozial-medizin die externe Qualitätssicherung. Datenrechtliche und ethische Grundsätze wurden durch die Sicherstellung der Daten durch den Bundesbeauftragten gewahrt. Der wissenschaftliche Beirat des RKIs führte im Rahmen der Planung und Vorbereitung der KiGGS-Studie vorab einen Testlauf durch. 
Methodik

Dieser Test wurde dann in den Jahren 2001 und 2002 mit 1630 Kindern und deren Eltern erfolgreich durchgeführt (Kurth 2007). Ein weiterer Schritt der Qualitätssicherung war die Prüfung der Fragebögen. Das ZUMA testete die Fragebögen auf Verständlichkeit, indem es prüfte, ab welchem Alter die Kinder fähig waren diesen Fragebogen selbstständig beantworten zu können. Zudem prüfte es die Zeit, die für das Ausfüllen des Fragebogens nötig war. Im Durchschnitt dauerte ein Befragungsablauf zwei Stunden und im Anschluss konnten die Teilnehmer an einem vertiefenden Modul teilnehmen. Die Fragebögen wurden von den Teilnehmern bewertet. Die durch die ZUMA ausgeführten Prüfungen zeigten eine hohe Validität und Akzeptanz des Fragebogens bei den Teilnehmern und somit wurde der Fragebogen als geeignetes Untersuchungsmittel für die KiGGS-Studie bewertet (Kurth 2007). So konnten die Daten zur Kinder- und Jugendgesundheit einschließlich der Angaben zum physischen und psychischen Wohlbefinden mit der erhofften Vollständigkeit erhoben werden.

\subsection{Bestimmung sozioökonomischer Parameter}

Soziodemographische Merkmale wurden mit einem hierfür entworfenen Fragebogen ermittelt (Hölling et al. 2007). Hierzu zählten unter anderem die Zugehörigkeit zur sozialen Schicht, der Schultyp und der Migrantenstatus (Lange et al. 2007). Die Kategorie Schultyp inklusive Schulabschluss lehnte sich an das deutsche Schulsystem an. Unter dem Schultyp wurden die Bildungseinrichtungen „Grundschule“, „Orientierungsstufe“, „Gymnasium“, „Realschule“, „Hauptschule“, „Gesamtschule“ und „Förderschule/Sonderschule“ erfasst (Lehmann et al. 1997).

Die sozioökonomische Schicht wurde durch drei ausgewählte Kategorien bestimmt. Diese wurden nach Angabe der Eltern zu der Schulbildung und beruflichen Qualifikation, der beruflichen Stellung und schließlich dem Nettohaushaltseinkommen aller Haushaltsmitglieder nach Abzug von Steuern und Sozialabgaben in Anlehnung an Winkler bestimmt (Lange et al. 2007). Die einzelnen Kategorien wurden einem Punktesystem zugeteilt, welches von 1 bis 7 reichte. In einigen Fällen fehlten Daten einer Kategorie. Mithilfe eines Berechnungsalgorithmus wurden die fehlenden Daten geschätzt. Da es sich um drei Kategorien handelte, konnte durch die Addition der Punkte aus den drei Kategorien eine Gesamtpunktzahl von 3 bis 21 Punkten erreicht werden (Winkler und Stolzenberg 1999). Die Gesamtpunktzahl wurde anschließend in drei sozioökonomische Gruppen eingeteilt mit den Punktwerten 1 bis 3. Ein niedriger Sozialstatus mit einer Gesamtpunktzahl von 3 bis 8 


\section{Methodik}

Punkten hatte den Punktwert 1. Ein mittlerer Sozialstatus wurde mit den Gesamtpunkten von 9 bis 14 zugeteilt und hatte den Punktwert 2. Zuletzt blieb der hohe Sozialstatus mit einer Punktzahl von 3, welcher ab einer Gesamtpunktzahl von 15 bis maximal 21 zugeteilt war. Es wurde zwischen der Punktzahl der Mutter und des Vaters differenziert und den Probanden die Punktzahl des Elternteils zugeordnet, welche höher war. Bei getrenntlebenden Eltern wurde die Punktzahl des Elternteils ausgewählt, mit dem das Kind einen längeren Zeitraum zusammenlebte (Lange et al. 2007).

Für den Migrationsstatus wurden die Probanden in zwei Gruppen mit oder ohne Migrationshintergrund eingeteilt. Als Migrant galten Kinder und Jugendliche, welche nicht aus Deutschland kamen. Des Weiteren galt ein Proband als Migrant, wenn beide Eltern oder ein Elternteil, also die Mutter oder der Vater, nicht in Deutschland geboren waren, sondern zugewandert waren. Zudem galten Probanden mit Eltern ohne deutsche Staatsangehörigkeit als Migranten (Schenk et al. 2007).

\subsection{Bestimmung der Körpermaße}

Um anthropometrische Messungen auszuführen, wurden ausgewählte Parameter festgelegt. Für die Probanden im Alter 0 bis 17 Jahre wurden die Körpergröße in Meter und das Körpergewicht in Kilogramm erfasst. Die Größe wurde ohne Schuhe im Stehen mit einem portablen Stadiometer der Firma Holtain Ltd., Crosswell, UK gemessen. Das Gewicht wurde bei den Kindern ab dem zweiten Lebensjahr mit einer elektronischen Waage (Typ SECA) bestimmt. (Stolzenberg et al. 2007). In der Altersgruppe von 6 bis 17 Jahre wurden zudem der Kopfumfang, die Oberarmlänge sowie die Hautfaltendicke am Rücken und am Oberarm gemessen. Bei der Altersgruppe 11 bis 17 Jahre wurden die Ellenbogenbreite und der Hüftund Taillenumfang erfasst (Stolzenberg et al. 2007). Mit einem flexiblen, nicht elastischen Maßband (Firma Siber Hegner, Zürich, Schweiz) konnte der Körperumfang bestimmt werden. Für den Taillenumfang wurde das Maßband horizontal zwischen dem höchsten Punkt des Darmbeinkamms und der letzten Rippe angelegt und an der schmalsten Stelle gemessen. Der Hüftumfang wurde ebenfalls horizontal gemessen, indem der Hüftumfang an der breitesten Stelle des Gesäßes gemessen wurde (Stolzenberg et al. 2007). Mit der Messung der Hautfaltendicke am Rücken und Oberarm wurde der Körperfettanteil bestimmt. Diese Messung erfolgte mit einem Harpenden-Caliper von Holtain Ltd (Stolzenberg et al. 2007). Am Rücken wurde die Hautdicke subskapulär im $45^{\circ}$ Winkel zur Vertikalachse und am Oberarm parallel zur Längsachse des Arms im Bereich der Trizepsmitte gemessen. Aus 
Methodik

diesen Messwerten wurde der Body Mass Index (BMI), die waist to height-ratio und die waist to hip-ratio bestimmt (Stolzenberg et al. 2007).

\subsection{Blutdruckmessung}

Die Blutdruck- und Pulsmessung erfolgte bei den Probanden im Alter von 3 bis 17 Jahren (Neuhauser und Thamm 2007). Die Messung erfolgte oszillometrisch mithilfe einer automatischen Datascope Accutorr Plus und Datascope-Blutdruckmanchette. Für die Messung konnte eine von vier Manchettengrößen ausgewählt werden. Diese wurde am Oberarm von der Axilla bis zur Ellenbogenbeuge angelegt, um diese mindestens um zwei Drittel des Oberarms zu bedecken. Die Markierung der Blutdruckmanschette wurde zur Arteria brachialis ausgerichtet. Die Probandin bzw. der Proband befand sich für die Messung in sitzender Position, mit dem rechten Oberarm frei und das Ellenbogengelenk auf Herzhöhe gelagert (Neuhauser und Thamm 2007). In dieser Lage wurden der systolische, diastolische und arterielle Mitteldruck sowie die Pulsfrequenz ermittelt. Der Blutdruck wurde zweimal gemessen. Vor der ersten Messung wurde eine kurze Ruhezeit von fünf Minuten eingehalten. Vor der zweiten Messung wurde eine Ruhepause von mindestens zwei Minuten gehalten. Aus den beiden Messungen konnte ein gemittelter Wert errechnet werden (Neuhauser und Thamm 2007).

\subsection{Probenentnahme und Aufbereitung}

Um eine hohe Genauigkeit der Ergebnisse zu erzielen, standen die Laboranalysen unter einer strengen internen und externen Qualitätssicherung. Im Gegensatz zu vorangegangenen Studien des RKIs wurden die KiGGS-Proben in externen Standorten bearbeitet, was die genaue Einhaltung von Richtlinien erforderte (Thierfelder et al. 2002). Unter anderem wurden die Messungen im Labor des Universitätsklinikum des Deutschen Herzzentrums in Berlin und dem epidemiologischen Forschungsinstitut des RKIs ausgeführt. Es wurde mit standardisierten Protokollen gearbeitet, was die Präanalytik der Proben, deren Transport und das eigentliche biochemische Analyseverfahren miteinbezog (Dortschy et al. 2009). Zudem wurde ein Laborvergleich im Rahmen einer Konsistenzprüfung durchgeführt und in manchen Fällen wurden Regressionsgeraden ermittelt (Thierfelder et al. 2002; Thierfelder et al. 2008). Die Blutentnahme erfolgte bei den Probanden eine halbe Stunde nach der Blutdruckmessung im Sitzen. Es wurde peripheres venöses Vollblut und Blutserum entnommen, 


\section{Methodik}

welches mit Ethylendiamintetraessigsäure (EDTA) als Antikoagulanz versetzt wurde. Die Zeit der letzten kalorischen Nahrungsaufnahme lag durchschnittlich zwei Stunden vor der Entnahme und wurde bei den Vollblutproben dokumentiert (Dortschy et al. 2009). Diese wurden zunächst in den Entnahmeröhrchen bei $4{ }^{\circ} \mathrm{C}$ gelagert. Für die Seren von älteren Kindern wurden speziell beschichtete EDTA-Röhrchen in einem Vakuumsystem verwendet (Dortschy et al. 2009). Die Blutproben wurden innerhalb von 45 min bearbeitet, indem sie koaguliert und anschließend zentrifugiert wurden, um daraus Serum zu erhalten. Ein Aliquot von $500 \mu \mathrm{l}$ der Serumproben wurde bei $-50{ }^{\circ} \mathrm{C}$ gelagert (Hölling et al. 2007).

\subsection{Labormessverfahren}

Die Laborparameter wurden anhand von bestimmten Gesundheitsrisikofaktoren ausgewählt und aus den gewonnenen Blutproben bestimmt. Eines dieser Laborparameter war Vitamin D (Thierfelder et al. 2002). Das im Serum enthaltene 25-Hydroxy-Vitamin-D eignete sich gut als Indikator für die Vitamin D-Konzentration der Probanden, da es eine hohe Konzentration im Serum aufweist und zudem eine lange Halbwertszeit besitzt (Hart et al. 2006). In der KiGGS-Studie wurde 25-Hydroxy-Vitamin-D (25(OH)D) quantitativ über ein automatisiertes Verfahren basierend auf einem Luminenszenz-Immunoassay (CLIA, DiaSorin) bestimmt (Souberbielle et al. 2005; Wallace et al. 2010).

Folgende hämatologische Parameter wurden mit dem automatisierten Analysegerät Abott Cell-Dyn 3500 (Abott diagnostics) bestimmt: die Erythrozytenzahl (RBC) [10\% $/ \mathrm{ml}$, das Hämoglobin $(\mathrm{Hb})[\mathrm{g} / \mathrm{dl}]$, der Hämatokrit $(\mathrm{Hct})[\%]$, der mittlere korpuskuläre Hämoglobingehalt $(\mathrm{MCH})[\mathrm{pg}]$, das mittlere korpuskuläre Erythrozytenvolumen (MCV) [fl] und die mittlere korpuskuläre Hämoglobinkonzentration (MCHC) $[\mathrm{g} / \mathrm{dl}]$. Mit dem automatisierten Gerät Hitachi 917 für biochemische Analysen wurde Eisen [ $\mu \mathrm{mol} / 1]$ mit der FerrozineMethode bestimmt, welche eine Deprotonierung nicht benötigte (Roche, Mannheim). Der lösliche Transferrinrezeptor (sTfR) [mg/l] wurde mithilfe eines verbesserten Latexagglutination-Assays mit dem BNA-Nephelometer (Behring, Marburg) gemessen. Mit dem Elecsys-E-2010-Gerät wurden mithilfe eines Elektrochemilumineszenz-Immunoassays (ECLIA) die Serumkonzentrationen von Ferritin [ $\mu \mathrm{g} / \mathrm{l}]$ und Vitamin $\mathrm{B}_{12}[\mathrm{ng} / \mathrm{l}]$ bestimmt. Das automatisierte Gerät Hitachi 917 für biochemische Analysen wurde ebenfalls für die Bestimmung weiterer Parameter verwendet. Die Kalziumkonzentration [mmol/1] wurde mit der ortho-Kresolphtalein-Komplexon-Methode bestimmt. Anorganisches Phosphat [mmol/1] wurde mit der Ammonium-Phosphomolybdat-Methode (Roche, Mannheim) gemessen. 
Methodik

Alkalische Phosphatase [U/l] wurde mithilfe der optimierten Standardmethode der International Federation for Clinical Chemistry (IFCC; Roche, Mannheim) bestimmt (Thierfelder et al. 2007). Zudem wurden die Blutlipide in den Fraktionen von HDL (bigh-density lipoproteins) und LDL (low-density lipoproteins), Triglyceride und Cholesterin gemessen. Diese Werte wurden ebenfalls mithilfe des Hitachi-917-Geräts ermittelt (Thierfelder et al. 2007). Für die Gesamtcholesterinbestimmung verwendete man die vollenzymatische Cholesterin-Phenol/Aminophenzazon/Peroxidase-Methode (PAP-Methode) mit dem hierfür konzipierten Kit der Firma Roche (Thierfelder et al. 2007). Zunächst wurden hierfür Cholesterinester mithilfe von Cholesterinasen gespalten. Die Produkte waren freie Fettsäuren und ungebundenes Cholesterin, welches mit Sauerstoff und Cholesterinoxidase (CHOD) oxidiert wurde. Dabei entstanden Cholestenon und Wasserstoffperoxid. Letzteres reagierte weiter in einer Reaktion mit 4-Amino-Phenazon (PAP) und Phenol unter Katalyse durch Peroxidase und bildete einen roten Farbstoff, welcher bei einer Wellenlänge von $546 \mathrm{~nm}$ absorbierte. Die photometrisch gemessene Produktmenge war dabei proportional zur Cholesterinkonzentration. Die Konzentrationen von HDL- und LDL-Cholesterin wurden über einen enzymatischen Farbtest bestimmt. Für die Triglyceridbestimmung verwendete man Glycerol-3-PhosphatOxidase (GPO) in einer PAP-Reaktion (Thierfelder et al. 2007).

\subsection{Bestimmung der Lebensqualität und der psychosozialen Stärken und Schwächen}

Die Bestimmung der Lebensqualität erfolgte mittels des KINDL-R-Fragebogens (RavensSieberer et al. 2007). Dieser Fragebogen ist ein generisches Instrument zur Erfassung der Lebensqualität und wurde 1994 von Bullinger entwickelt und 1998 gemeinsam mit Sieberer revidiert (Ravens-Sieberer und Bullinger 1998; Ravens-Sieberer 2000). In mehreren Studien zeigte der KINDL-R-Fragebogen eine hohe Akzeptanz, Reliabilität und Validität (RavensSieberer 2000). Es lagen drei Versionen vor, mit welchen man Daten von den Probanden ab einem Alter von 3 bis 17 Jahren erfassen konnte. Für diese Auswertung wurde der Fragebogen für die Altersklasse 11 bis 17 Jahre herangezogen. In dieser Altersklasse lagen ein Selbstbeurteilungsfragebogen der Kinder und Jugendlichen und ein Fragebogen für die Eltern vor, sodass es neben der Eigen- auch eine Fremdbeurteilung durch die Eltern gab. Der KINDL-R-Fragebogen bestand aus 24 Fragen. Die Antwortmöglichkeiten waren positiv oder negativ in einer Rensis-Likert-Skala angelegt. Die Skala war in äquidistanten Abständen aufgebaut (Ravens-Sieberer und Bullinger 2000). Die Module des Fragebogens zielten auf 


\section{Methodik}

die Erfassung der Lebensqualität im Zusammenhang von chronischen Erkrankungen, längeren Krankenhausaufenthalten sowie ausgewählten Beschwerden und Erkrankungen, wie beispielsweise Adipositas, Krebs, Epilepsie oder Diabetes ab (Ravens-Sieberer und Bullinger 2000). Der Fragebogen war in den Subskalen körperliches Wohlbefinden, psychisches Wohlbefinden, Selbstwertgefühl, familiäre Komponente und Freundschaften aufgebaut (RavensSieberer und Bullinger 2000). Die Antwortmöglichkeiten wurden fünf Werten zugeordnet. Diese waren: nie $=1$, selten $=2$, manchmal $=3$, oft $=4$ und immer $=5$. Die Skala ging von 0 bis 100 , wobei 0 die niedrigste Lebensqualität und 100 die höchste Lebensqualität auszeichnete. Daher mussten einige Fragen umgepolt werden, bevor man diese in den Skalenwert umrechnete (Ravens-Sieberer und Bullinger 2000; Ravens-Sieberer et al. 2007). Basierend auf den vorangegangenen Messwerten der einzelnen Kategorien wurde eine totale Lebensqualität als übergreifender Messwert errechnet (Ravens-Sieberer et al. 2007). Für die Bestimmung der psychosozialen Stärken und Schwächen wurde im Kinder- und Jugendsurvey der Strength and Difficulties Quentionnaire (SDQ) eingesetzt (Hölling et al. 2007). Der Fragebogen wurde in Großbritannien zur Erfassung von Verhaltensauffälligkeiten und Stärken entwickelt (Goodman 1997). Die deutsche Version liegt seit 1997 vor, welche die Subskalen „Emotionale Probleme“, „Verhaltensauffälligkeiten“, „Hyperaktivität“”, „Probleme mit Gleichaltrigen“, „Prosoziales Verhalten“ und einen „Gesamtproblemwert“ beinhaltet (Klasen et al. 2000). Der SDQ-Fragebogen wurde positiv auf Validität, Anwendbarkeit und Aussagekraft zur Aufdeckung von psychosozialen Auffälligkeiten bei Kindern und Jugendlichen getestet (Goodman et al. 2000). Der SDQ-Fragebogen kam bei Kindern ab dem vierten Lebensjahr in Form eines Fremdbeurteilungsfragebogens mit Angaben der Eltern bzw. Erziehungsberechtigten zum Einsatz. Ab dem elften Lebensjahr kam ein Selbstbeurteilungsfragebogen für die Kinder und Jugendlichen hinzu (Goodman et al. 1998). Für diese Arbeit wurden der Eltern- und Kinderfragebogen für die Altersgruppe 11 bis 17 Jahre herangezogen. Die Fragebögen bestanden aus den Subskalen „Emotionale Probleme“, „Verhaltensauffälligkeiten“, „Hyperaktivität“, „Probleme mit Gleichaltrigen“, „Prosoziales Verhalten“, welche drei Antwortmöglichkeiten mit den jeweiligen Werten einschloss: nicht zutreffend $=0$, teilweise zutreffend $=1$ und eindeutig zutreffend $=2$ (Goodman 1997). Um einen Gesamtproblemwert zu errechnen, mussten einige Subskalen umgepolt werden (Goodman et al. 1998). Die Skala des Gesamtproblemwerts erstreckte sich von 0 bis 40, 0 mit dem niedrigsten Problemwert und 40 mit dem höchsten Problemwert. „Prosoziales Verhalten“ wurde bei der Berechnung des übergeordneten Gesamtproblemwertes nicht miteinbezogen, da dieses nicht als Indikator für ein psychisch auffälliges Verhalten herangezogen werden konnte (Goodman et al. 1998). 


\subsection{Bestimmung der Arzneimittelanwendung}

In dieser Arbeit wurde der Einfluss von Kontrazeptiva bei weiblichen Jugendlichen im Alter von 13 bis 17 Jahren untersucht. Über ein computergestütztes Interview (CAPI) erfasste der Arzt spezielle Krankheiten, den Impfstatus und die Medikamenteneinnahme der letzten sieben Tage. Über dieses Verfahren wurde unter anderem die Einnahme von Kontrazeptiva erfasst (Hölling et al. 2007). Hierbei wurde für jedes Medikament die Anwendungsdauer angeben. Es konnte zwischen einer Dauer von $<1$ Woche, 1 bis $<4$ Wochen, 1 bis $<12$ Monaten, 1 Jahr oder länger differenziert werden. Die Indikation der Medikamenteneinnahme wurde nach dem International Classification of Diseases (ICD)-Code (ICD 10. Revision der WHO) aufgenommen (Knopf, 2007). Es konnten ein bis zwei Indikationen pro Medikament angegeben werden. Das RKI wertete den Fragebogen direkt aus und erstellte eine Rangliste mit den zehn am häufigsten angewendeten Arzneimittelgruppen in den letzten sieben Tagen vor der Befragung in der Altersgruppe 11 bis 17 Jahren (Bundeszentrale für gesundheitliche Aufklärung (BZgA) 2006).

Medikamente selbst wurden in einem Freitextfeld aufgenommen, welcher sich nach der anatomisch-therapeutisch-chemischen (ATC)-Klassifikation richtete. Kontrazeptiva sind im ATC-Index unter dem Code G03A „Hormonelle Kontrazeptiva zur systemischen Anwendung“ zu finden. Es wird zwischen drei Präparattypen unterschieden. Das fixe Kombipräparat, welches Gestagene und Estrogene enthält, ist mit dem Code G03AA versehen. Das Sequenzial-Präparat welches ebenfalls Gestagene und Estrogene enthält, hat den Code G03AB. Das Einzelpräparat mit Gestagenen wird mit dem Code G03AC gekennzeichnet. Des Weiteren bestehen Untergruppen, welche sich nochmals in ihrer Zusammensetzung unterscheiden, wie etwa in das Kombipräparat Levonorgestrel und Estrogen G03AA07, das Sequenzial-Präparat Norethisteron und Estrogen G03AB04 und zuletzt Desogestrel G03AC09. Einige Studienteilnehmerinnen nahmen nicht orale Kontrazeptiva ein. Diese Mädchen wurden in der Analyse nicht berücksichtigt. Zu den Medikamenten zählten Depotgestagene in Form einer Dreimonatsspritze, Verhütungspflaster wie Evra, vaginale Verhütungsringe z.B. Nuva-Ring, subkutane Gestagenimplantate in Form eines Verhütungsstäbchens, z.B. Implanon. Auch Notfallkontrazeptiva wie die „Pille danach“ waren von der Analyse ausgeschlossen (Hölling et al. 2007). Für weitere Untersuchungen wurden in dieser Arbeit aus den im Fragebogen erfassten weiblichen Studienteilnehmern zwei Gruppen erstellt: die Gruppe der Anwenderinnen und die der Nichtanwenderinnen von oralen Kontrazeptiva. 


\subsection{Statistische Datenanalyse}

Die statistische Datenanalyse wurde mit dem Statistikprogramm Statistical Package for the Social Sciences version 24 (SPSS Inc., Chicago, IL, United States), kurz SPSS-24, der Firma IBM vorgenommen. Das RKI sammelte die erhobenen Daten der Basiserhebung 2003-2006 in einem Public Use File des KiGGS (2003-2006) und stellte sie der Klinik für Psychosomatische Medizin und Psychotherapie für wissenschaftliche Zwecke zur Verfügung. Die Daten wurden zudem in Zusammenarbeit mit dem ZUMA in Mannheim mit einem zweistufigen Gewichtsfaktor korrigiert, um somit einen für Deutschland repräsentativen Datensatz zu erhalten (Kamtsiuris et al. 2007a). Anhand der Bevölkerungsstruktur wurden Abweichungen für das Alter, dem Geschlecht, der Region (Ost, West, Berlin) und der Staatsangehörigkeit korrigiert (Ravens-Sieberer et al. 2007). In der ersten Stufe wurden regionale Abweichungen korrigiert. Beim Stichprobendesign wurde die umgekehrte Proportionalität der Gewichte zur Auswahlwahrscheinlichkeit der Probanden miteinbezogen. Um die Auswahlwahrscheinlichkeit der Probanden in einer Gemeinde zu bestimmen, wurde die Auswahlwahrscheinlichkeit der Gemeinde mit der Auswahlwahrscheinlichkeit innerhalb einer Gemeinde multipliziert. Die Auswahlwahrscheinlichkeit der Gemeinde ist proportional zur Anzahl der Kinder und Jugendlichen in der Gemeinde. Die Auswahlwahrscheinlichkeit innerhalb einer Gemeinde ist die Zahl der Probanden pro Alter und Geschlecht dividiert durch die Gesamtzahl der Kinder und Jugendlichen, welche in der Gemeinde sind. Nach dem gleichen Verfahren wurde die Gewichtung nach der Region vorgenommen. Die Regionen waren in Ostdeutschland, Westdeutschland und Berlin eingeteilt und für jede dieser Regionen fand eine Designgewichtung statt.

In der zweiten Stufe wurden Abweichungen von den Kreuzklassifikationen Alter, Geschlecht, Region und Staatsangehörigkeit entsprechend der Bevölkerung zum Stand 31.12.2004 korrigiert. Schließlich wurden das Designgewicht und das Anpassungsgewicht multipliziert und normiert (Kamtsiuris et al. 2007a). Am stärksten wurde die Gewichtung durch den Faktor „Alter“ beeinflusst. Bei dem regionalen Faktor fand eine Verminderung der Gewichtung der Teilnehmer aus Ostdeutschland statt. Teilnehmer mit Migrationshintergrund mussten hingegen hoch gewichtet werden. Die Nichtteilnehmerrate der Studie wurde allerdings nur bedingt durch die Gewichtung korrigiert.

Um die Gruppen der Anwenderinnen und Nichtanwenderinnen zu charakterisieren, verwendeten wir als Rechnungsmethode die deskriptive Statistik und errechneten Mittelwerte und Standardabweichungen. Es wurden die beiden Gruppen der Anwenderinnen und Nichtanwenderinnen von Sexualhormonen und/oder Modulatoren des Genitalsystems miteinan- 


\section{Methodik}

der verglichen. Der Vergleich wurde mittels des Student-t-Tests nach Fisher für unabhängige Variablen und des Chi-Quadrattests für kategoriale Variablen gezogen. Der Student-t-Test untersucht, ob sich der Mittelwert von zwei unabhängigen Stichproben unterscheidet. Es wurden die Variablen vollendetes Lebensjahr (Alter), BMI, Migrantenstatus, soziale Schicht, Schultyp, systolischer, diastolischer und arterieller Blutdruck, RBC, Hämatokrit, Hb, MCH, MCV, MCHC, sTfR, Eisen, Ferritin, Vitamin D, Vitamin B $_{12}$, Kalzium, alkalische Phosphatase, anorganisches Phosphat, HDL-Cholesterin, LDL-Cholesterin, Triglyceride und zuletzt auch das Gesamtcholesterin auf Unterschiede in ihrer Verteilung mit dem Student-tTest geprüft. Mit dem Chi-Quadrattest sollte überprüft werden, ob zwei oder mehrere Variablen statistisch unabhängig waren. Für die kategorialen Variablen Alter, Schultyp, soziale Schicht und Migrantenstatus wurde der Chi-Quadrattest vorgenommen.

Um einen linearen Zusammenhang zwischen dem Serum-Vitamin D und den hämatologischen Parametern inklusive des Vitamin-B ${ }_{12}$-Spiegels zu untersuchen, wurde die Korrelation nach Pearson als geeignete Methode ausgewählt. Hierfür wurden die Parameter getestet, welche zuvor als signifikant befunden wurden. Die Parameter alkalische Phosphatase, Ferritin, löslicher Transferrinrezeptor, Vitamin $\mathrm{B}_{12}$, Vitamin D, HDL-Cholesterin, LDLCholesterin, und Triglyceride wurden logarithmiert, da sie nicht einer Normverteilung entsprachen. Mit den logarithmierten Parametern konnte die Korrelation nach Pearson und im Anschluss auch die lineare Regression ausgeführt werden. Bei der Korrelation wurde untersucht, ob eine Assoziation zwischen Vitamin D und den hämatologischen Parametern RBC, Hämatokrit, Hb, MCH, MCHC, MCV, Eisen, sTfR, Ferritin sowie Vitamin $\mathrm{B}_{12}$ bestand.

Anschließend wurden zwei multivariate logistische Regressionsmodelle erstellt. Mit der multivariaten logistischen Regression sollte ein Zusammenhang zwischen der Anwendung von Kontrazeptiva und den hämatologischen Parametern nach Adjustierung auf klinisch relevante, konfundierende Variable aufgezeigt werden. Für diese Modelle wählten wir als abhängige Variable wieder den Parameter der Anwendung von Kontrazeptiva und die hämatologischen Parameter RBC, Hkt, Hb, MCH, MCHC, MCV, Eisen, Ferritin und sTfR als unabhängige Variable. Als konfundierende Variable adjustierten wir zunächst in unseren Regressionsmodellen die Parameter Alter, BMI, Migrantenstatus. Da sich bei der univariaten Auswertung ein signifikanter Unterschied zwischen den beiden Gruppen der Anwenderinnen und Nichtanwenderinnen in den Parametern systolischer Blutdruck, anorganisches Phosphat, alkalische Phosphatase, Kalzium und Vitamin $\mathrm{B}_{12}$ herausstellte, wurden diese als konfundierende Variable in den Modellen hinzugefügt. Zudem stellte sich in Vorarbeiten ein Einfluss von 25(OH)-Vitamin D auf hämatologische Parameter heraus (Doudin et al. 2018), sodass auch dieser Parameter zu den konfundierenden Variablen hinzufügt wurde. In einem 


\section{Methodik}

zweiten Regressionsmodell fügten wir das HDL- und LDL-Cholesterin sowie Triglyceride als konfundierende Variable zusätzlich hinzu, um den Einfluss der Lipide auf die hämatologischen Parameter zu prüfen (Naz et al. 2012).

Für den Student-t-Test, den Chi-Quadrattest und die Korrelation nach Pearson wurde ein pWert von $<0,05$ als signifikant erachtet. Die lineare Regression wurde nach Bonferroni korrigiert. Für die lineare Regression galt ein Signifikanzniveau von $\alpha=5 \%$, was einen statistisch signifikanten $\mathrm{p}$-Wert von $<0,0056$ bedeutete. Als Fehlergrenze wurde ein 95\%iges Konfidenzintervall für den Exponent von Beta (95\%-CI) angegeben. 


\section{Ergebnisse}

\subsection{Beschreibung des Studienkollektivs}

In der KiGGS-Studie wurde eine Anzahl von n $=2775$ weiblichen Studienteilnehmern im Alter von 13 bis 17 Jahren erfasst. Die erstmalige Anwendung von Kontrazeptiva konnte ab dem 13. Lebensjahr festgestellt werden, woraus sich ein Kollektiv von weiblichen Studienteilnehmerinnen im Alter von 13 bis 17 Jahren ergab. Das betrachtete Kollektiv wurde in zwei Gruppen geteilt: Anwenderinnen und Nichtanwenderinnen von Sexualhormonen bzw. Modulatoren des Genitalsystems. Die betrachtete Gruppe der jugendlichen Anwenderinnen im Alter von 13 bis 17 Jahren wies eine Anzahl von $n=541$ auf. Für die Gruppe der Nichtanwenderinnen im gleichen Alter wurde eine Anzahl von $n=2234$ ermittelt. Diese beiden Gruppen wurden im Hinblick auf hämatologische und klinische Laborparameter miteinander verglichen.

\subsection{Prävalenz der Einnahme von Kontrazeptiva mit zunehmendem Lebensalter}

Die Ergebnisse aus der deskriptiven Statistik zeigen, dass sich das mittlere Alter von Anwenderinnen und Nichtanwenderinnen unterschied. Das mittlere Alter der Anwenderinnen war mit 16,77 \pm 0,84 Jahren höher im Vergleich zu dem mittleren Alter der Nichtanwenderinnen von 15,24 $\pm 1,36(\mathrm{p}<0,001)$. Hinsichtlich der Altersverteilung war erkennbar, dass mit zunehmendem Alter auch der Anteil der Anwenderinnen von Kontrazeptiva anstieg. Die prozentuale Verteilung der Anwenderinnen ist in der Abbildung 1 im Säulendiagramm graphisch dargestellt. Es ließ sich eine stetige Steigerung des prozentualen Anteils der Anwenderinnen (dargestellt mit roten Säulen im Gegensatz zu den blauen Säulen der Nichtanwenderinnen) mit zunehmendem Alter erkennen. Im Alter von 17 Jahren wurde die Differenz der Anzahl beider Vergleichsgruppen geringer, was sich im Diagramm widerspiegelt (Abb. 1). 


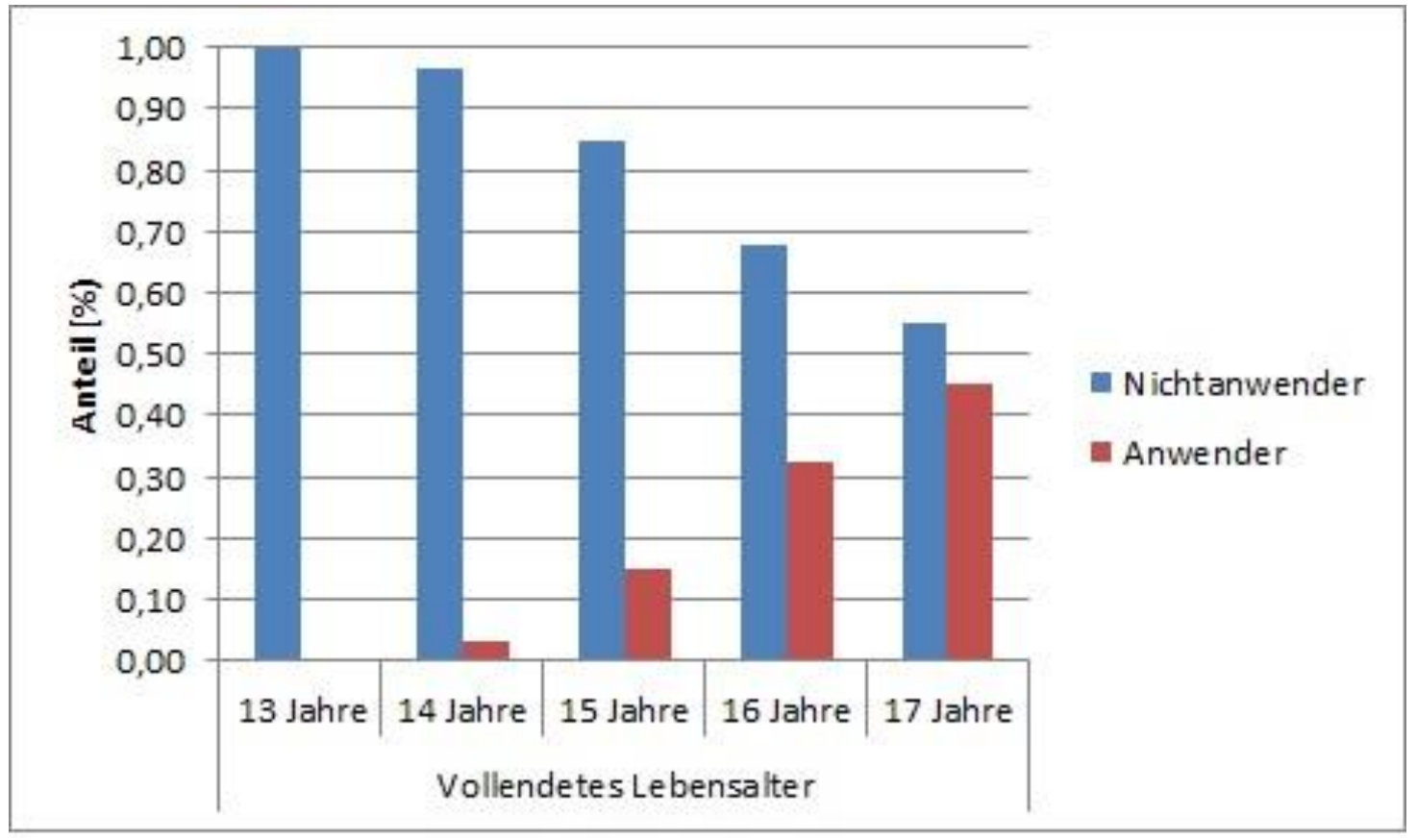

Abbildung 1: Zunehmender prozentualer Anteil der Anwenderinnen von Kontrazeptiva mit steigendem Lebensalter der weiblichen Jugendlichen

Die prozentuale Zunahme des Anteils der Anwenderinnen gegenüber den Studienteilnehmerinnen ohne gegenwärtigen Kontrazeptiva-Gebrauch ist der Tabelle 1 zu entnehmen. Im Alter von 13 Jahren fand sich eine einzige Anwenderin, was einem prozentualen Anteil an Anwenderinnen von 0,2\% dieser Altersgruppe entspricht. Mit zunehmendem Lebensalter wurden es immer mehr Anwenderinnen. So verhüteten im Alter von 14 Jahren eine Anzahl von 18 Mädchen, was einem prozentualen Anteil von 3,2\% entspricht. Im Alter von 15 Jahren gab es eine Steigung der Anwendung mit einer Anzahl von 84 Nutzerinnen; dies entspricht einem Anteil von 15\% Nutzerinnen in dieser Altersgruppe. Im Alter von 16 Jahren waren es 184 Mädchen. Mit 16 Jahren bestand ein Anteil von 32,2\% an Anwenderinnen von Kontrazeptiva. In der ältesten Altersgruppe von 17 Jahren waren es insgesamt 254 Mädchen, welche unter dem Einsatz von oralen Kontrazeptiva verhüteten. Dies entsprach einem prozentualen Anteil von 45,0\%. Die Anzahl der Nichtanwenderinnen wurde mit zunehmendem Alter geringer. Die niedrigste Anzahl der erfassten Teilnehmerinnen fand sich in der Altersgruppe der 13-Jährigen mit einer Anzahl von 515 Probandinnen und die höchste Anzahl lag bei 571 in der Gruppe der 16-Jährigen. Der Durchschnitt an Studienteilnehmerinnen pro Lebensjahr lag bei 555. Der durchschnittliche prozentuale Wert der Anwenderinnen in allen Altersgruppen lag bei 19,5\%. 
Tabelle 1: Altersverteilung der Anwenderinnen und Nichtanwenderinnen von Sexualhormonen und Modulatoren des Genitalsystems

\begin{tabular}{|l|c|c|c|}
\hline $\begin{array}{l}\text { Lebensjahr in } \\
\text { vollendeten Jahren }\end{array}$ & $\begin{array}{c}\text { Nichtanwenderinnen } \\
(\mathrm{n}=2234)\end{array}$ & $\begin{array}{c}\text { Anwenderinnen } \\
(\mathrm{n}=541)\end{array}$ & $\begin{array}{c}\text { Nutzerinnen in der } \\
\text { Altersgruppe }\end{array}$ \\
\hline 13 & 514 & 1 & $0,2 \%$ \\
\hline 14 & 547 & 18 & $3,2 \%$ \\
\hline 15 & 476 & 84 & $15,0 \%$ \\
\hline 16 & 387 & 184 & $32,2 \%$ \\
\hline 17 & 310 & 254 & $45,0 \%$ \\
\hline gesamt & 2234 & 541 & $19,5 \%$ \\
\hline
\end{tabular}

\subsection{Vergleich der Anwenderinnen und Nichtanwenderinnen von Kontrazeptiva hinsichtlich klinisch-chemischer Parameter}

Der Student-t-Test gab Aufschluss darüber, inwiefern sich relevante Variablen vom Mittelwert in den beiden Gruppen der Anwenderinnen und Nichtanwenderinnen von Kontrazeptiva unterschieden. Über diesen Test konnten statistisch signifikante Variable ermittelt werden. Die Mittelwerte und p-Werte der getesteten Variablen sind in Tabelle 2 dargestellt. Als Grundparameter wurden das Alter und der BMI getestet. Das Alter wurde bereits ausführlich mithilfe der Kreuztabelle untersucht. Die Ergebnisse des t-Tests zeigten, dass die Anwenderinnen von Kontrazeptiva einen signifikant höheren Mittelwert des BMI als die Nichtanwenderinnen hatten, welcher bei $22,43 \pm 3,54 \mathrm{~kg} / \mathrm{m}^{2}$ lag. Letztere hatten im Vergleich dazu einen mittleren BMI von 21,69 $\pm 4,17 \mathrm{~kg} / \mathrm{m}^{2}(\mathrm{p}<0,001)$.

Des Weiteren wurden Parameter des sozialen Umfeldes der Studienteilnehmerinnen, wie der Migrantenstatus, der sozioökonomische Status nach Winkler und der Bildungsgrad mithilfe des Chi-Quadrattest analysiert. Ein signifikanter Zusammenhang bestand zwischen der Anwendung von Kontrazeptiva und dem Vorliegen eines Migrationshintergrundes $(p<0,001)$. Mädchen mit einem Migrationshintergrund nahmen verglichen mit ihren Geschlechtsgenossinnen ohne Migrationshintergrund eher keine Kontrazeptiva ein. Die prozentuale Verteilung der Migranten lag bei 6,5\%. Das Ergebnis zeigte einen deutlich höheren Prozentsatz der Nichtanwendung von Kontrazeptiva bei Mädchen mit Migrationshintergrund $(22,0 \%)$ versus ohne Migrationshintergrund (7,5\%). 
Der sozioökonomische Status nach Winkler erwies sich als nicht signifikant unterschiedlich hinsichtlich der Verteilung von Anwenderinnen und Nichtanwenderinnen chemischer Verhütungsmethoden. Es konnte kein Einfluss der sozialen Schicht $(p=0,652)$ sowie des Schultyps bzw. Bildungsgrades $(\mathrm{p}=0,566)$ der Studienteilnehmerinnen auf die Einnahme von Kontrazeptiva gezeigt werden. Die Verteilung der niedrigen sozialen Schicht lag in der Gruppe der Anwenderinnen bei 25,8\% und der Nichtanwenderinnen bei 27,1\%. Die mittlere soziale Schicht zeigte ebenso kaum einen Unterschied der Verteilung von Anwenderinnen bei $49,2 \%$ und Nichtanwenderinnen bei 47,0\%. Insgesamt war die mittlere soziale Schicht am stärksten vertreten. Die höhere soziale Schicht hatte einen prozentualen Anteil von 25,0\% Anwenderinnen und 25,9\% Nichtanwenderinnen. Die Verteilung auf den niedrigen und hohen Sozialstatus lag, wie auch bei der mittleren sozialen Schicht, etwa bei der Hälfte. Daher zeigte die Anwendung von Kontrazeptiva keine Bevorzugung einer bestimmten sozialen Schicht. Des Weiteren wurde die Häufigkeit der Anwendung nach dem Bildungsgrad untersucht. In den weiterführenden Schulen Hauptschule, Realschule, Gymnasium, Gesamtschule und Förderschule/Sonderschule wurden Anwenderinnen registriert. Die prozentuale Verteilung entsprechend des Bildungsgrades ergab folgende Ergebnisse: In der Hauptschule waren es 16,2\% Anwenderinnen und 17,3\% Nichtanwenderinnen. Zur Realschule gingen 32,3\% Anwenderinnen und 31,4\% Nichtanwenderinnen. Auf dem Gymnasium befanden sich 42,8\% Anwenderinnen und 40,2\% Nichtanwenderinnen. Die Gesamtschule hatte 7,1\% Anwenderinnen und 8,7\% Nichtanwenderinnen. Schließlich hatte die Förderschule/-Sonderschule einen Anwenderinnenanteil von 1,6\% und 2,0\% von Nichtanwenderinnen. Beim Bildungsgrad gab es keine Bevorzugung hinsichtlich der Anwendung von Kontrazeptiva. Anwenderinnen und Nichtanwenderinnen waren in allen Schultypen annähernd gleichmäßig verteilt. Der höchste prozentuale Anwenderanteil lag bei den Gymnasialschülerinnen mit $42,8 \%$.

Zudem wurde der Blutdruck in Bezug auf den Kontrazeptiva-Gebrauch untersucht. Die Ergebnisse aus dem Student-t-Test zeigten signifikant höhere Mittelwerte für den Blutdruck unter der Einnahme von Kontrazeptiva (Tab. 2). Hierzu gehörten der mittlere systolische Blutdruck mit einem Mittelwert von 115,6 \pm 9,0 mmHg $(\mathrm{p}<0,001)$, der mittlere arterielle Mitteldruck mit einem Wert von $88,1 \pm 7,4 \mathrm{mmHg}(\mathrm{p}<0,001)$ und der diastolische Blutdruck mit einem Mittelwert von 70,5 $\pm 6,9 \mathrm{mmHg}(\mathrm{p}<0,001)$. Bei den Nichtanwenderinnen lag der Mittelwert des systolischen Blutdrucks dagegen bei 113,3 \pm 9,2 $\mathrm{mmHg}$, der Wert des arteriellen Mitteldrucks bei 85,9 \pm 7,6 $\mathrm{mmHg}$ und des diastolischen Blutdrucks bei 68,3 \pm 7,1 $\mathrm{mmHg}$. 
Bei der Untersuchung der klinisch-chemischen Laborparameter konnten einige signifikant unterschiedliche Mittelwerte ermittelt werden. Es bestand eine Signifikanz bei dem RBC $(\mathrm{p}<0,001)$. Der im Blut ermittelte Mittelwert mit Standardabweichung von RBC war bei Anwenderinnen mit einem Wert von 4,46 $\pm 0,31 \times 10^{6} / \mathrm{ml}$ erniedrigt im Vergleich zu den Nichtanwenderinnen mit einem Wert von 4,52 \pm 0,3 x10\% $/ \mathrm{ml}$. Der Vergleich des MCH zeigte ebenso eine Signifikanz $(p<0,001)$ mit einer mittleren Konzentration von 29,10 \pm 1,59 pg/1 bei Nichtanwenderinnen und einer höheren Konzentration von 29,41 \pm 1,79 pg/1 bei den Anwenderinnen. Des Weiteren zeigte die Untersuchung des MCV einen signifikanten Unterschied ( $p<0,001)$. Dieser lag bei den Anwenderinnen im Median mit einem Wert von 86,6 \pm 3,8 fl erhöht vor, wohingegen der Median der Nichtanwenderinnen von MCV bei 85,8 \pm 3,9 fl lag. Der Eisenwert der Blutproben hatte ebenfalls einen signifikanten Unterschied in den beiden Gruppen ergeben $(\mathrm{p}<0,001)$. Die Konzentration des Eisens lag bei den Nichtanwenderinnen bei 14,64 \pm 6,46 $\mu \mathrm{g} / \mathrm{dl}$ und war im Vergleich dazu bei den Anwenderinnen erniedrigt, die einen mittleren Wert von 16,35 \pm 7,59 $\mu \mathrm{g} / \mathrm{dl}$ hatten. Zudem war Ferritin bei den Nichtanwenderinnen bei 32,0 $\pm 22,18 \mu \mathrm{g} / 1$ und in den Blutproben der Anwenderinnen mit 34,6 $\pm 24,4 \mu \mathrm{g} / 1$ erhöht. Der Unterschied in der mittleren Ferritin-Konzentration zwischen beiden Gruppen war mit $(p=0,02)$ statistisch signifikant. Die mittlere sTfR-Konzentration war ebenso signifikant unterschiedlich in beiden Gruppen $(\mathrm{p}<0,001)$ und lag bei Nichtanwenderinnen bei 1,56 \pm 0,51 mg/l, in der Gruppe der Anwenderinnen mit einem Wert von 1,39 \pm 0,45 mg/l erniedrigt vor. Für die Parameter Hkt ( $p=0,158), \mathrm{Hb}(\mathrm{p}=0,263)$ und MCHC ( $\mathrm{p}=0,337)$ konnte kein signifikanter Unterschied zwischen den beiden getesteten Gruppen ermittelt werden.

Für das Vitamin $B_{12}(p<0,001)$ und das Vitamin D $(p<0,001)$ konnten in beiden untersuchten Gruppen signifikante Unterschiede in deren jeweiligen Serumspiegeln festgestellt werden. Der Mittelwert mit Standardabweichung für Vitamin B 12 lag bei Nichtanwenderinnen bei 509 $\pm 210 \mathrm{pg} / \mathrm{ml}$. Im Vergleich dazu war der Mittelwert von $352 \pm 156 \mathrm{pg} / \mathrm{ml}$ bei den Anwenderinnen erniedrigt. Im Blutserum der Probanden lag der Vitamin-D-Gehalt in der Gruppe der Nichtanwenderinnen bei $43 \pm 25 \mathrm{ng} / \mathrm{ml}$ und in der Gruppe der Anwenderinnen im Vergleich dazu mit einem Wert von $59 \pm 33 \mathrm{ng} / \mathrm{ml}$ höher. Zudem zeigten die getesteten Parameter Kalzium [mmol/1], alkalische Phosphatase [U/l], anorganisches Phosphat [mmol/l] und die Lipidparameter HDL-Cholesterin [mg/dl], LDL-Cholesterin [mg/dl], Triglyceride $[\mathrm{mg} / \mathrm{dl}]$ und Gesamtcholesterin $[\mathrm{mg} / \mathrm{dl}]$ statistisch signifikante Unterschiede von $\mathrm{p}<0,001$. Der Wert von Kalzium mitsamt der Standardabweichung lag bei den Nichtanwenderinnen bei $2,51 \pm 0,11 \mathrm{mmol} / 1$ und bei den Anwenderinnen im Vergleich dazu mit einem Wert von 2,49 $\pm 0,10 \mathrm{mmol} / 1$ niedriger. Die bei den Probanden der Nichtanwenderinnen ermittelten 


\section{Ergebnisse}

Werte der alkalischen Phosphatase waren 120,9 \pm 64,4 U/1; bei den Anwenderinnen lag dieser Wert erniedrigt vor bei 68,0 \pm 18,8 U/1. Das anorganische Phosphat wurde bei den Nichtanwenderinnen mit einem Blutserumwert von 1,40 $\pm 0,18 \mathrm{mmol} / 1$ gemessen und bei den Anwenderinnen war dieser Wert von 1,29 \pm 0,16 mmol/l im Vergleich niedriger. Die Lipidwerte im Blutserum der Kohorte waren in der Gruppe der Anwenderinnen im Gegensatz zu der Gruppe der Nichtanwenderinnen erhöht. Das HDL-Cholesterin lag bei den Nichtanwenderinnen bei $58 \pm 12 \mathrm{mg} / \mathrm{dl}$ und bei den Anwenderinnen bei $61 \pm 15 \mathrm{mg} / \mathrm{dl}$. Die mittleren Blutserumwerte für LDL-Cholesterin lagen bei den Nichtanwenderinnen bei $92 \pm 25 \mathrm{mg} / \mathrm{dl}$ und bei den Anwenderinnen bei $109 \pm 35 \mathrm{mg} / \mathrm{dl}$. Der mittlere Blutwert von Triglycerid war bei den Nichtanwenderinnen niedriger als bei den Anwenderinnen (99,6 \pm $63 \mathrm{mg} / \mathrm{dl}$ versus $126 \pm 56 \mathrm{mg} / \mathrm{dl}$ ). Zudem war auch das Gesamtcholesterin in der Gruppe der Anwenderinnen im Vergleich zu den Nichtanwenderinnen erhöht. Erstere hatten einen Wert von $185 \pm 38 \mathrm{mg} / \mathrm{dl}$, Letztere wiesen einen Wert von $162 \pm 28 \mathrm{mg} / \mathrm{dl}$ auf.

Tabelle 2: Ergebnisse der deskriptiven Statistik, inklusive der zugehörigen Mittelwerte und p-Werte, aus dem Gruppenvergleich der weiblichen Studienteilnehmer mit und ohne Kontrazeptiva-Anwendung

\begin{tabular}{|l|c|c|c|}
\hline & $\begin{array}{c}\text { Nichtanwenderinnen } \\
(\mathrm{n}=2234)\end{array}$ & $\begin{array}{c}\text { Anwenderinnen } \\
(\mathrm{n}=541)\end{array}$ & $\mathrm{p}$-Wert \\
\hline Vollendetes Lebensalter [Jahre] & $15,24 \pm 1,36$ & $16,77 \pm 0,85$ & $<0,001$ \\
\hline BMI $\left[\mathrm{kg} / \mathrm{m}^{2}\right]$ & $21,69 \pm 4,17$ & $22,43 \pm 3,54$ & $<0,001$ \\
\hline Migrantenstatus (Migrant) & $19,4 \%$ & $6,5 \%$ & $<0,001$ \\
\hline Soziale Schicht n. Winkler & $27,1 \%$ & $25,8 \%$ & \\
(niedriger, mittlerer, hoher Sozialstatus) & $47,0 \%$ & $49,2 \%$ & 0,566 \\
\hline Schultyp (inkl. Schulabschluss) & $25,9 \%$ & $25,0 \%$ & \\
Grundschule & & & \\
Orientierungsstufe & $0,2 \%$ & $0,0 \%$ & \\
Hauptschule & $0,2 \%$ & $0,0 \%$ & \\
Realschule & $17,3 \%$ & $16,2 \%$ & \\
Gymnasium & $31,4 \%$ & $32,3 \%$ & \\
Gesamtschule & $40,2 \%$ & $42,8 \%$ & \\
Förderschule/ Sonderschule) & $8,7 \%$ & $7,1 \%$ & \\
& $2,0 \%$ & $1,6 \%$ & \\
\hline
\end{tabular}




\begin{tabular}{|c|c|c|c|}
\hline & $\begin{array}{c}\text { Nichtanwenderinnen } \\
(\mathrm{n}=2234)\end{array}$ & $\begin{array}{l}\text { Anwenderinnen } \\
(\mathrm{n}=541)\end{array}$ & p-Wert \\
\hline Systolischer Blutdruck [mmHg] & $113,30 \pm 9,24$ & $115,63 \pm 8,96$ & $<0,001$ \\
\hline Arterieller Mitteldruck [mmHg] & $85,87 \pm 7,58$ & $88,12 \pm 7,43$ & $<0,001$ \\
\hline Diastolischer Blutdruck [mmHg] & $68,29 \pm 7,06$ & $70,47 \pm 6,9$ & $<0,001$ \\
\hline Erythrozytenzahl $\left[\mathrm{x} 10^{6} / \mathrm{mL}\right]$ & $4,52 \pm 0,3$ & $4,46 \pm 0,31$ & $<0,001$ \\
\hline Hämatokrit $[\%]$ & $38,73 \pm 2,49$ & $38,55 \pm 2,58$ & 0,158 \\
\hline $\mathrm{Hb}[\mathrm{g} / \mathrm{dl}]$ & $13,14 \pm 0,91$ & $13,09 \pm 0,88$ & 0,263 \\
\hline $\mathrm{MCH}[\mathrm{pg}]$ & $29,10 \pm 1,59$ & $29,41 \pm 1,79$ & $<0,001$ \\
\hline $\mathrm{MCHC}[\mathrm{g} / \mathrm{dl}]$ & $33,92 \pm 0,86$ & $33,97 \pm 1,18$ & 0,337 \\
\hline $\mathrm{MCV}[\mathrm{fl}]$ & $85,8 \pm 3,89$ & $86,56 \pm 3,81$ & $<0,001$ \\
\hline $\operatorname{sTfR}[\mathrm{mg} / \mathrm{l}]$ & $1,56 \pm 0,51$ & $1,39 \pm 0,45$ & $<0,001$ \\
\hline Eisen $[\mu \mathrm{mol} / 1]$ & $14,64 \pm 6,46$ & $16,35 \pm 7,59$ & $<0,001$ \\
\hline Ferritin $[\mu \mathrm{g} / \mathrm{l}]$ & $32,0 \pm 22,18$ & $34,63 \pm 24,37$ & 0,02 \\
\hline Vitamin D [nmol/l] & $43,00 \pm 25,3$ & $59,4 \pm 33,03$ & $<0,001$ \\
\hline $\operatorname{Vitamin~}_{12}[\mathrm{ng} / \mathrm{l}]$ & $509,1 \pm 209,9$ & $352,2 \pm 156,3$ & $<0,001$ \\
\hline Kalzium [mmol/l] & $2,51 \pm 0,11$ & $2,49 \pm 0,1$ & $<0,001$ \\
\hline Alkalische Phosphatase [U/1] & $120,9 \pm 64,4$ & $68,0 \pm 18,8$ & $<0,001$ \\
\hline Anorganisches Phosphat [mmol/l] & $1,4 \pm 0,18$ & $1,29 \pm 0,16$ & $<0,001$ \\
\hline HDL-Cholesterin[mg/dl] & $57,8 \pm 12,4$ & $61,5 \pm 14,9$ & $<0,001$ \\
\hline LDL-Cholesterin $[\mathrm{mg} / \mathrm{dl}]$ & $91,6 \pm 24,8$ & $108,8 \pm 34,6$ & $<0,001$ \\
\hline Triglyceride $[\mathrm{mg} / \mathrm{dl}]$ & $99,6 \pm 63,4$ & $126,1 \pm 56,1$ & $<0,001$ \\
\hline Cholesterin gesamt $[\mathrm{mg} / \mathrm{dl}]$ & $161,7 \pm 27,7$ & $184,9 \pm 37,7$ & $<0,001$ \\
\hline
\end{tabular}

\subsection{Unterschiede hinsichtlich der Anwendung oraler Kontrazeptiva innerhalb der jeweiligen Altersgruppe}

Je nach Lebensalter ergaben sich unterschiedliche Mittelwerte der klinisch-chemischen Parameter der Anwenderinnen. Die jüngste Anwenderin von oralen Kontrazeptiva war im 13. Lebensjahr und sie war die Einzige in ihrer Altersgruppe. Gegenüber dem Median der Nichtanwenderinnen war der mittlere systolische Blutdruck dieser Probandin mit einem Wert von 
Ergebnisse

112,3 mmHg gegenüber dem ihrer Alters- und Geschlechtsgenossinnen erhöht. Der mittlere arterielle Blutdruck mit einem Wert von 80,2 mmHg und der mittlere diastolische Blutdruck mit einem Wert von $63,8 \mathrm{mmHg}$ lagen bei dieser Anwenderin hingegen unterhalb des Medians ihrer Altersgruppe.

Die hämatologischen Parameter RBC (4,3 x10\% / ml), Hkt (38,39\%), Hb (12,9 g/dl), Ferritin $(16,5 \mu \mathrm{g} / \mathrm{l})$, sTfR (1,4 mg/l) und Vitamin B 12 (364 ng/l) lagen bei der Anwenderin gegenüber dem Median ebenfalls erniedrigt vor. Ebenso erniedrigt waren bei der einzigen Anwenderin in dieser jüngsten Altersgruppe die Parameter der alkalischen Phosphatase (83,2 U/1), des anorganisches Phosphats $(1,31 \mathrm{mmol} / \mathrm{l})$, des Gesamtcholesterins $(147 \mathrm{mg} / \mathrm{dl})$, des HDL$(43,9 \mathrm{mg} / \mathrm{dl})$ und des LDL-Cholesterins $(109 \mathrm{mg} / \mathrm{dl})$. Dahingegen waren bei dieser Anwenderin die Parameter MCH (29,4 pg), MCV (86,8 fl), Eisen $(18 \mu \mathrm{mol} / \mathrm{l})$, Kalzium (2,55 $\mathrm{mmol} / \mathrm{l})$, Triglyceride $(109 \mathrm{mg} / \mathrm{dl})$ und der 25(OH)-Vitamin-D-Spiegel (38 nmol/l) gegenüber dem Median der Nichtanwenderinnen erhöht. Der Median der MCHC lag in der Vergleichsgruppe mit einem Wert von 33,9 g/dl auf gleicher Höhe.

Nutzerinnen oraler Kontrazeptiva hatten im Alter von 14 Jahren gegenüber gleichaltrigen Nichtanwenderinnen einen erniedrigten Mittelwert der alkalischen Phosphatase (130 \pm 59 versus $80 \pm 19 \mathrm{U} / 1 ; \mathrm{p}<0,001)$. Des Weiteren war der Mittelwert von Vitamin $\mathrm{B}_{12}$ bei den Anwenderinnen im Vergleich zu den Nichtanwenderinnen erniedrigt (300 \pm 159 versus $516 \pm$ 208 ng/l; p <0,001). Erhöhte Mittelwerte zeigten die Anwenderinnen bei den gemessenen Lipidparametern von Gesamtcholesterin $(186 \pm 31 \mathrm{mg} / \mathrm{dl})$ und LDL-Cholesterin $(114 \pm 26$ $\mathrm{mg} / \mathrm{dl}) \mathrm{im}$ Vergleich zu den gleichaltrigen Nichtanwenderinnen $(162 \pm 27 \mathrm{mg} / \mathrm{dl}$ bzw. $91 \pm$ $24 \mathrm{mg} / \mathrm{dl}$; beide $\mathrm{p}<0,001)$.

Bei den Untersuchungen der Anwenderinnen mit 15 Jahren konnten erniedrigte Mittelwerte der alkalischen Phosphatase (74 $\pm 23 \mathrm{U} / \mathrm{l} ; \mathrm{p}<0,001)$, des anorganischen Phosphats $(1,31 \pm$ 0,15 mmol/l; $\mathrm{p}=0,001)$ und des Vitamin-B ${ }_{12}$-Gehalts (383 $\left.\pm 196 \mathrm{ng} / \mathrm{l} ; \mathrm{p}<0,001\right)$ ermittelt werden. Bei den Nichtanwenderinnen dieser Altersgruppe lagen die Mittelwerte der alkalischen Phosphatase bei $97 \pm 32 \mathrm{U} / \mathrm{l}$, des anorganischen Phosphats bei 1,37 \pm 0,16 mmol/1 und des Vitamin-B ${ }_{12}-$ Gehalts bei $485 \pm 179 \mathrm{ng} / \mathrm{l}$. Es konnten in der Gruppe der Anwenderinnen mit 15 Jahren erhöhte Werte der Triglyceride (123 $\pm 65 \mathrm{mg} / \mathrm{dl} ; \mathrm{p}=0,008)$, des LDL-Cholesterins $(106 \pm 27 \mathrm{mg} / \mathrm{dl} ; \mathrm{p}<0,001)$, des Gesamtcholesterins $(178 \pm 32 \mathrm{mg} / \mathrm{dl}$; $\mathrm{p}<0,001)$ und des Serumspiegels von $25(\mathrm{OH})$-Vitamin D $(55,7 \pm 33,2 \mathrm{nmol} / \mathrm{l} ; \mathrm{p}=0,018)$ festgestellt werden. Die Mittelwerte der Nichtanwenderinnen dieser signifikant unterschiedlichen Para-meter lagen für die Triglyceride bei 99,34 \pm 70,53 mg/dl, für das LDL-Cholesterin bei 90,09 $\pm 23,03 \mathrm{mg} / \mathrm{dl}$, für das Gesamtcholesterin bei $160 \pm 28 \mathrm{mg} / \mathrm{dl}$ und für die 25(OH)-Vitamin D-Konzentration bei 44,6 $\pm 27,7 \mathrm{nmol} / \mathrm{l}$. 


\section{Ergebnisse}

Mädchen, die 16 Jahre alt waren und Kontrazeptiva einnahmen, wiesen signifikant erniedrigte Mittelwerte von der alkalischer Phosphatase (68,3 \pm 18,6 U/1; $\mathrm{p}<0,001)$, dem anorganischem Phosphat (1,29 \pm 0,14 mmol/l; $\mathrm{p}<0,001)$, Kalzium $(2,49 \pm 0,1 \mathrm{mmol} / \mathrm{l} ; \mathrm{p}=0,004)$, dem $\operatorname{sTfR}(1,34 \pm 0,31 \mathrm{mg} / \mathrm{l} ; \mathrm{p}<0,001)$ und Vitamin $\mathrm{B}_{12}(364 \pm 177 \mathrm{ng} / \mathrm{l} ; \mathrm{p}<0,001)$ auf. Bei den Nichtanwenderinnen dieser Altersgruppe lagen die Mittelwerte im Blut von der alkalischen Phosphatase bei 87,1 \pm 30,8 U/1, anorganischem Phosphat bei 1,34 \pm 0,14 mmol/1, Kalzium bei 2,52 $\pm 0,1 \mathrm{mmol} / \mathrm{l}$, sTfR bei $1,61 \pm 0,57 \mathrm{mg} / 1$ und Vitamin $B_{12}$ bei $500 \pm 224 \mathrm{ng} / \mathrm{l}$

Einige Mittelwerte waren in der Gruppe der Anwenderinnen von Kontrazeptiva im Alter von 16 Jahren gegenüber den Nichtanwenderinnen erhöht. Zu diesen Variablen gehörten $\mathrm{MCH}(29,62 \pm$ 1,99 pg; p = 0,037), MCHC (34,0 \pm 1,7 g/dl; p = 0,029), Eisen (16,0 \pm 7,7 $\mu \mathrm{mol} / \mathrm{l} ; \mathrm{p}=0,04)$, Ferritin $(35,6 \pm 25,4 \mu \mathrm{g} / \mathrm{l} ; \mathrm{p}=0,003)$ und die Lipide HDL-Cholesterin $(61,1 \pm 15,5 \mathrm{mg} / \mathrm{dl} ; \mathrm{p}=0,027)$ und LDL-Cholesterin $(109 \pm 41 \mathrm{mg} / \mathrm{dl} ; \mathrm{p}<0,001)$ sowie das Gesamtcholesterin (186 $\pm 42 \mathrm{mg} / \mathrm{dl} ; \mathrm{p}<0,001)$. Des Weiteren war der Mittelwert von 25(OH)-Vitamin D (57,2 $\pm 31,7 \mathrm{nmol} / \mathrm{l} ; \mathrm{p}<0,001)$ in der Altersgruppe der 16-jährigen Anwenderinnen erhöht. Im Vergleich dazu lagen die Mittelwerte der Nichtanwenderinnen im Falle des MCH bei 29,27 \pm 1,75 pg, der MCHC bei 33,9 $\pm 0,1 \mathrm{~g} / \mathrm{dl}$, des Serumeisens bei 15,0 \pm 7,0 $\mu \mathrm{mol} / \mathrm{l}$, des Serumgehalts an Ferritin bei 29,4 \pm 20,4 $\mu \mathrm{g} / \mathrm{l}$, des HDL-Cholesterins bei $58,5 \pm 13 \mathrm{mg} / \mathrm{dl}$, des LDL-Cholesterins bei $93 \pm 24 \mathrm{mg} / \mathrm{dl}$ und des Gesamtcholesterins bei $163 \pm 27 \mathrm{mg} / \mathrm{dl}$. Der Serumwert von 25(OH)-Vitamin D lag in dieser Altersgruppe bei 44,0 $\pm 25,6 \mathrm{nmol} / 1$.

In der ältesten Altersgruppe von 17 Jahren fand sich bei den Mittelwertvergleichen mithilfe des t-Tests die höchste Zahl signifikanter p-Werte in Bezug auf die Anwendung von Kontrazeptiva. Es konnten für folgende Parameter erhöhte Mittelwerte bei den Anwenderinnen festgestellt werden: der mittlere systolische Blutdruck mit $117 \pm 9 \mathrm{mmHg}$ gegenüber $114 \pm$ $9 \mathrm{mmHg}$ bei den Nichtanwenderinnen $(\mathrm{p}=0,001)$, der mittlere arterielle Blutdruck von 89 $\pm 7 \mathrm{mmHg}$ gegenüber $87 \pm 7 \mathrm{mmHg}(\mathrm{p}<0,001)$ und der mittlere diastolische Blutdruck von $72 \pm 7 \mathrm{mmHg}$ bei Anwenderinnen versus $70 \pm 7 \mathrm{mmHg}$ bei den Nichtanwenderinnen $(\mathrm{p}=$ 0,002). Zudem fanden sich erhöhte Mittelwerte für den Eisenwert im Blut (17,2 \pm 7,7 $\mu \mathrm{mol} / \mathrm{l})$, welcher bei Nichtanwenderinnen bei 14,4 $\pm 7 \mu \mathrm{mol} / 1 \mathrm{lag}(\mathrm{p}<0,001)$. Der sTfRSpiegel lag in der Gruppe der Anwenderinnen bei 1,41 \pm 0,36 mg/l und war bei den Nichtanwenderinnen mit 1,55 \pm 0,5 mg/l signifikant erhöht $(p=0,002)$. Die Lipidwerte der Anwenderinnen mit einem vollendeten 17. Lebensjahr lagen für das HDL-Cholesterin bei 63,2 $\pm 14,5 \mathrm{mg} / \mathrm{dl}(\mathrm{p}<0,001)$, das LDL-Cholesterin bei $109 \pm 32 \mathrm{mg} / \mathrm{dl}(\mathrm{p}<0,001)$, die Triglyceride bei $120 \pm 52 \mathrm{mg} / \mathrm{dl}(\mathrm{p}=0,002)$ und das Gesamtcholesterin bei $187 \pm 36 \mathrm{mg} / \mathrm{dl}$ $(\mathrm{p}<0,001)$. Der Mittelwert von 25(OH)-Vitamin D lag bei $62 \pm 32 \mathrm{nmol} / 1(\mathrm{p}=0,002)$. Bei 
Ergebnisse

gleichaltrigen Nichtanwenderinnen der Studie lagen diese im Falle des HDL-Cholesterins bei 57,8 \pm 11,4 mg/dl, des LDL-Cholesterins bei 93,7 \pm 28,7 mg/dl, der Triglyceride bei $104 \pm$ $66 \mathrm{mg} / \mathrm{dl}$ und des Gesamtcholesterins bei $164 \pm 31 \mathrm{mg} / \mathrm{dl}$. Der Mittelwert der 25(OH)Vitamin D-Messwerte lag in dieser Gruppe bei $51 \pm 31 \mathrm{nmol} / \mathrm{l}$. Es lagen für folgende Blutparameter erniedrigte Mittelwerte vor: alkalische Phosphatase (64,9 \pm 16,2 U/l; p<0,001), anorganisches Phosphat $(1,28 \pm 0,17 \mathrm{mmol} / \mathrm{l} ; \mathrm{p}=0,001)$, Kalzium $(2,49 \pm$ 0,11 mmol/l; $\mathrm{p}$ $=0,001), \operatorname{sTfR}(1,41 \pm 0,36 \mathrm{mg} / \mathrm{l} ; \mathrm{p}=0,001)$ und Vitamin $\mathrm{B}_{12}(338 \pm 121 \mathrm{ng} / \mathrm{l} ; \mathrm{p}<0,001)$. Der Mittelwert der alkalischen Phosphatase bei Nichtanwenderinnen im vollendeten 17. Lebensjahr betrug $74 \pm 19 \mathrm{U} / \mathrm{l}$, des anorganischen Phosphats 1,33 \pm 0,17 mmol/l und von Kalzium 2,51 \pm 0,1 mmol/l. Der Mittelwert von sTfR bei den Nichtanwenderinnen lag bei 1,6 \pm 0,51 mg/l und der von Vitamin $B_{12}$ bei $470 \pm 189 \mathrm{ng} / \mathrm{l}$. Mit dem steigenden Lebensalter konnte somit eine zunehmende Anzahl signifikant unterschiedlicher Parameter im Gruppenvergleich zwischen den Anwenderinnen und den Nichtanwenderinnen von Kontrazeptiva festgestellt werden.

\subsection{Bestimmung der Lebensqualität bei Anwenderinnen von Kontrazeptiva}

Des Weiteren wurde die Lebensqualität der Probandinnen mithilfe des KINDL-R- und des SDQ-Fragebogens bei den beiden Gruppen unter Verwendung des Student-t-Tests bestimmt. Die Ergebnisse des KINDL-R-Fragebogens in der Selbstbeurteilung der Jugendlichen zeigten im Gruppenvergleich eine statistische Signifikanz in der „gesamten Lebensqualität“ ( $p=0,007)$, beim ,körperlichen Wohlbefinden“ ( $p<0,001)$ und in der „Schule“ ( $p$ $=0,006)$. Zudem gab es in der Kategorie der „Familie“ eine Signifikanz im Vergleich der beiden Gruppen Anwenderinnen und Nichtanwenderinnen ( $p=0,035)$. Die genannten Parameter waren bei den Anwenderinnen von Kontrazeptiva im Vergleich zu der Gruppe der Nichtanwenderinnen erniedrigt. Die Jugendlichen empfanden insgesamt eine leichte Verschlechterung der Lebensqualität, wenn sie Kontrazeptiva einnahmen.

Die Ergebnisse des KINDL-R-Fremdbeurteilungsfragebogen durch die Eltern deckten sich teilweise mit denen der Jugendlichen. Sie zeigten signifikante Unterschiede im „körperlichen Wohlbefinden“ $(p<0,001)$ und in der Kategorie „Schule“ $(p=0,001)$. Außerdem war der Parameter „Freunde“ bei den Eltern signifikant $(p<0,001)$ unterschiedlich zwischen beiden Gruppen (Tab. 3). 


\section{Ergebnisse}

Tabelle 3: Auswertung des KINDL-Fragebogens in der Selbst- und Fremdbefragungsversion anhand der Dichotomisierung von Nutzerinnen oraler Verhütungsmittel gegenüber den Nichtanwenderinnen oraler Kontrazeptiva, inklusive der Angabe der zugehörigen pWerte und Mittelwerte für den Gruppenvergleich

\begin{tabular}{|l|c|c|c|}
\hline & $\begin{array}{c}\text { Nichtanwenderinnen } \\
(\mathrm{n}=2234)\end{array}$ & $\begin{array}{c}\text { Anwenderinnen } \\
(\mathrm{n}=541)\end{array}$ & p-Wert \\
\hline KINDL Total Quality of life (KFB) & $70,31 \pm 10,82$ & $69,04 \pm 11,28$ & $\mathbf{0 , 0 0 7}$ \\
\hline KINDL Familie (KFB) & $80,37 \pm 16,91$ & $78,59 \pm 19,01$ & $\mathbf{0 , 0 3 5}$ \\
\hline KINDL Freunde (KFB) & $75,20 \pm 15,33$ & $76,49 \pm 14,45$ & 0,079 \\
\hline KINDL Körperliches Wohlbefinden (KFB) & $66,05 \pm 16,84$ & $61,11 \pm 17,36$ & $<\mathbf{0 , 0 0 1}$ \\
\hline KINDL Psychisches Wohlbefinden (KFB) & $79,48 \pm 14,78$ & $79,29 \pm 14,11$ & 0,78 \\
\hline KINDL Schule (KFB) & $64,33 \pm 17,39$ & $62,00 \pm 17,49$ & $\mathbf{0 , 0 0 6}$ \\
\hline KINDL Selbstwert (KFB) & $56,36 \pm 18,46$ & $56,43 \pm 18,36$ & 0,93 \\
\hline & & & \\
\hline KINDL Total Quality of life (EFB) & $73,28 \pm 10,16$ & $72,89 \pm 10,61$ & 0,43 \\
\hline KINDL Familie (EFB) & $76,07 \pm 14,89$ & $76,99 \pm 16,35$ & 0,21 \\
\hline KINDL Freunde (EFB) & $75,90 \pm 14,27$ & $79,46 \pm 11,84$ & $<\mathbf{0 , 0 0 1}$ \\
\hline KINDL Körperliches Wohlbefinden (EFB) & $70,96 \pm 17,74$ & $67,38 \pm 18,34$ & $<\mathbf{0 , 0 0 1}$ \\
\hline KINDL Psychisches Wohlbefinden (EFB) & $78,82 \pm 13,14$ & $78,23 \pm 13,52$ & 0,36 \\
\hline KINDL Schule (EFB) & $71,17 \pm 15,66$ & $68,60 \pm 16,42$ & $\mathbf{0 , 0 0 1}$ \\
\hline KINDL Selbstwert (EFB) & $66,84 \pm 15,27$ & $66,61 \pm 15,89$ & 0,75 \\
\hline
\end{tabular}

Zudem wurden die psychosozialen Stärken und Schwächen der Probanden mit dem SDQFragebogen erfasst. Die Ergebnisse der Selbstbeurteilung der Jugendlichen zeigten bei der Auswertung einen signifikanten Unterschied bei den „emotionalen Problemen“ ( $p=0,005)$ Bei den Anwenderinnen gab es eine Zunahme der „emotionalen Probleme“. Im Fremdbeurteilungsfragebogen der Eltern zeigten die „Peer-Probleme“ der Jugendlichen signifikante Unterschiede $(p=0,002)$, denn die Eltern empfanden geringere „Peer-Probleme“ unter der Einnahme von Kontrazeptiva (Tab. 4). 
Ergebnisse

Tabelle 4: Auswertung des SDQ-Fragebogens mit der deskriptiven Statistik inklusive der pWerte und Mittelwerte. Die Abkürzung KFB bezieht sich auf den Kinderfragebogen; EFB meint Elternfragebogen.

\begin{tabular}{|l|c|c|c|}
\hline & $\begin{array}{c}\text { Nichtanwenderinnen } \\
(\mathrm{n}=2234)\end{array}$ & $\begin{array}{c}\text { Anwenderinnen } \\
(\mathrm{n}=541)\end{array}$ & p-Wert \\
\hline SDQ Emotionale Probleme (KFB) & $3,10 \pm 2,14$ & $3,39 \pm 2,11$ & $\mathbf{0 , 0 0 5}$ \\
\hline SDQ Hyperaktivität (KFB) & $3,57 \pm 1,99$ & $3,58 \pm 2,00$ & 0,875 \\
\hline SDQ Peer-Probleme (KFB) & $2,04 \pm 1,57$ & $1,95 \pm 1,39$ & 0,188 \\
\hline SDQ Prosoziales Verhalten (KFB) & $8,25 \pm 1,53$ & $8,22 \pm 1,47$ & 0,691 \\
\hline SDQ Verhaltensprobleme (KFB) & $1,92 \pm 1,33$ & $2,01 \pm 1,32$ & 0,140 \\
\hline & & & \\
\hline SDQ Emotionale Probleme (EFB) & $1,90 \pm 1,87$ & $1,99 \pm 1,90$ & 0,286 \\
\hline SDQ Hyperaktivität (EFB) & $2,18 \pm 1,95$ & $2,18 \pm 1,91$ & 0,986 \\
\hline SDQ Peer-Probleme (EFB) & $1,47 \pm 1,60$ & $1,23 \pm 1,37$ & $\mathbf{0 , 0 0 2}$ \\
\hline SDQ Prosoziales Verhalten (EFB) & $7,95 \pm 1,68$ & $7,80 \pm 1,63$ & 0,062 \\
\hline SDQ Verhaltensprobleme (EFB) & $1,75 \pm 1,42$ & $1,87 \pm 1,62$ & 0,085 \\
\hline
\end{tabular}

\subsection{Korrelation zwischen 25(OH)-Vitamin D und hämatologischen Parametern unter der Einnahme von Kontrazeptiva}

Um die Zusammenhänge zwischen der Einnahme von Kontrazeptiva bei Jugendlichen und den hämatologischen Parametern zu prüfen, wurde der Korrelationskoeffizient nach Pearson bestimmt. Zuvor wurden einige Parameter logarithmiert, um der Normalverteilungskurve der Laborparameter näher zu kommen. Dies wurde für 25(OH)-Vitamin D, der alkalischen Phosphatase, Ferritin, dem löslichen Transferrinrezeptor, Vitamin $\mathrm{B}_{12}$, HDL-Cholesterin, das gesamte Cholesterin, Triglyceride und LDL-Cholesterin vorgenommen. In den Abbildungen (Abb. 2 bis 10) wurde die Verteilung dieser Parameter entsprechend mit Korrektur durch Logarithmierung im Histogramm graphisch dargestellt. 
Ergebnisse

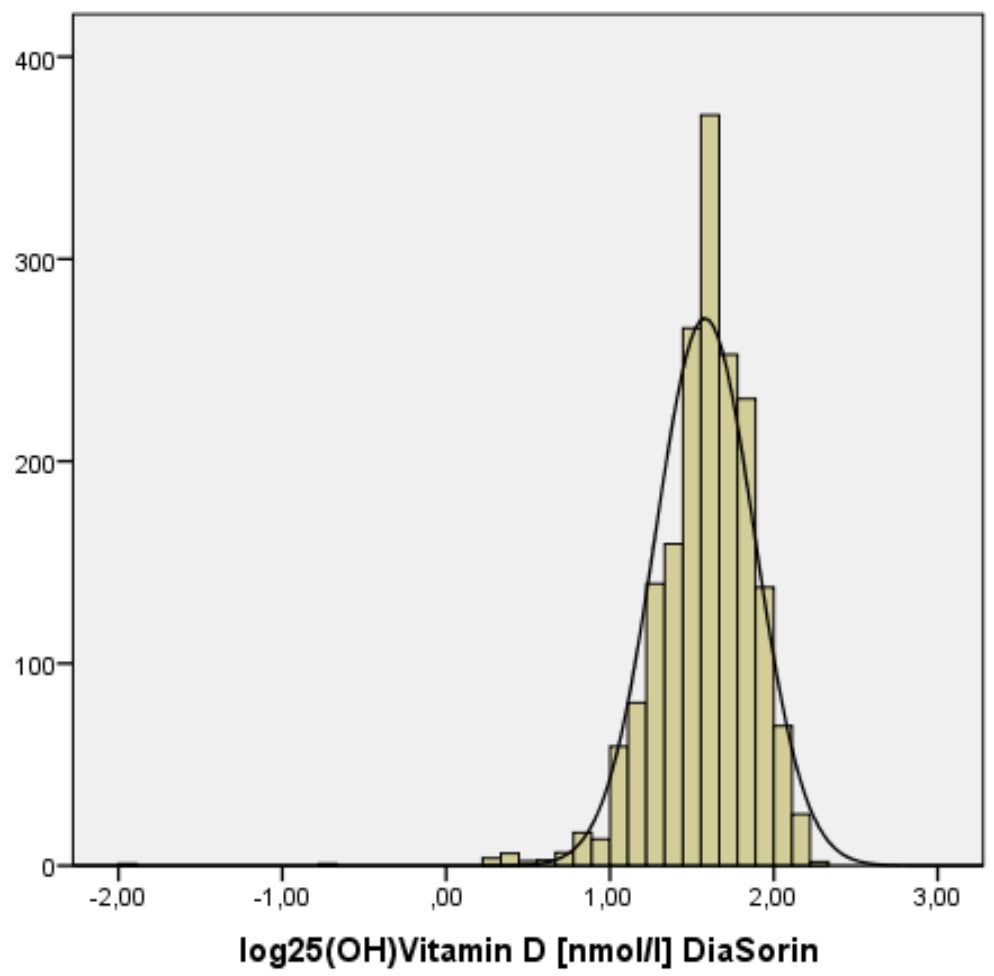

Abbildung 2: Verteilungskurve der logarithmierten Serumkonzentrationen von 25(OH)Vitamin D in der gesamten Untersuchungspopulation.

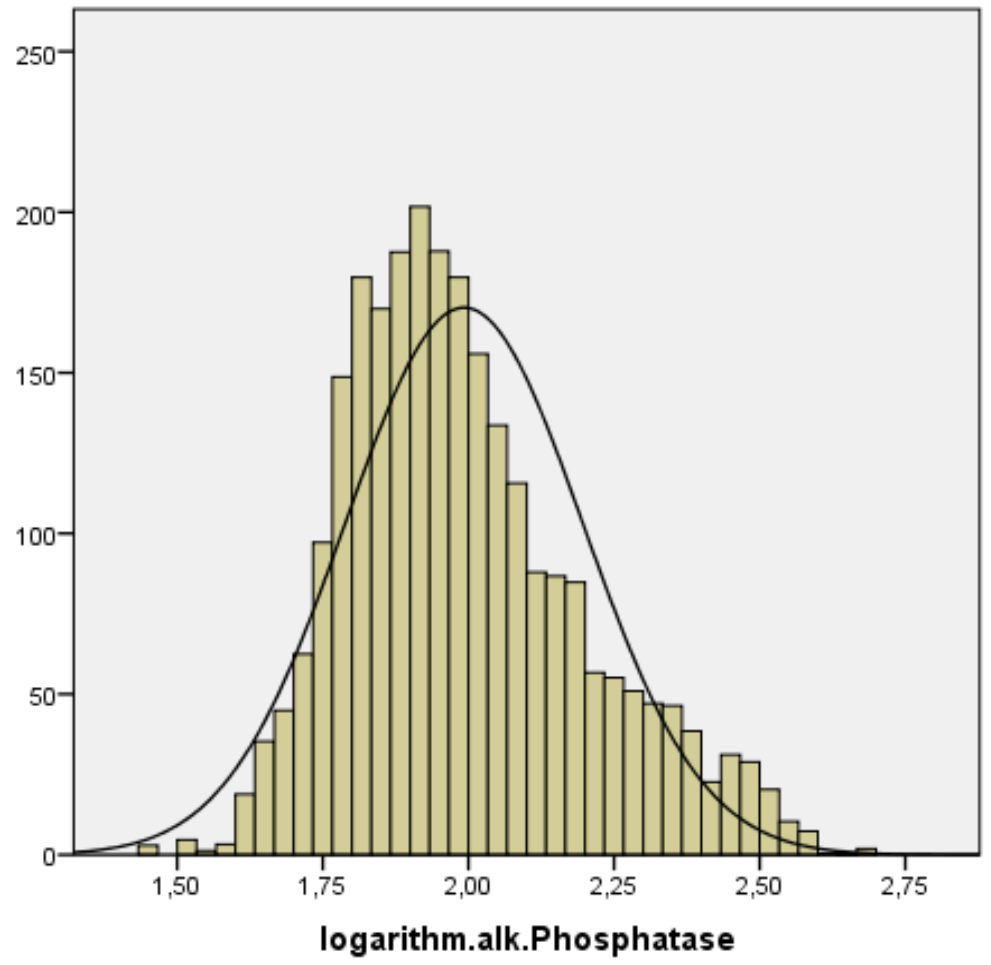

Abbildung 3: Normverteilungskurve der logarithmierten Werte der alkalischen Phosphatase. 


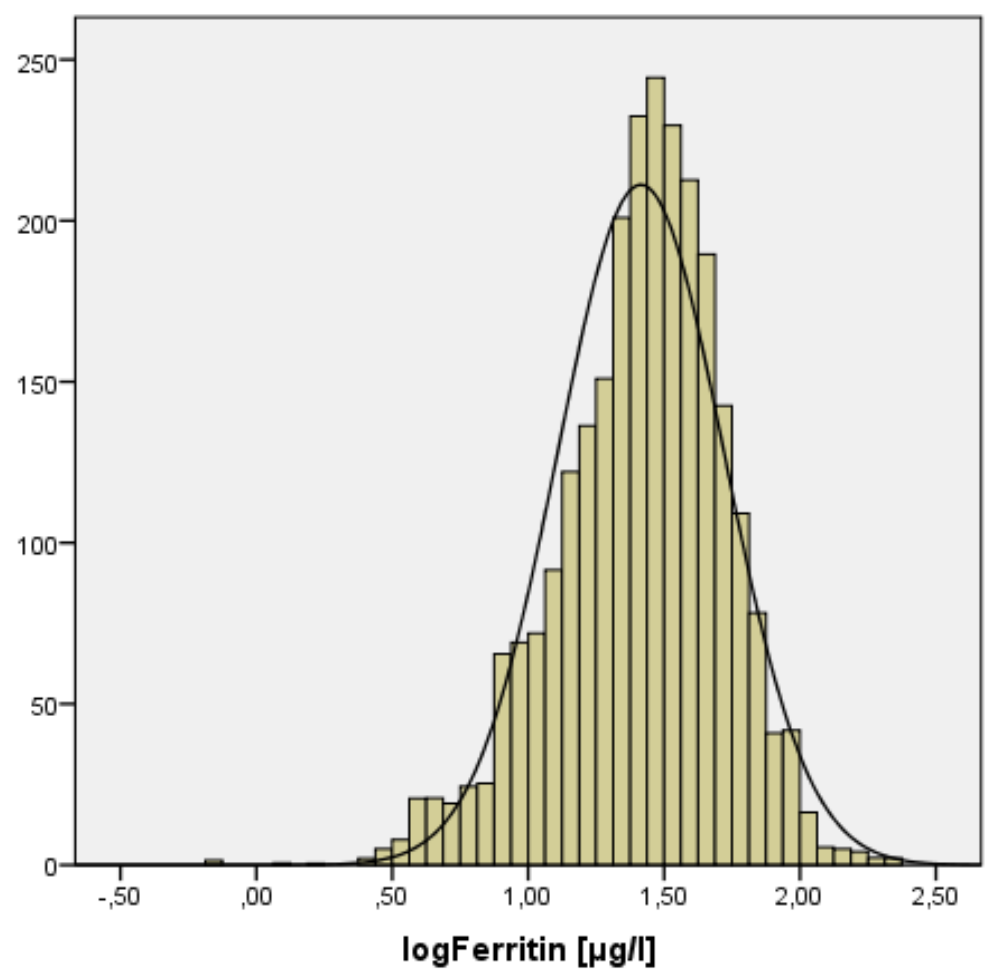

Abbildung 4: Verteilung der Häufigkeitskurve von logarithmierten Ferritin.

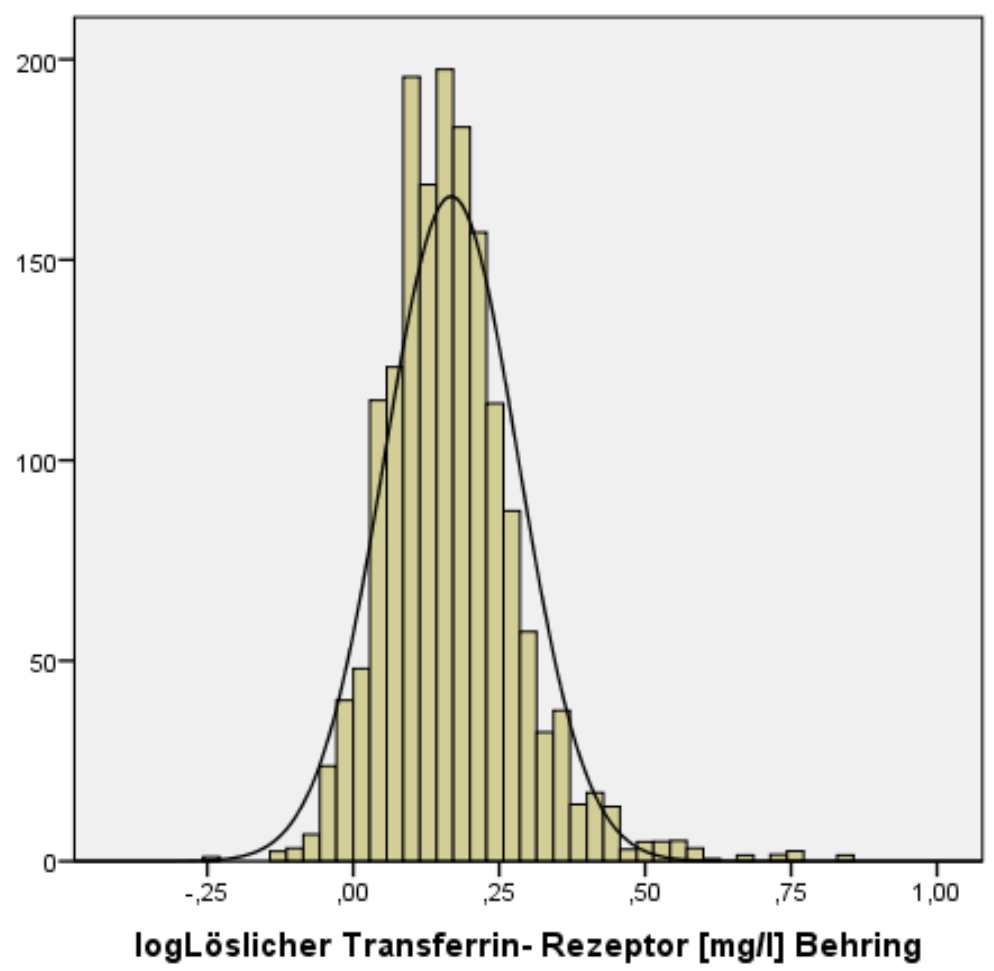

Abbildung 5: Verteilungskurve der ermittelten Laborwerte des logarithmierten sTfR. 
Ergebnisse

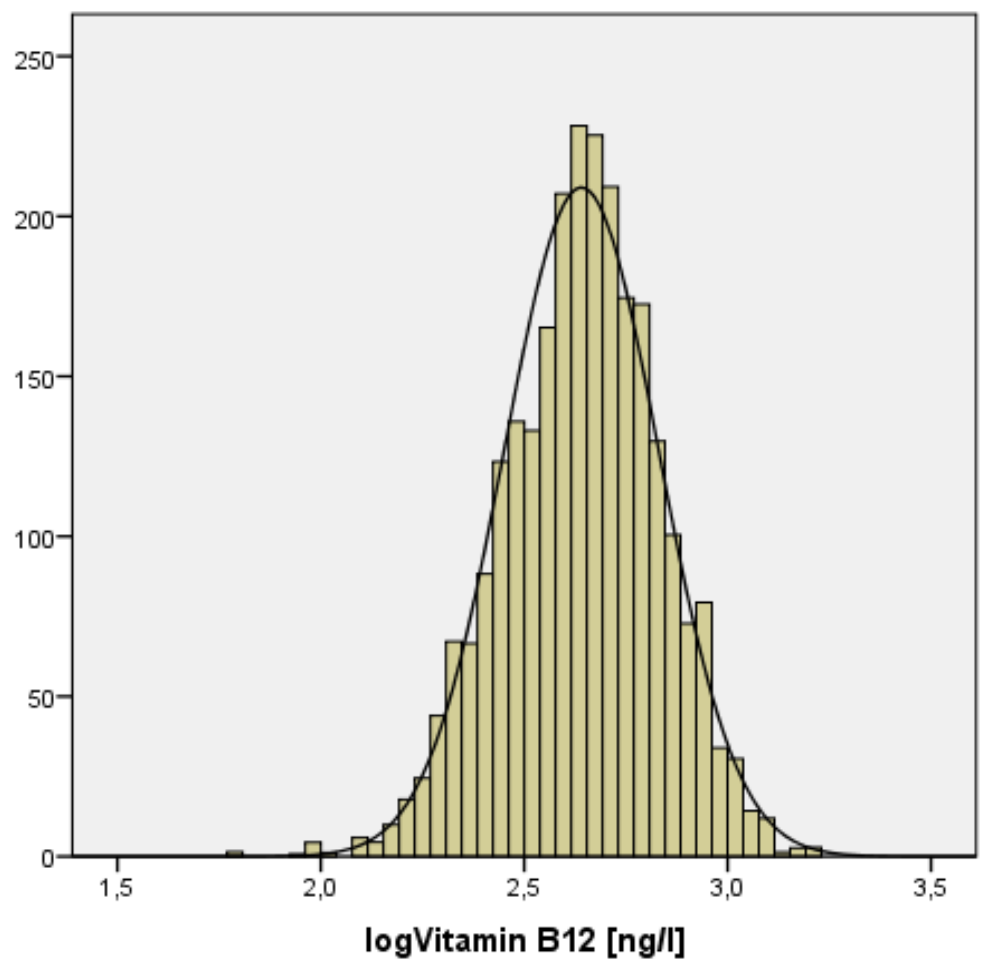

Abbildung 6: Darstellung der Häufigkeitsverteilung der Serumkonzentration von Vitamin $\mathrm{B}_{12}$ im logarithmierten Maßstab.

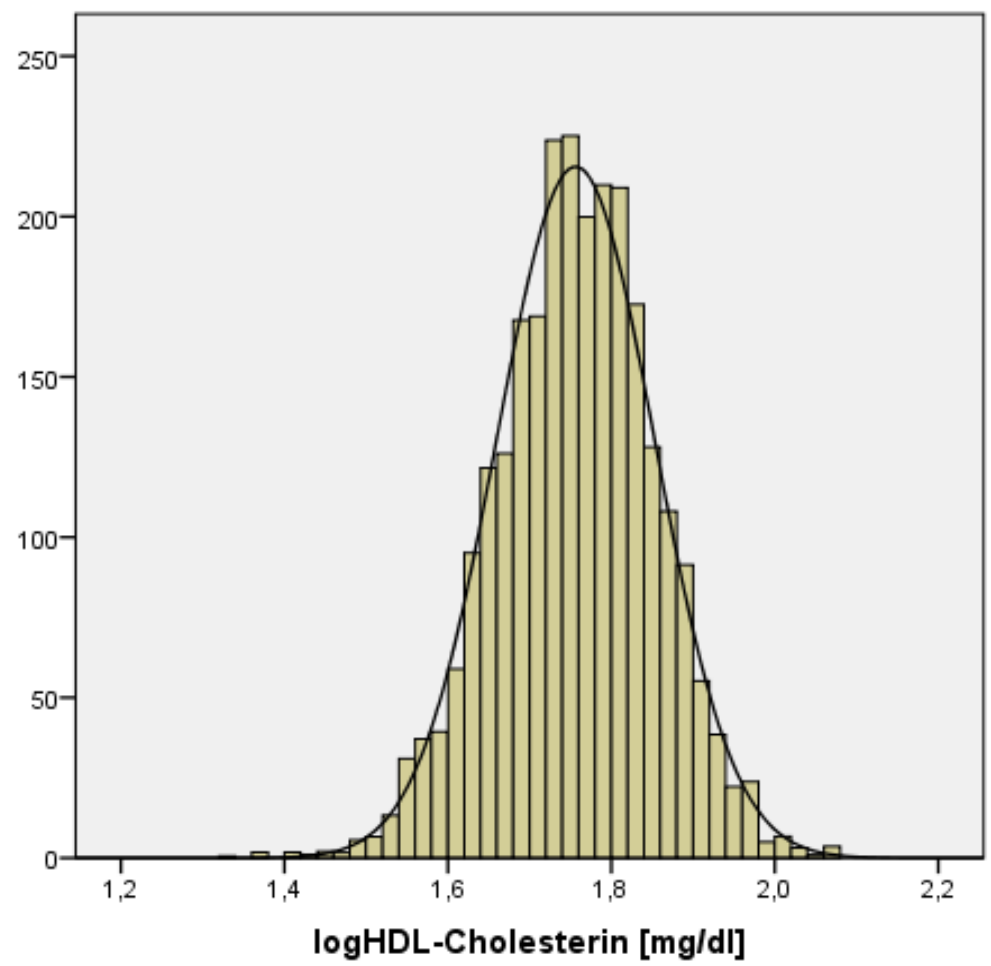

Abbildung 7: Darstellung der logarithmierten Häufigkeitskurve von HDL-Cholesterin in der Untersuchungskohorte. 
Ergebnisse

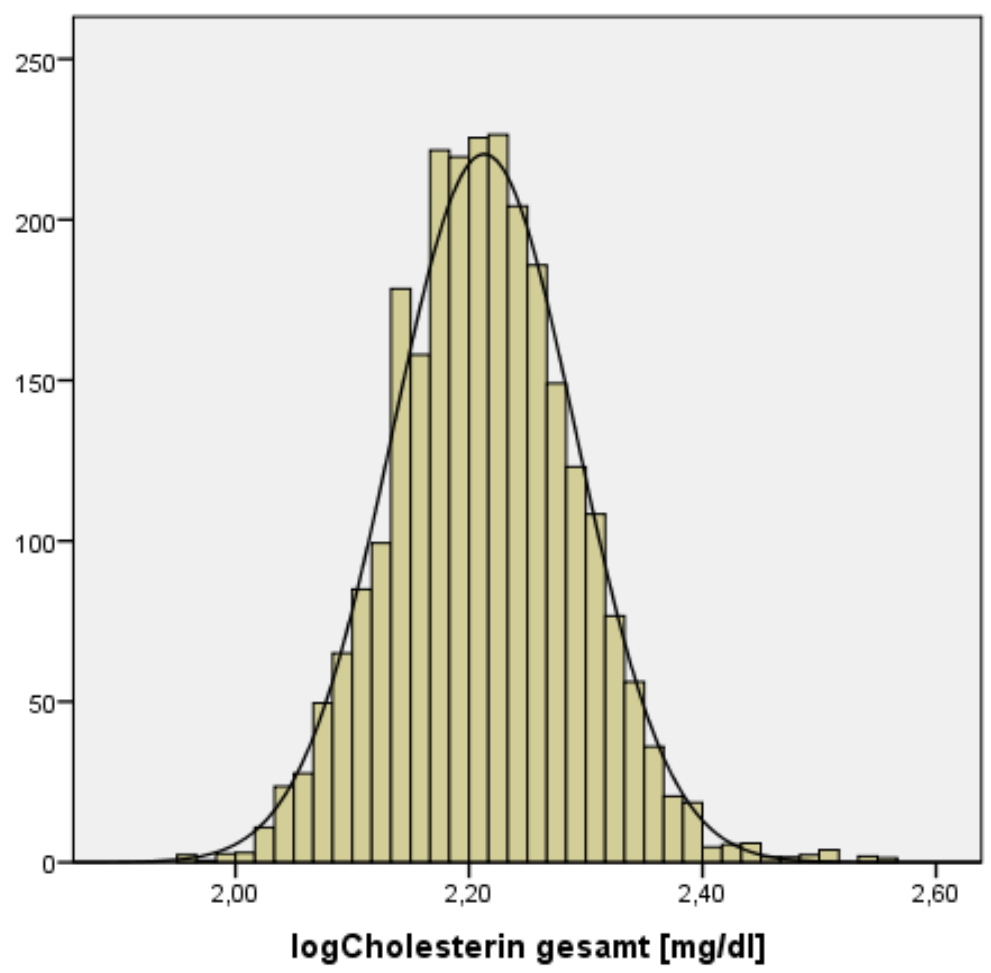

Abbildung 8: Darstellung der logarithmierten Häufigkeitsverteilung von Cholesterin.

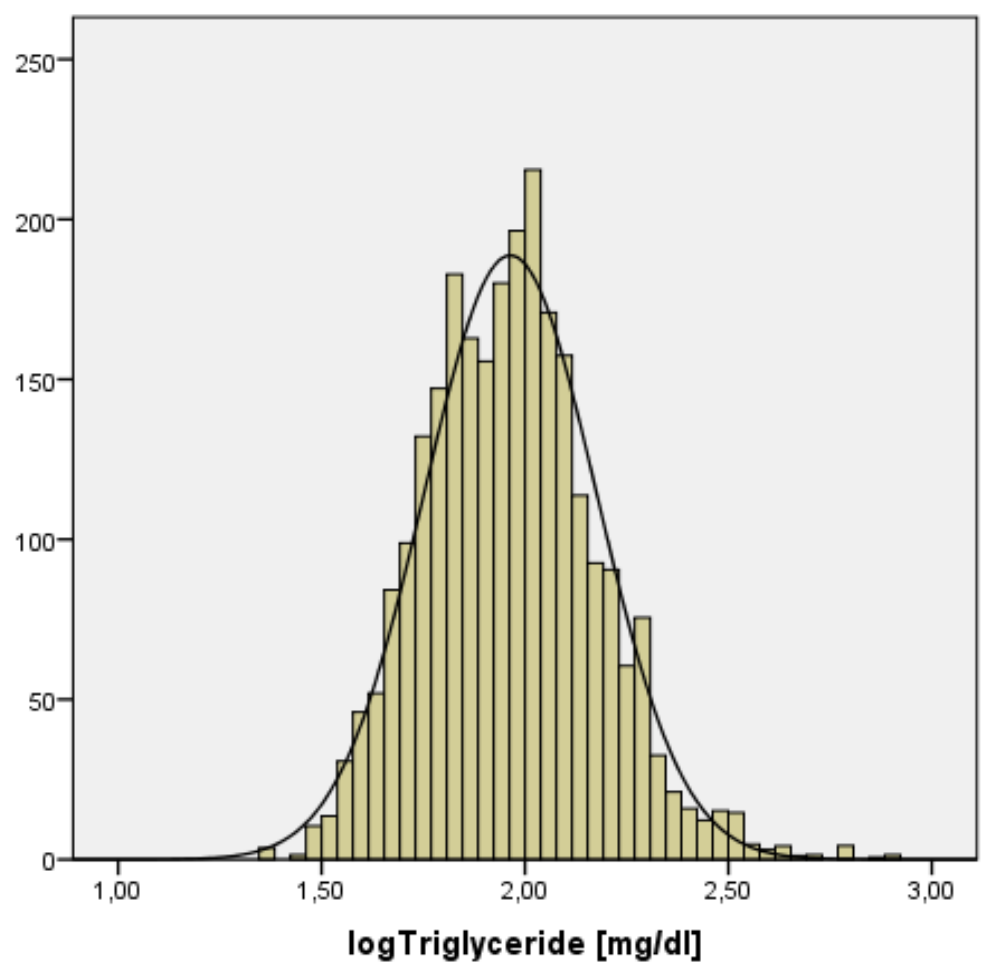

Abbildung 9: Logarithmierte Verteilung der Werte von Triglycerid im Blutserum. 


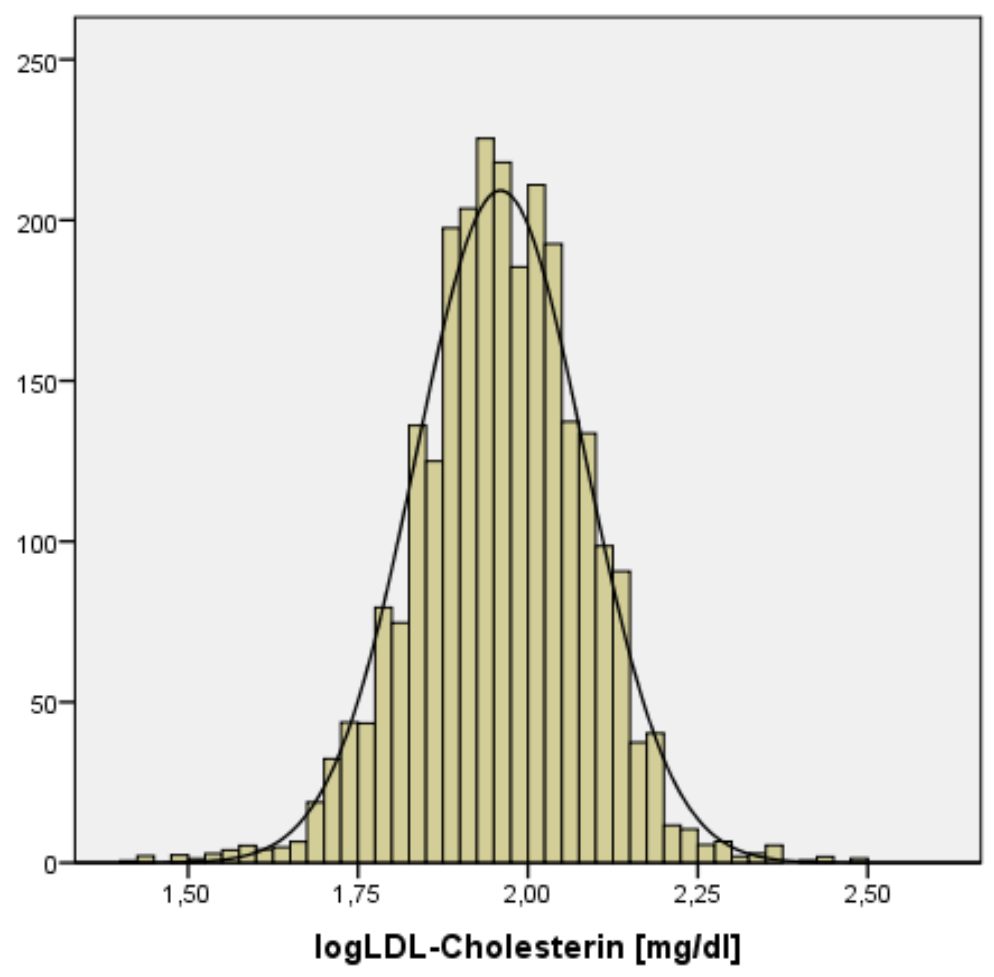

Abbildung 10: Darstellung der Häufigkeitsverteilung des logarithmierten LDL-Cholesterins.

Um einen Zusammenhang zwischen den hämatologischen Parametern unter Einnahme von Kontrazeptiva zu zeigen, wurde mit den logarithmierten Parametern anschließend der Korrelationkoeffizient nach Pearson mit dem zugehörigen p-Wert für die Gesamtkohorte bestimmt. Die Korrelation wurde mit der Variable Vitamin D geprüft, welche als ein Parameter für den Knochenstoffwechsel eingeführt ist.

Die Ergebnisse der Korrelation zeigten, dass das 25(OH)-Vitamin D negative Assoziationen mit dem RBC ( $\mathrm{r}=-0,072 ; \mathrm{p}=, 002)$, der MCHC ( $\mathrm{r}=-0,111 ; \mathrm{p}<0,001)$, dem sTfR-Gehalt $(\mathrm{r}$ $=-0,123 ; \mathrm{p}<0,001)$ und Vitamin $\mathrm{B}_{12}(\mathrm{r}=-0,058 ; \mathrm{p}=0,014)$ zeigte. Positive Korrelationen unter Kontrazeptiva-Einnahme gab es zwischen dem Blutserumspiegel von Vitamin D und $\operatorname{der} \mathrm{MCH}(\mathrm{r}=0,047 ; \mathrm{p}=0,043)$ sowie dem MCV ( $\mathrm{r}=0,136 ; \mathrm{p}<0,001)$ der Erythrozyten der Probandinnen. 


\section{Ergebnisse}

Tabelle 5: Zusammenhänge zwischen Vitamin D und den aufgeführten hämatologischen Parameter in der Untersuchungskohorte mithilfe der Korrelation nach Pearson, inklusive des jeweiligen Korrelationskoeffizienten und p-Wertes

\begin{tabular}{|l|c|c|}
\hline & Korrelationskoeffizient r & p-Wert \\
\hline RBC $\left[\mathrm{x} 10^{6} / \mathrm{ml}\right]$ & $-0,072$ & $\mathbf{0 , 0 0 2}$ \\
\hline Hämatokrit $[\%]$ & 0,012 & 0,601 \\
\hline $\mathrm{Hb}[\mathrm{g} / \mathrm{dl}]$ & $-0,037$ & 0,113 \\
\hline $\mathrm{MCH}[\mathrm{pg}]$ & 0,047 & $\mathbf{0 , 0 4 3}$ \\
\hline $\mathrm{MCHC}[\mathrm{g} / \mathrm{dl}]$ & $-0,111$ & $<\mathbf{0 , 0 0 1}$ \\
\hline $\mathrm{MCV}[\mathrm{fl}]$ & 0,136 & $<\mathbf{0 , 0 0 1}$ \\
\hline Eisen $[\mu \mathrm{mol} / \mathrm{l}]$ & 0,023 & 0,326 \\
\hline sTfR $[\mathrm{mg} / \mathrm{l}]$ & $-0,123$ & $<\mathbf{0 , 0 0 1}$ \\
\hline Ferritin $[\mu \mathrm{g} / \mathrm{l}]$ & 0,04 & 0,088 \\
\hline Vitamin $\mathrm{B}_{12}[\mathrm{ng} / \mathrm{l}]$ & $-0,058$ & $\mathbf{0 , 0 1 4}$ \\
\hline
\end{tabular}

Das Ergebnis der Post-hoc-Analyse zeigte bereits eine signifikant erhöhte 25(OH)-VitaminD-Konzentration im Blutserum der Anwenderinnen. Die Ergebnisse der einzelnen Korrelationen zwischen dem 25(OH)-Vitamin D im Serum und den klinisch-chemischen Parametern wurden in den Abb. 11 bis 20 graphisch für die Gesamtkohorte dargestellt. Diese sind im Blot-Spot-Diagramm graphisch für log sTfR, MCV, MCH, Hkt, log Ferritin, Eisen, $\log$ Vitamin $\mathrm{B}_{12}, \mathrm{RBC}, \mathrm{Hb}$ und MCHC dargestellt. Hierbei ist eine Rechtsverschiebung von 25(OH)-Vitamin D in der Gruppe der Anwenderinnen (hellgrau) von Kontrazeptiva in allen Grafiken zu erkennen. Die Steigung der Geraden zeigte an, ob sich mit zunehmender Serumkonzentration von 25(OH)-Vitamin D die Durchschnittskonzentration des geprüften Parameters stieg oder sank. Bei Anwenderinnen ist die Gerade als gestrichelte Linie und bei Nichtanwenderinnen als durchgehende Linie dargestellt. 
Ergebnisse

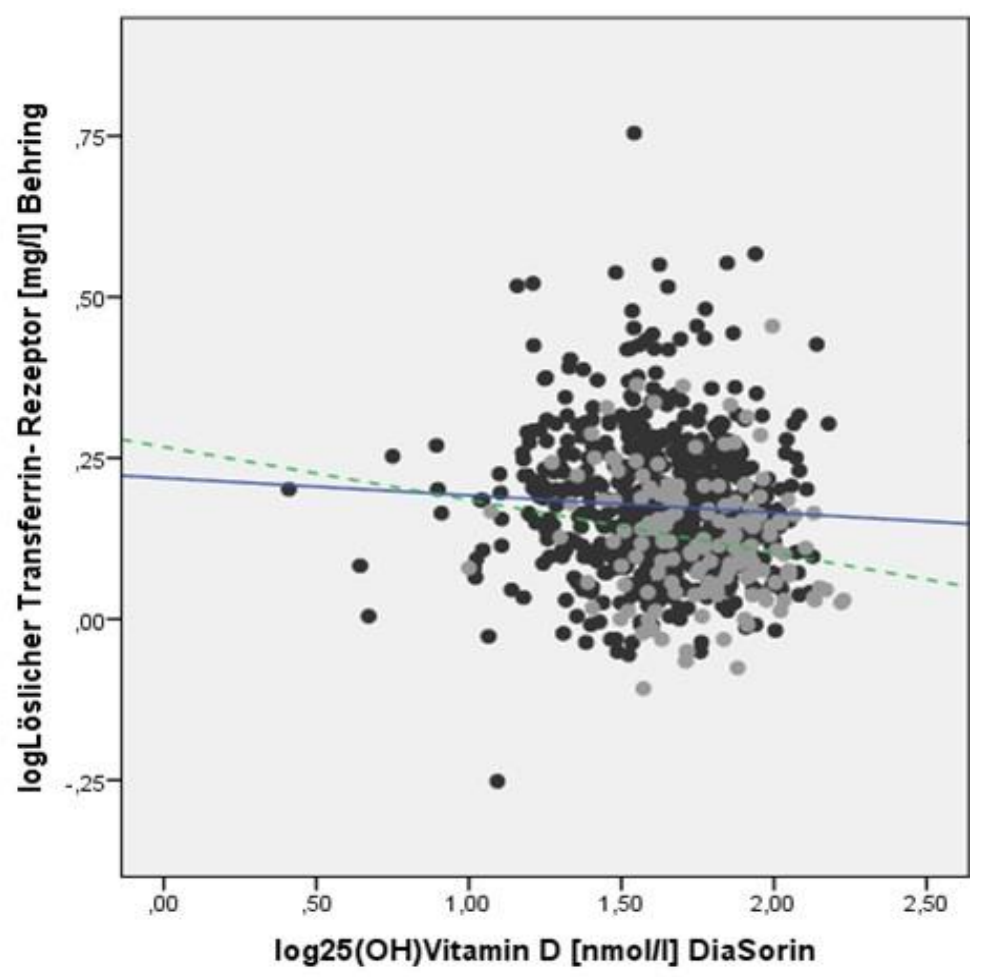

Abbildung 11: Darstellung der Korrelation im Blot-Spot-Diagramm zwischen log 25(OH)Vitamin D und log sTfR. Rechtsverschiebung der Anwenderinnen (hellgrau) im Vergleich zu den Nichtanwenderinnen (dunkelgrau). Abfallende Steigung der Anwenderinnen (gestrichelt) und leicht abfallende Steigung der Nichtanwenderinnen (durchgezogene Linie). 
Ergebnisse

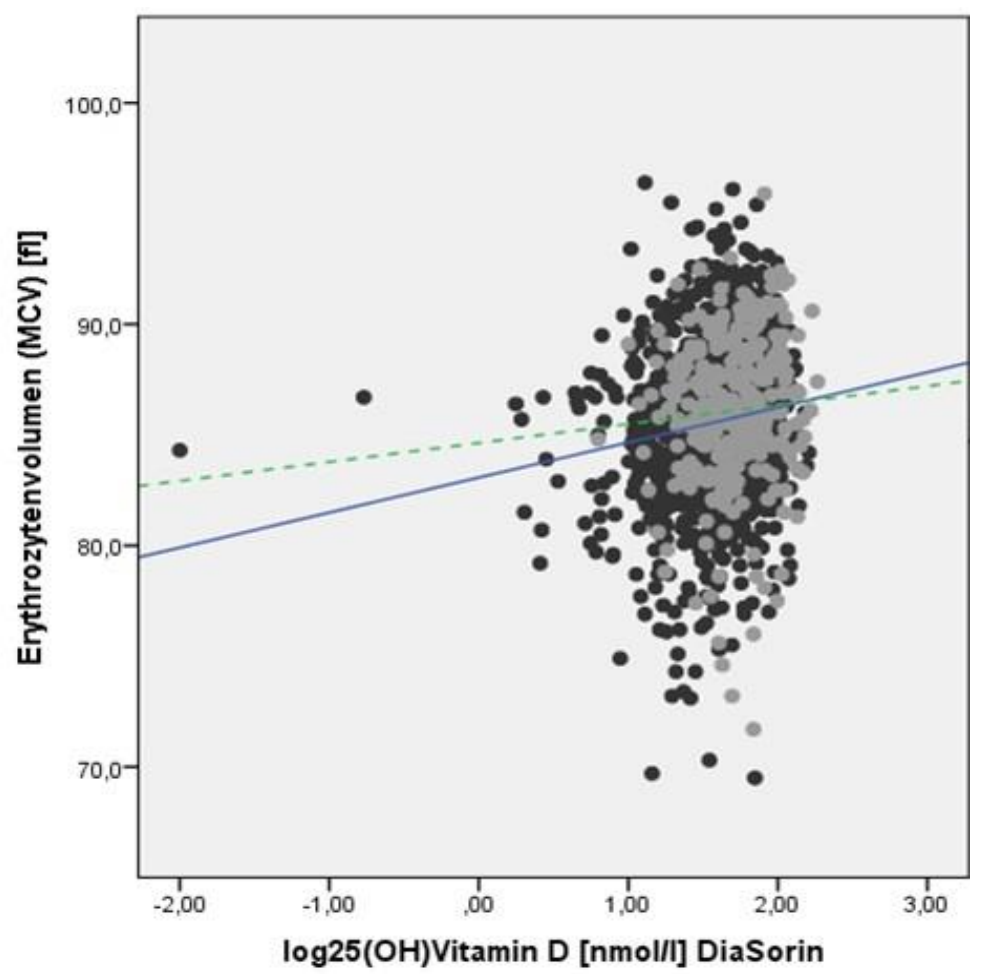

Abbildung 12: Korrelation von log 25(OH)-Vitamin D und MCV. Rechtsverschiebung der Anwenderinnen (hellgrau) im Vergleich zu den Nichtanwenderinnen (dunkelgrau). Positive Steigung der Anwenderinnen (gestrichelt) und stärker positive Steigung der Nichtanwenderinnen (durchgezogene Linie). 
Ergebnisse

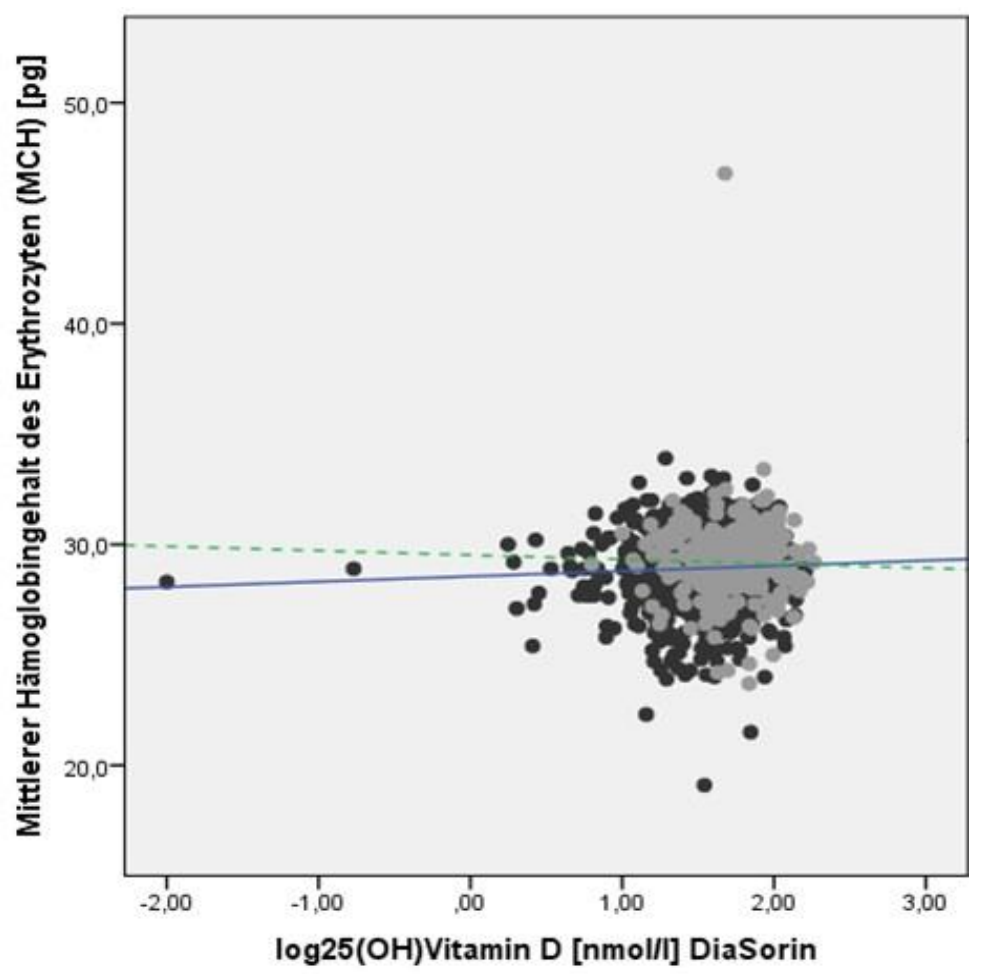

Abbildung 13: Darstellung der Korrelation zwischen $\log 25(\mathrm{OH})-$ Vitamin D und MCH. Rechtsverschiebung der Anwenderinnen (hellgrau) im Vergleich zu den Nichtanwenderinnen (dunkelgrau). Nahezu horizontale Lage der Korrelationsgeraden zur x-Achse bei den Anwenderinnen (gestrichelt) und positive Steigung der Gerade bei den Nichtanwenderinnen (durchgezogene Linie). 
Ergebnisse

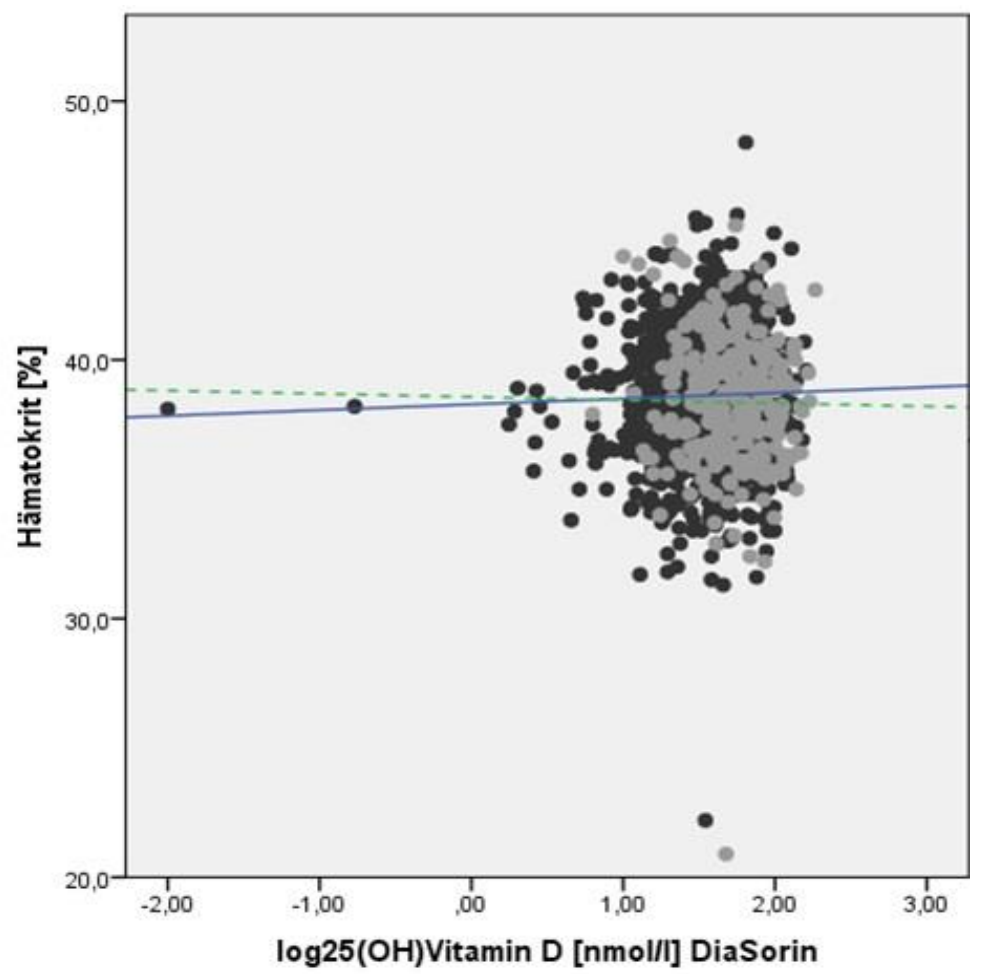

Abbildung 14: Korrelation zwischen $\log 25(\mathrm{OH})$-Vitamin D und dem Hkt im Blot-SpotDiagramm. Rechtsverschiebung der Anwenderinnen (hellgrau) im Vergleich zu den Nichtanwenderinnen (dunkelgrau). Schwach ausgeprägte Steigung der Ausgleichsgeraden bei den Anwenderinnen (gestrichelt) und positive Steigung bei den Nichtanwenderinnen (durchgezogene Linie). 


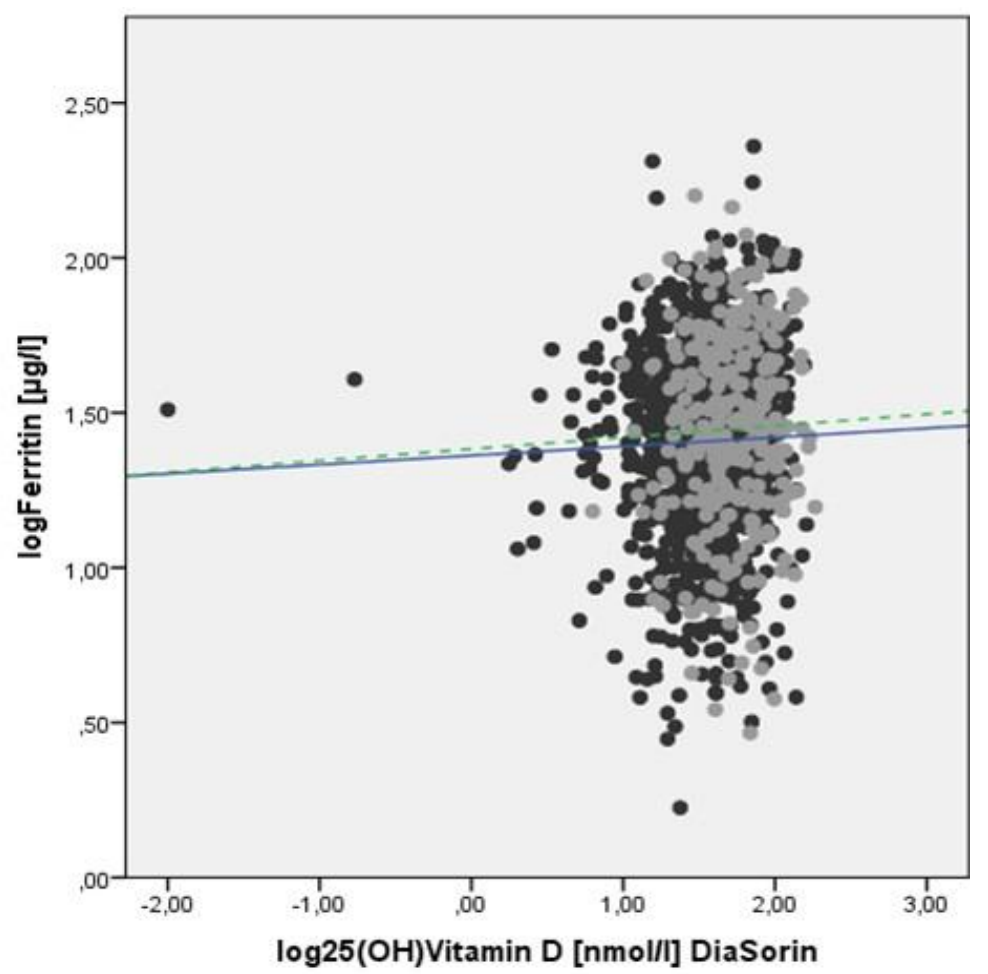

Abbildung 15: Blot-Spot-Diagramm von $\log 25(\mathrm{OH})$-Vitamin D und log Ferritin. Dargestellt ist die Rechtsverschiebung der Anwenderinnen (hellgrau) im Vergleich zu den Nichtanwenderinnen (dunkelgrau). Anwenderinnen (gestrichelt) weisen eine positive Steigung und Nichtanwenderinnen (durchgezogene Linie) eine schwächere, aber dennoch positive Steigung der Ausgleichsgeraden auf. 
Ergebnisse

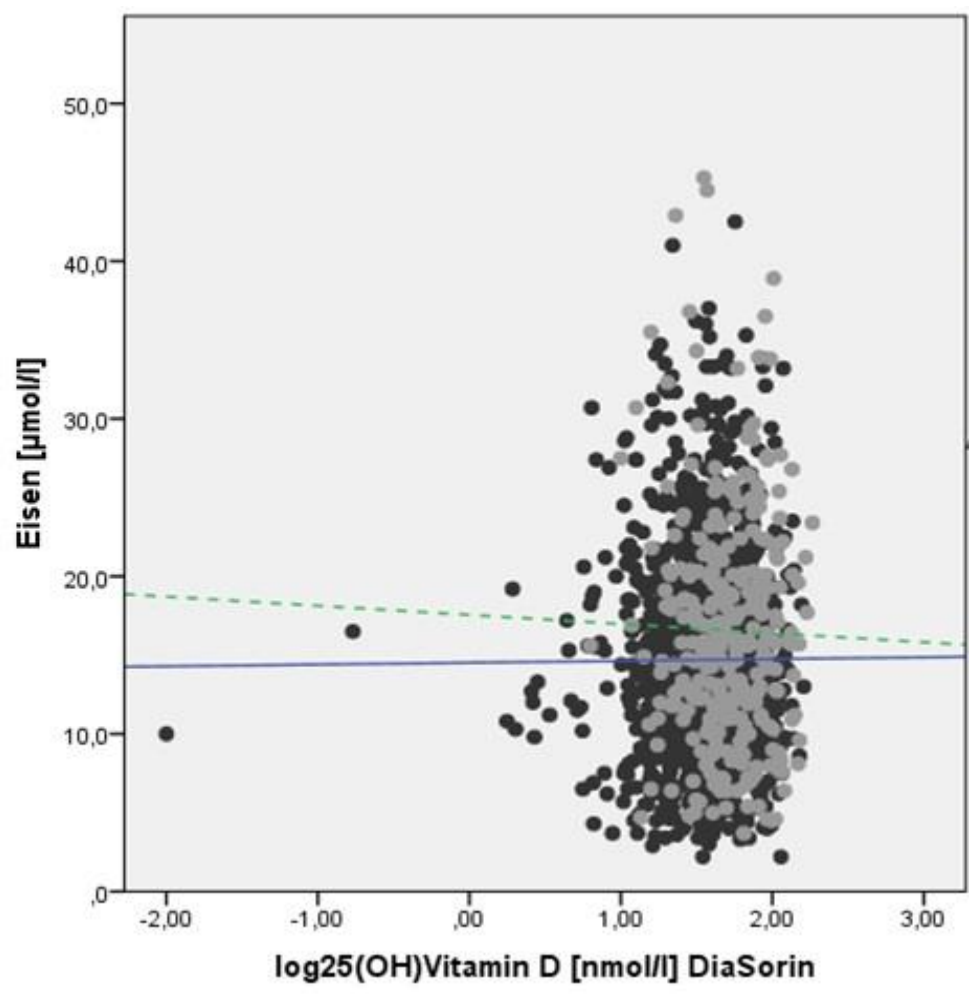

Abbildung 16: Darstellung der Korrelation im Blot-Spot-Diagramm zwischen log 25(OH)Vitamin D und Eisen. Die Anwenderinnen (hellgrau) haben eine Rechtsverschiebung der Punktewolke im Vergleich zu den Nichtanwenderinnen (dunkelgrau). Die Anwenderinnen zeigen eine Ausgleichsgerade (gestrichelt) mit einer negativen Steigung und die Nichtanwenderinnen (durchgezogene Linie) mit einer schwach positiven Steigung. 


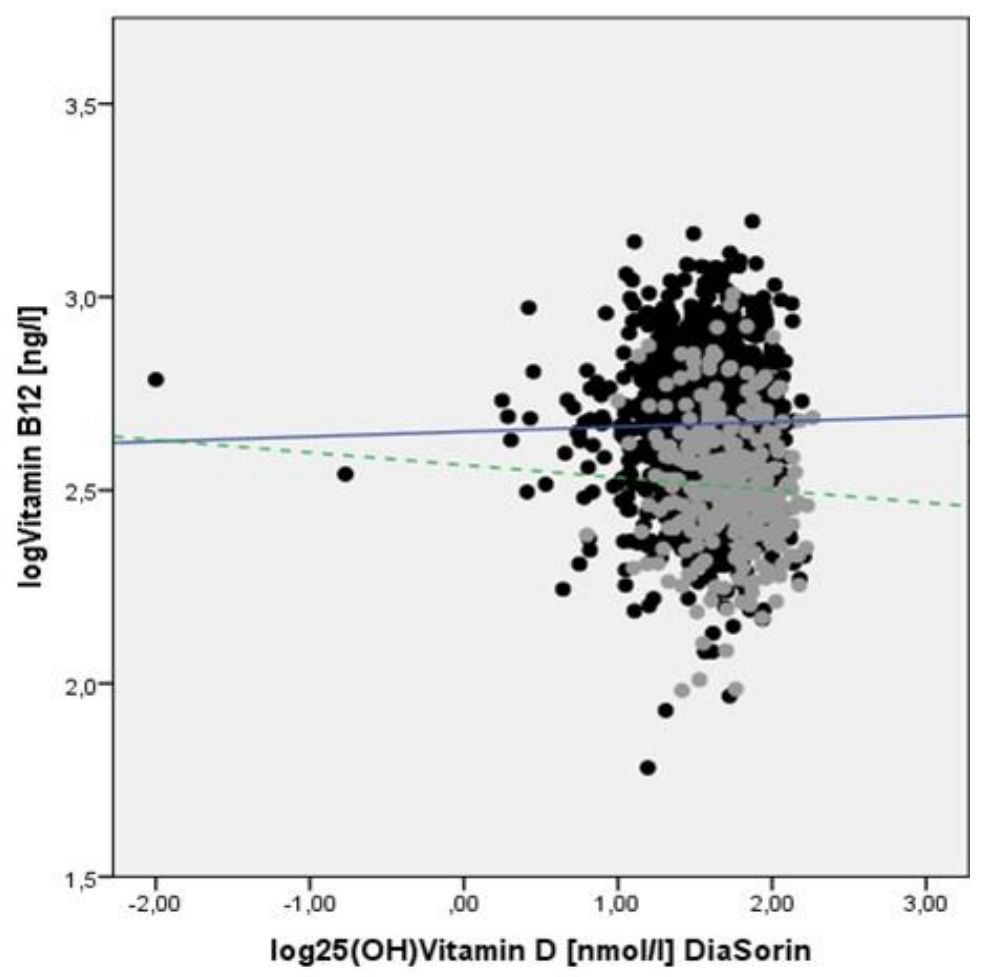

Abbildung 17: Korrelation zwischen $\log 25(\mathrm{OH})$-Vitamin D und $\log$ Vitamin $\mathrm{B}_{12}$ im BlotSpot-Diagramm abgebildet. Die Datenpunkte haben bei den Anwenderinnen (hellgrau) haben sich im Vergleich zu den Nichtanwenderinnen (dunkelgrau) rechtsverschoben und zu niedrigeren Vitamin- $B_{12}$-Werten verlagert. Gezeigt sind die beiden Ausgleichsgeraden mit negativer Steigung bei den Anwenderinnen (gestrichelt) und positiver Steigung bei den Nichtanwenderinnen (durchgezogene Linie). 


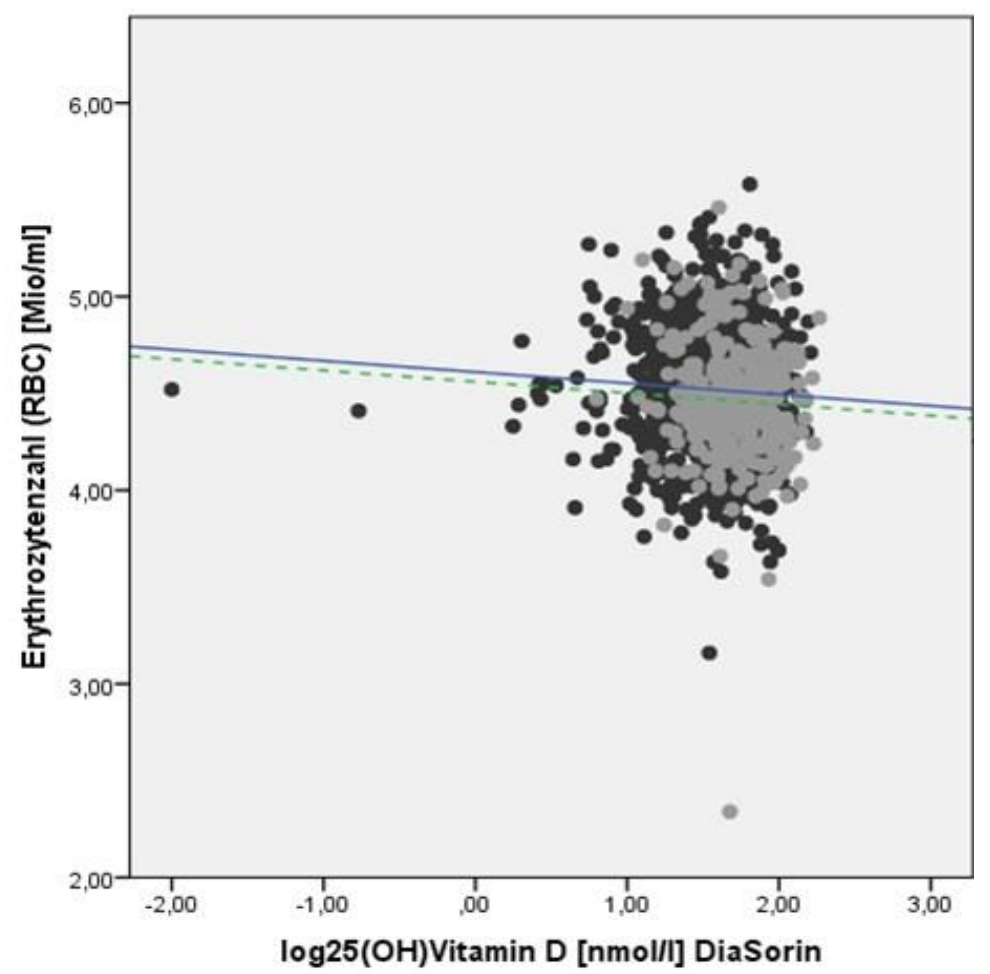

Abbildung 18: Darstellung der Korrelation von log 25(OH)-Vitamin D und der RBC. Wieder ist eine Rechtsverschiebung der Anwenderinnen (hellgrau) im Vergleich zu den Nichtanwenderinnen (dunkelgrau) zu erkennen. Abfallende Steigung der Korrelationsgeraden bei den Anwenderinnen von oralen Kontrazeptiva (gestrichelt) und nahezu parallel verlaufende negative Steigung der Geraden bei den Mädchen ohne Anwendung pharmakologischer Verhütungsmethoden (durchgezogene Linie). 
Ergebnisse

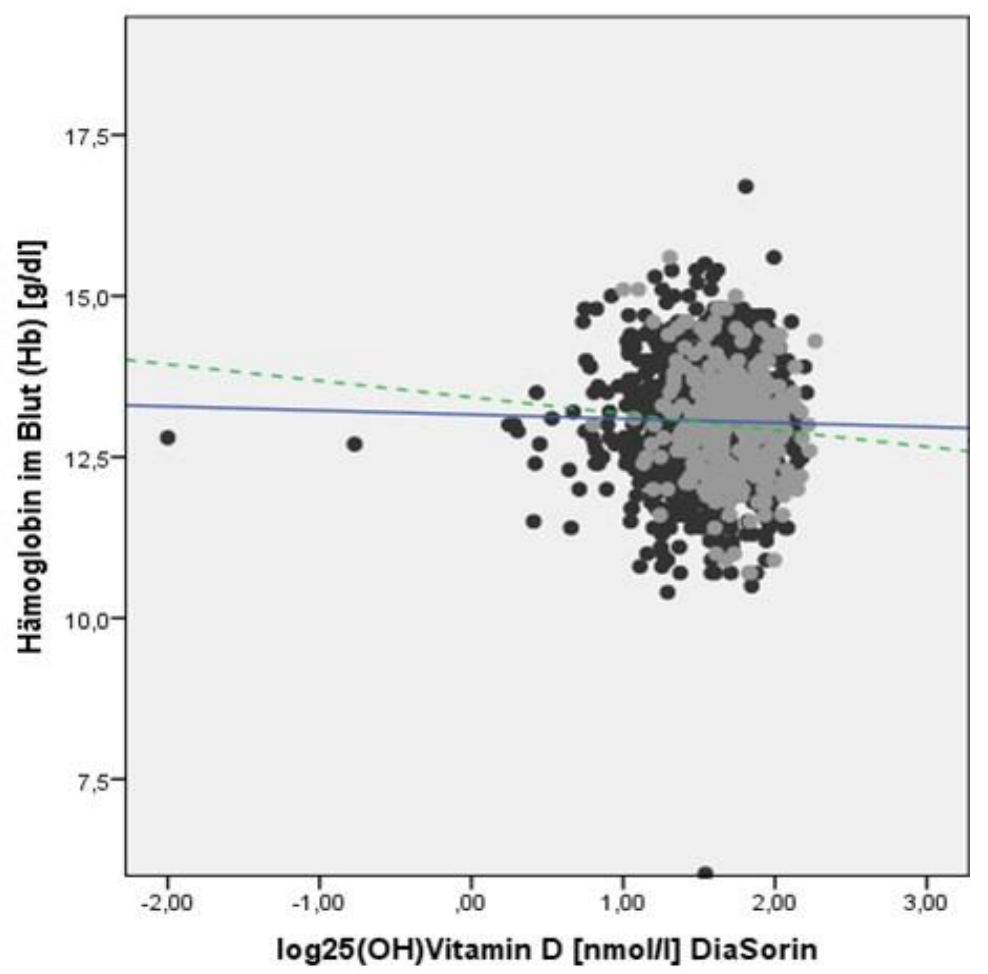

Abbildung 19: Korrelation zwischen $\log 25(\mathrm{OH})$-Vitamin $\mathrm{D}$ und $\mathrm{Hb}$ im Blot-SpotDiagramm dargestellt. Rechtsverschiebung der Verteilung der Datenpunkte bei den Anwenderinnen (hellgrau) im Vergleich zu den Nichtanwenderinnen (dunkelgrau). Die Ausgleichsgerade zeigt eine negative Steigung in der Kohorte der Anwenderinnen (gestrichelt) und eine abflachende Gerade mit negativer Steigung bei den Nichtanwenderinnen (durchgezogene Linie). 


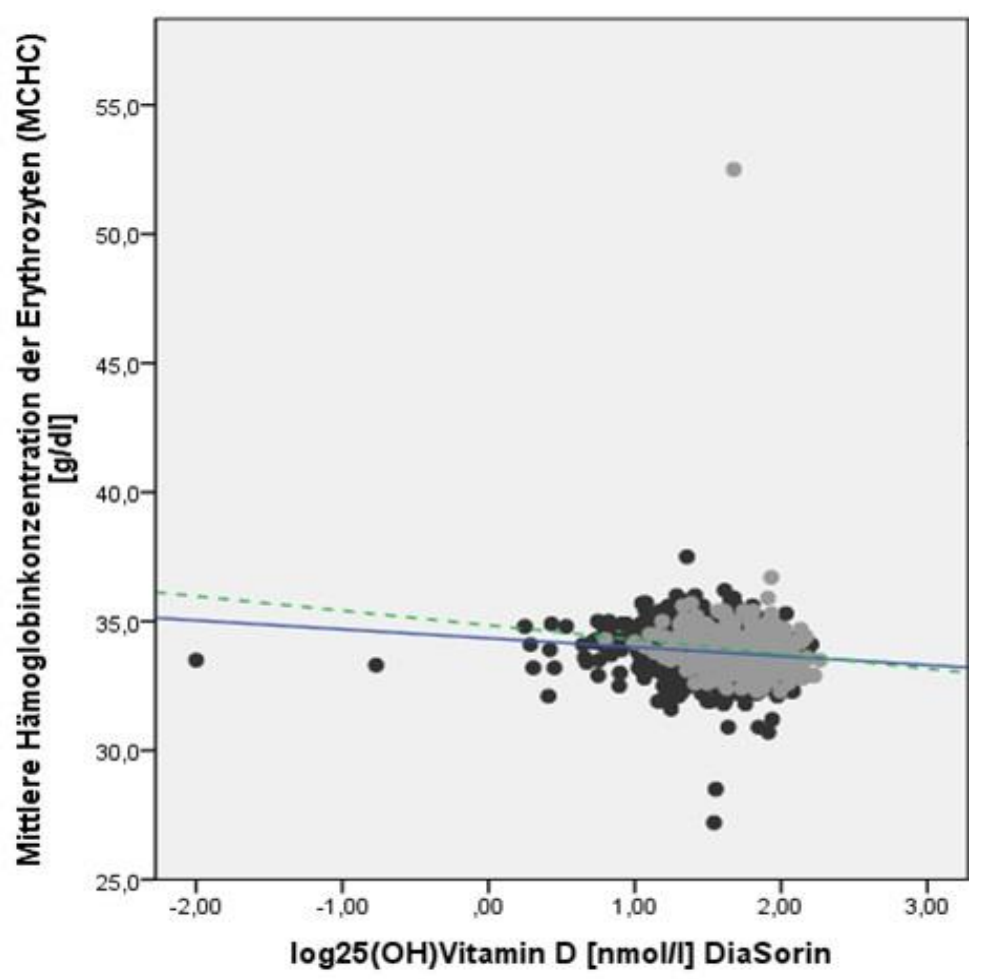

Abbildung 20: Darstellung der Korrelation im Blot-Spot-Diagramm zwischen log 25(OH)Vitamin D und MCHC. Rechtsverlagerung der Datenpunkte bei den Anwenderinnen (hellgrau) im Vergleich zu den Nichtanwenderinnen (dunkelgrau). Eingezeichnet sind die Ausgleichsgeraden mit den negativen Steigungen bei der erst genannten Gruppe (gestrichelt) sowie der Gruppe der Studienteilnehmer ohne Kontrazeptiva-Gebrauch (durchgezogene Linie).

\subsection{Hämatologische Parameter als Prädiktoren für die Einnahme oraler Kontrazeptiva}

Mittels logistischer Regressionsanalyse wurde untersucht, welche hämatologischen Parameter eine prädiktive Bedeutung für die Einnahme von Kontrazeptiva bei den weiblichen Jugendlichen haben. In jedem dieser Modelle wurden die folgenden, konfundierenden Variablen verwendet: Alter, Migrantenstatus, BMI, mittlerer systolischer Blutdruck, Vitamin $B_{12}$ sowie die mit dem Knochenstoffwechsel assoziierten Parameter Vitamin D, alkalische Phosphatase, anorganisches Phosphat und Kalzium. Die Werte wurden nach Bonferroni korrigiert. Es wurde mit den logarithmierten Parametern von sTfR, Ferritin, Vitamin $B_{12}$, Vitamin D, alkalische Phosphatase, HDL-Cholesterin, LDL-Cholesterin und Triglyceride gerechnet. Signifikante Parameter für die Vorhersage der Anwendung von Kontrazeptiva konnten für drei der geprüften Parameter ermittelt werden. Eisen $(\beta=0,022 ; 95 \%$-CI $=1,001-1,045 ; \mathrm{p}=$ 


\section{Ergebnisse}

0,043), s'TfR $(\beta=-3,472 ; 95 \%-C I=0,003-0,282 ; \mathrm{p}=0,002)$ und MCV $(\beta=-0,053 ; 95 \%$ $\mathrm{CI}=0,907-0,992 ; \mathrm{p}=0,022)$ waren signifikante Prädiktoren, während sich die anderen Parameter in diesem Modell als nicht signifikant erwiesen (Tab. 6). Bei dem Modell mit Einbeziehung der sTfR-Variable wurde als Pseudo-Bestimmtheitsmaß ein $\mathrm{R}^{2}$-Wert nach Cox und Snell von 0,346 ermittelt. Das gesamte Modell zeigte eine hohe Signifikanz $(\mathrm{p}<0,001)$.

Tabelle 6: Ergebnisse aus einer Serie von neun logistischen Regressionsmodellen mit hämatologischen Parametern als unabhängige Variable und der Anwendung von Kontrazeptiva als abhängiger Prädiktor. Adjustierung des Modells mit den Parametern Alter, BMI, Migrationshintergrund, Vitamin D, mittlerer systolischer Blutdruck, Kalzium, anorganisches Phosphat, alkalische Phosphatase und Vitamin $\mathrm{B}_{12}$.

\begin{tabular}{|l|c|c|c|c|}
\hline & Regressionskoeffizient $\beta$ & $95 \%-C l$ & T-Wert & p-Wert \\
\hline RBC $\left[\mathrm{x} 10^{6} / \mathrm{ml}\right]$ & 0,080 & $0,644-1,825$ & 1,084 & 0,762 \\
\hline Hämatokrit $[\%]$ & $-0,075$ & $0,775-1,110$ & 0,928 & 0,412 \\
\hline $\mathrm{Hb}[\mathrm{g} / \mathrm{dl}]$ & $-0,037$ & $0,904-1,026$ & 0,963 & 0,247 \\
\hline $\mathrm{MCH}[\mathrm{pg}]$ & $-0,063$ & $0,885-1,033$ & 0,939 & 0,196 \\
\hline $\mathrm{MCHC}[\mathrm{g} / \mathrm{dl}]$ & 0,082 & $0,897-1,314$ & 1,086 & 0,399 \\
\hline $\mathrm{MCV}[\mathrm{fl}]$ & $-0,053$ & $0,907-0,992$ & 0,949 & $\mathbf{0 , 0 2 2}$ \\
\hline Eisen $[\mu \mathrm{mol} / \mathrm{l}]$ & 0,022 & $1,001-1,045$ & 1,022 & $\mathbf{0 , 0 4 3}$ \\
\hline sTfR $[\mathrm{mg} / \mathrm{l}]$ & $-3,472$ & $0,003-0,282$ & 0,031 & $\mathbf{0 , 0 0 2}$ \\
\hline Ferritin $[\mu \mathrm{g} / \mathrm{l}]$ & 0,326 & $0,838-2,292$ & 1,386 & 0,204 \\
\hline
\end{tabular}

Im Folgenden wird das komplette logistische Modell mit MCV $(\beta=-0,053 ; 95 \%-C I=0,907$ $-0,992 ; \mathrm{p}=0,022)$ als abhängige Variable zusammen mit allen konfundierenden Variablen präsentiert. Die konfundierenden Variablen Alter $(\beta=0,712$; $95 \%$-CI $=1,728-2,406$; $\mathrm{p}<0,001)$, Migrantenstatus $(\beta=1,737 ; 95 \%-C I=3,238-9,971 ; \mathrm{p}<0,001)$, anorganisches Phosphat $(\beta=-1,454 ; 95 \%-C I=0,083-0,659 ; p=0,006)$, Vitamin $\mathrm{D}(\beta=1,059 ; 95 \%-C I$ $=1,555-5,365 ; \mathrm{p}<0,001)$, Alkalische Phosphatase $(\beta=-6,868 ; 95 \%-\mathrm{CI}=0,000-0,005$; $\mathrm{p}<0,001)$ und Vitamin $\mathrm{B}_{12}(\beta=-4,178 ; 95 \%-\mathrm{CI}=0,006-0,038 ; \mathrm{p}<0,001)$ wiesen eine Signifikanz auf. 


\section{Ergebnisse}

Tabelle 7: Modell der binär logistischen Regression mit MCV als unabhängiger Variable und der Anwendung von Kontrazeptiva als abhängiger Variable. Adjustierung des Modells mit den Parametern Alter, Migrationshintergrund, BMI, mittlerer systolischer Blutdruck, anorganisches Phosphat, Vitamin D, alkalische Phosphatase, Kalzium und Vitamin B ${ }_{12}$.

\begin{tabular}{|l|c|c|c|c|}
\hline & $\begin{array}{c}\text { Regressions- } \\
\text { koeffizient } \beta\end{array}$ & $95 \%-C l$ & T-Wert & p-Wert \\
\hline Vollendetes Lebensalter [Jahre] & 0,712 & $1,728-2,406$ & 2,039 & $<\mathbf{0 , 0 0 1}$ \\
\hline Migrantenstatus [Migrant] & 1,737 & $3,238-9,971$ & 5,682 & $<\mathbf{0 , 0 0 1}$ \\
\hline BMI [kg/m²] & $-0,25$ & $0,934-1,019$ & 0,975 & 0,266 \\
\hline Systolischer Blutdruck [mmHg] & 0,016 & $0,998-1,035$ & 1,016 & 0,074 \\
\hline Anorganisches Phosphat [mmol/1] & $-1,454$ & $0,083-0,659$ & 0,234 & $\mathbf{0 , 0 0 6}$ \\
\hline Vitamin D [nmol/1] & 1,059 & $1,550-5,365$ & 2,884 & $\mathbf{0 , 0 0 1}$ \\
\hline Alkalische Phosphatase [U/1] & $-6,868$ & $0,000-0,005$ & 0,001 & $<\mathbf{0 , 0 0 1}$ \\
\hline Kalzium [mmol/1] & $-0,960$ & $0,083-1,756$ & 0,383 & 0,217 \\
\hline Vitamin B 12 [ng/l] & $-4,178$ & $0,006-0,038$ & 0,15 & $<\mathbf{0 , 0 0 1}$ \\
\hline MCV [f] & $-0,053$ & $0,907-0,992$ & 0,949 & $\mathbf{0 , 0 2 2}$ \\
\hline
\end{tabular}

In einem zweiten Satz von Modellen wurden die Parameter des Lipidstoffwechsels HDL, LDL und Triglyceride als zusätzliche konfundierende Variable hinzugefügt (Tabelle 8). Das bewirkte signifikante Veränderungen bei den Parametern sTfR $(\beta=-3,397 ; 95 \%$-CI $=0,003$ $--0,324 ; \mathrm{p}=0,003)$. In dem Modell mit sTfR als abhängige Variable wurde als PseudoBestimmtheitsmaß ein $\mathrm{R}^{2}$-Wert nach Cox und Snell von 0,385 ermittelt; das gesamte Model erwies sich als hochsignifikant $(\mathrm{p}<0,001)$. 


\section{Ergebnisse}

Tabelle 8: Ergebnisse aus einer weiteren Serie von logistischen Regressionsmodellen mit jeweils einem hämatologischen Parameter als unabhängiger Variable und KontrazeptivaGebrauch als abhängige Variable. Adjustierung des Modells mit den Parametern Alter, BMI, Migrationshintergrund, Vitamin D, mittlerer systolischer Blutdruck, Kalzium, anorganisches Phosphat, alkalische Phosphatase und Vitamin $\mathrm{B}_{12}$. Zudem wurden die Parameter des Lipidstoffwechsels HDL-, LDL-Cholesterin und Triglyceride hinzugefügt.

\begin{tabular}{|l|c|c|c|c|}
\hline & Regressionskoeffizient $\beta$ & $95 \%-\mathrm{Cl}$ & T-Wert & $\mathrm{p}$-Wert \\
\hline RBC $\left[\mathrm{x} 10^{6} / \mathrm{ml}\right]$ & 0,068 & $0,602-1,902$ & 1,070 & 0,818 \\
\hline Hämatokrit [\%] & $-0,064$ & $0,767-1,147$ & 0,938 & 0,533 \\
\hline $\mathrm{Hb}[\mathrm{g} / \mathrm{dl}]$ & $-0,031$ & $0,903-1,040$ & 0,969 & 0,384 \\
\hline $\mathrm{MCH}[\mathrm{pg}]$ & $-0,051$ & $0,856-1,055$ & 0,950 & 0,337 \\
\hline $\mathrm{MCHC}[\mathrm{g} / \mathrm{dl}]$ & 0,075 & $0,874-1,329$ & 1,078 & 0,485 \\
\hline $\mathrm{MCV}[\mathrm{fl}]$ & $-0,045$ & $0,910-1,005$ & 0,956 & 0,078 \\
\hline Eisen $[\mu \mathrm{mol} / \mathrm{l}]$ & 0,022 & $0,999-1,047$ & 1,023 & 0,065 \\
\hline sTfR $[\mathrm{mg} / \mathrm{l}]$ & $-3,397$ & $0,003--0,324$ & 0,033 & $\mathbf{0 , 0 0 3}$ \\
\hline Ferritin $[\mu \mathrm{gg} / \mathrm{l}]$ & 0,485 & $0,927-2,843$ & 1,624 & 0,090 \\
\hline
\end{tabular}

Der Vergleich beider Modelle zeigte, dass es durch die zusätzliche Adjustierung auf Lipide als konfundierende Variable in einer zweiten Serie von Regressionsmodellen zu keinem wesentlichen Unterschied in der Signifikanz des Parameter sTfR kam, wobei sich die $\mathrm{R}^{2}$ Werte der beiden Modellserien durch die Berücksichtigung der Lipide erhöhten. 
Diskussion

\section{Diskussion}

\subsection{Signifikante Unterschiede hämatologischer Parameter bei Anwenderinnen gegenüber Nichtanwenderinnen von Kontrazeptiva}

In dieser Post-hoc-Analyse wurden die Daten aus der KiGGS-Studie von Mädchen im Alter von 13 bis 17 Jahren untersucht. Es fand sich, dass Anwenderinnen von Kontrazeptiva sowohl in den univariaten als auch in den multivariaten Modellen signifikante Unterschiede in einigen hämatologischen Parametern gegenüber Nichtanwenderinnen aufwiesen. Die Ergebnisse zeigten eine positive Korrelation zwischen der Serumkonzentration von 25(OH)Vitamin D und den erythrozytären Parametern MCV und MCH. Das 25(OH)-Vitamin D in den Serumproben korrelierte in der Gesamtkohorte hingegen negativ mit den Parametern RBC, MCHC und Vitamin $\mathrm{B}_{12}$. In den multivariaten Regressionsmodellen waren die Parameter Eisen, sTfR und MCV signifikant unterschiedlich zwischen den beiden Gruppen.

Die Ergebnisse aus der deskriptiven Statistik zeigten eine kontinuierliche Zunahme der Einnahme von Kontrazeptiva mit steigendem Alter. Die zunehmende Prävalenz der Anwendung von Kontrazeptiva als Verhütungsmittel war mutmaßlich mit der zunehmenden sexuellen Reife der Jugendlichen im Laufe der Pubertät verbunden. Die Beobachtungen aus der KiGGS-Studie belegen, dass Mädchen mit Migrationshintergrund weniger Kontrazeptiva verwenden als gleichaltrige Mädchen ohne Migrationshintergrund. Als Ursache hierfür käme in Anbetracht, dass sie aus traditionellen unterschiedlichen Werten und Normen anderen Verhütungsmethoden als der pharmakologischen Kontrazeptiva den Vorzug geben. Bereits publizierte Ergebnisse aus dem Kinder- und Jugendsurvey zeigen, dass Migrantinnen in der Pubertät weniger häufig einen Gynäkologen in Anspruch nahmen als Mädchen deutscher Herkunft (Kamtsiuris et al. 2007b).

Die Auswertung der KINDL-Fragebögen sowie ähnliche Ergebnisse unter Einsatz des SDQ-Instrumentes zeigten tendenziell eine Verschlechterung der Lebensqualität in der Gruppe der Anwenderinnen gegenüber den Nichtanwenderinnen. Dies könnte damit erklärt werden, dass sich nach dem Eintritt der Geschlechtsreife und der Anwendung hormoneller Verhütungsmittel für in der Pubertäts- oder Postpubertätsphase befindlichen Anwenderinnen vermehrt zwischenmenschliche Probleme ergeben. Die Kontaktaufnahme zum männlichen Geschlecht könnte von den sexuell aktiven Mädchen mit einem Unsicherheits- und Verlustgefühl gegenüber ihren Geschlechtspartnern verbunden sein, der aversiv erlebt wird. Hinsichtlich der hämatologischen Parameter konnten signifikante Unterschiede zwischen den beiden Gruppen der Anwenderinnen und Nichtanwenderinnen von Kontrazeption fest- 


\section{Diskussion}

gestellt werden. Es lag eine Erhöhung des systolischen, mittleren und diastolischen arteriellen Blutdrucks in der Gruppe der Anwenderinnen vor. Die univariate Untersuchung der klinischchemischen Laborparameter ergab einen erhöhten Mittelwert für MCV, MCH, Eisen und erniedrigte Mittelwerte für RBC, Vitamin $\mathrm{B}_{12}$ und sTfR in den Blutproben der Anwenderinnen von Kontrazeptiva. In der univariaten Analyse waren diese Parameter statistisch signifikant; in der multivariaten Analyse fanden sich lediglich signifikante Unterschiede hinsichtlich der Anwendung von Kontrazeptiva für Eisen, sTfR und MCV.

In Bezug auf Parameter des Knochenstoffwechsels zeigten die Ergebnisse aus der univariaten Analyse eine statistische Signifikanz; es lagen erhöhte Mittelwerte für die Serumkonzentration von 25(OH)-Vitamin D in der Gruppe der Anwenderinnen vor. Des Weiteren fanden sich erniedrigte Mittelwerte für die Serumkonzentration von Kalzium, anorganischem Phosphat und alkalischer Phosphatase in der Gruppe der Anwenderinnen. Außerdem zeigte das Ergebnis der univariaten Analyse signifikante Unterschiede in den Lipidwerten im Blutserum mit erhöhten Mittelwerten der Lipide in der Gruppe der Anwenderinnen. Dies betraf die Erhöhung von HDL-, LDL-Cholesterin und Triglyceriden sowie der Gesamtcholesterinwerte.

Die Korrelationsanalyse in der Gesamtkohorte zeigte für Serumkonzentrationen von 25(OH)-Vitamin D eine negative Korrelation mit den untersuchten hämatologischen Parametern RBC, MCHC und Vitamin $\mathrm{B}_{12}$, hingegen waren MCV und MCH mit 25(OH)Vitamin D positiv korreliert. Eine zentrale Beobachtung bestand darin, dass sich morphologische Charakteristika der Erythrozyten bei den weiblichen Jugendlichen mit der Einnahme von Kontrazeptiva gegenüber Nichtanwenderinnen unterschieden, welche durch eine Volumenvergrößerung (Erhöhung des MCV) und einen Konzentrationsanstieg von erythrozytärem Hämoglobin $(\mathrm{MCH})$ gekennzeichnet war. Zudem schien ein erhöhter 25(OH)Vitamin-D-Spiegel unter der Einnahme von Kontrazeptiva vorzuliegen. Der Zusammenhang aus der Korrelationsanalyse zwischen den veränderten hämatologischen Parametern und den Knochenstoffwechselparametern lässt einen Zusammenhang mit der Erythropoese vermuten. Die Analyse der multivariaten Regressionsmodelle adjustiert für Alter, BMI, Migrantenstatus, systolischen Blutdruck, anorganisches Phosphat, alkalische Phosphatase, Kalzium, Vitamin D und Vitamin $\mathrm{B}_{12}$ als konfundierende Variablen zeigte signifikante Unterschiede für Eisen, sTfR und MCV zwischen den beiden untersuchten Gruppen der Anwenderinnen und Nichtanwenderinnen. In einem zweiten Modell additiv adjustiert für HDL-, LDL-Cholesterin und Triglyceride zeigte sich ein signifikanter Unterschied für den Parameter sTfR hinsichtlich der Vorhersage der Anwendung von Kontrazeptiva. Die Auswertung dieser Arbeit zeigte einen Effekt durch die Anwendung von Kontrazeptiva auf die 


\section{Diskussion}

untersuchten Parameter. Es kann vermutet werden, dass die in Kontrazeptiva enthaltenen Sexualhormone Progesteron und Estrogen eine physiologische Wirkung auf die Erythropoese ausüben.

\subsection{Vergleich der Beobachtungen mit anderen Studien}

Bei der Auswertung wurden geschlechtsspezifische Unterschiede in der Anwendungshäufigkeit von Arzneimitteln beschrieben (BZgA 2006; Heßling und Bode 2013). So haben Mädchen im Alter von 14 Jahren eine Prävalenz der Einnahme von Arzneimitteln von 61,5\% und Jungen eine Prävalenz von 40,5\%. 14-jährige Mädchen haben um 21 Prozentpunkte eine höhere Arzneimittelprävalenz als gleichaltrige Jungen. Außerdem konnte festgestellt werden, dass Jungen mit zunehmendem Alter eine geringere Häufigkeit der Arzneimitteleinnahme aufwiesen. Bei Mädchen setzte ab dem 14. Lebensjahr ein Anstieg der Medikamenteneinnahme ein. Diese geschlechtsspezifische Differenz vergrößerte sich mit zunehmendem Alter und war ab einem Alter von 14 Jahren signifikant. Hauptverantwortlich für diesen Anstieg war die Einnahme von oralen Kontrazeptiva. Daher wurde die Rangliste der am häufigsten angewendeten Arzneimittel ab einem Alter von 14 Jahren erstellt. Die Einnahme bezog sich auf einen Zeitraum der letzten 7 Tage vor der Befragung. Auf dem ersten Rang lag mit 11,3\% die Arzneimittelgruppe der Analgetika (BZgA 2006). An zweiter Stelle standen mit 9,2\% Sexualhormone und Modulatoren des Genitalsystems. An dritter Stelle standen mit 7,7\% Vitamine. Rang 4 belegten mit 7,5\% Husten- und Erkältungspräparate. An Rang 5 standen Rhinologika mit einer Häufigkeit von 5,3\%. An sechster Stelle standen Homöopathika (5,1\%), an siebter Stelle topische Mittel gegen Gelenk- und Muskelschmerzen (4,0\%), an achter Stelle Mittel bei obstruktiven Atemwegserkrankungen (3,8\%), an neunter Stelle Aknemittel (3,1\%) und an Rang 10 waren es Schilddrüsenpräparate mit ebenfalls 3,1\%. Eine hohe Arzneimittelprävalenz war auf die Anwendung oraler Kontrazeptiva, genutzt als Pille zur Schwangerschaftsverhütung, bei den Mädchen zurückzuführen.

In einer weiteren Auswertung der KiGGS-Studie von 2003 bis 2007 in Bezug auf die Anwendung von oralen Kontrazeptiva von Du (2011) wurde ebenfalls ein Kollektiv von Mädchen im Alter von 13 bis 17 Jahren in Deutschland untersucht. Es zeigte sich, dass die Gruppe der Anwenderinnen ein erhöhtes Risiko für kardiovaskuläre Erkrankungen hatten und dass die Mädchen eine Prävalenz für ein schlechtes gesundheitliches Verhalten aufwiesen. Dies äußerte sich durch vermehrtes Rauchen (56\% versus 20\%), regelmäßigen Alkoholkonsum (38\% versus 14\%) und der verringerten Teilnahme an sportlichen Freizeitaktivitäten $(24 \%$ 


\section{Diskussion}

versus 15\%). Zudem wurde bei den Anwenderinnen ein leichter medikamentös bedingter Anstieg des systemischen Blutdrucks festgestellt, was sich mit dem Ergebnis dieser Arbeit deckt. In der öffentlichen Verwendungsdatei wurden allerdings weder die Art noch die Angabe der kontrazeptiven Arzneimittel angegeben. Du und Co-Autoren berichteten, dass bei KiGGS-Teilnehmern die am häufigsten verwendeten oralen Kontrazeptiva ( $>90 \%)$ einphasige kombinierte Präparate mit einer festen Menge an Ethinyl-estradiol und Gestagen waren, wobei fast die Hälfte der Konsumenten das Medikament mindestens ein Jahr lang einnahmen (Du et al. 2011).

Bereits in früheren Studien wurden Einflüsse auf den Stoffwechsel in Zusammenhang mit der Einnahme von Kontrazeptiva untersucht. Dabei wurde festgestellt, dass sich der Vitamin- $B_{12}$-Spiegel unter der Einnahme von Kontrazeptiva erniedrigte (Anderson et al. 1976), was mit dem Ergebnis dieser Arbeit vereinbar ist. In der Arbeit von Mountifield (1986) wurden 98 Frauen im Alter zwischen 16 und 45 Jahren in Kanada untersucht, wovon 43 Frauen Anwenderinnen von oralen Kontrazeptiva waren. Es konnte, wie auch in dieser Arbeit aus Daten der KiGGS-Analyse, keine Veränderung der Hb- und Hkt-Werte festgestellt werden. Ebenso wurde ein erniedrigter Gehalt an Vitamin $B_{12}$ bei den Anwenderinnen von oralen Kontrazeptiva altersunabhängig bei der Altersgruppe zwischen 16 und 45 Jahren beschrieben (Mountifield 1986). Eine weitere Studie in Amerika mit einer größeren untersuchten Gruppe von 805 Teilnehmerinnen, davon 245 Anwenderinnen von oralen Kontrazeptiva, zeigte ebenfalls einen erniedrigten Vitamin-B $B_{12}$-Spiegel. In dieser Studie wurde eine Altersgruppe von 16 bis 33 Jahren untersucht (Berenson und Rahman 2012). Des Weiteren bestätigen australische Studienergebnisse einen Zusammenhang zwischen der Einnahme von oralen Kontrazeptiva und einem erniedrigten Vitamin-B B $_{12}$-Spiegel (McArthur et al. 2013). Hierfür wurde das Blut von Probandinnen im Alter von 18 bis 35 Jahren untersucht. Die Hb- und MCV-Werte der Probandinnen waren in dieser Studie nicht signifikant verändert (McArthur et al. 2013), was sich von den Ergebnissen dieser Arbeit unterscheidet, da sich hier in der multivariaten Regressionsanalyse eine signifikante Vorhersagekraft von MCV hinsichtlich eines Kontrazeptiva-Gebrauchs ergab. In den erwähnten Studien wurde der Zusammenhang mit Parametern der Erythropoese allerdings nicht genauer untersucht. Interessanterweise ergab die vorliegende Post-hoc-Analyse aus den KiGGS-Daten in der Gruppe der Anwenderinnen einen signifikanten Zusammenhang zwischen der Kontrazeptiva-Medikation und dem Vitamin-D-Spiegel. Dieser war bei den Anwenderinnen von oralen Kontrazeptiva erhöht. Das Ergebnis könnte auf eine Modulation der Zellproliferation unter der Einnahme dieser Medikamente hindeuten. Interessant ist dieser Aspekt in Anbetracht dessen, dass auch die Erythropoese als Folge einer Interaktion durch die in den Kon- 


\section{Diskussion}

trazeptiva-Präparationen enthaltenen Pharmaka betroffen sein könnte. Ein solcher Zusammenhang zwischen dem Vitamin-D-Gehalt und der Erythropoese wurde bereits in einer früheren Auswertung der KiGGS-Studie festgestellt (Doudin et al. 2018). Hierbei wurde eine Anzahl von 5066 männlicher und weiblicher Probanden im Alter zwischen 11 und 17 Jahren näher betrachtet. Es konnte eine negative Korrelation zwischen dem 25(OH)-Vitamin-DGehalt im Blutserum und den hämatologischen Parameter Hb, MCH, RBC, sTfR und eine positive Korrelation mit MCV ermittelt werden, was auf einen inhibitorischen Einfluss von Vitamin D auf die Erythropoese hindeutet (Doudin et al. 2018). Vitamin D könnte damit ein entscheidender Regulator für die Erythropoese sein. Unklar bleibt, ob es sich hierbei um einen direkten Einfluss der hormonellen Wirkung der Kontrazeptiva oder einen indirekten Mechanismus über den Einfluss der Kontrazeptiva auf den Vitaminspiegel handelt. In vergangenen Untersuchungen konnten Übereinstimmungen mit den Ergebnissen dieser Arbeit gefunden werden, nämlich dass der Hkt- und der Hb-Wert unter der Einnahme von Kontrazeptiva keine signifikanten Veränderungen zeigte (Larsson et al. 1992; Mountifield 1986). Zudem zeigte eine Studie von 1992 mit einer Teilnehmerzahl von 20 weiblichen Probandinnen im Gegensatz zu unseren Ergebnissen eine Tendenz zu erhöhten Blutserumwerten von Ferritin unter dem Einfluss von Kontrazeptiva (Larsson et al. 1992). Andere Untersuchungen zeigten Abweichungen zu dieser Arbeit. In der französischen Studie aus dem Jahr 1995 wurden die Daten von 339 Probandinnen erhoben (Macaigne et al. 1995). Es lagen erniedrigte Hb-Werte sowie erniedrigte RBC-Werte bei den Anwenderinnen von oralen Kontrazeptiva vor. Sexuell aktive weibliche Personen zeigten einen verminderten Gehalt an Vitamin $B_{12}$ im Blutserum (Wertalik et al. 1972). Die Anwendung von oralen Kontrazeptiva erbrachte bei jungen weiblichen Adoleszenten in den USA im Alter von 12 bis 19 Jahren mögliche Hinweise auf eine protektive Wirkung gegenüber einem Eisenmangel (Grace et al. 1982). Ebenfalls zeigten die Ergebnisse dieser Studie keine signifikanten Unterschiede zwischen Anwenderinnen und Nichtanwenderinnen im Hb-Wert.

\subsection{Mögliche Wirkmechanismen}

Um im Kontext der dargestellten Ergebnisse aus dieser Auswertung mögliche Zusammenhänge mit der Einnahme von oralen Kontrazeptiva hypothesengenerierend aufzuzeigen, sollen im Folgenden einige Vermutungen über mögliche Wirkmechanismen aufgestellt werden. Wie beschrieben enthalten Kontrazeptiva als Kombinations-Präparate die Hormone Estrogen und Progesteron. Es stellt sich die Frage, welchen genauen Einfluss die einzelnen 


\section{Diskussion}

Hormone auf die Erythropoese ausüben. Es wird vermutet, dass Progesteron direkt mit der Plasmamembran der Erythrozyten interagiert und die Fluidität der Membran beeinflusst, so wie es Versuche aus in-vitro-Studien zeigten (Tsuda et al. 2002). Die Zugabe von Progesteron erniedrigte signifikant die Werte von den Parametern 5-Nitroxid-Stearat und dem 16Nitroxid-Stearat im elektronparamagnetischen Resonanzspektrum der Erythrozytenmembran. Das Ergebnis ließ darauf schließen, dass Progesteron die Membranfluidität der Erythrozyten erhöhte und die Mikroviskosität der Erythrozytenmembran veränderte. Der Effekt von Progesteron wurde durch die Gabe von Stickstoffmonooxid (NO), S-Nitroso-N-Acetylpenicillinamin (SNAP) und einem Analog zu dem zyklischen Guanosinmonophosphat (cGMP) signifikant verstärkt. Durch den Einsatz von NO-Inhibitoren wurde die durch Progesteron gesteigerte Membranfluidität wiederum gehemmt (Tsuda et al. 2002). Eine andere Studie zeigte, dass das 17- $\alpha$-Hydroxy-Progesteron einen stabilisierenden Effekt auf die Erythrozytenmembran gegenüber der Hämolyse hatte (Kaya und Saito 1985).

Ferner stellte sich eine Veränderung der Fettsäurenzusammensetzung der Erythrozytenphospholipide und der Plasma-Cholinphosphoglyceride (CPG) unter Anwendung oraler Kontrazeptiva heraus (Fehily et al. 1982). Die in dieser Studie untersuchten Teilnehmerinnen nahmen orale Kombinationspräparate aus Estrogen und Progesteron ein und wiesen eine höhere Konzentration an Palmitinsäure und Linolsäure auf. Die Konzentrationen von Stearinsäure, langkettigen mehrfach ungesättigten Fettsäuren (LCP), insbesondere der Arachidonsäure und Eicosapentaensäure, waren bei den Anwenderinnen von oralen Kontrazeptiva erniedrigt (Fehily et al. 1982). Die Ergebnisse einer in-vitro-Untersuchung der Erythrozyten mithilfe von Lichtmikroskopie, Rasterelektronenmikroskopie und Thromboelastographie (TEG) zeigten unter dem Einfluss von Progesteron und Estrogen, dass sich die Erythrozytenmorphologie veränderte. Die Erythrozytenmembran war unter der Zufuhr von Progesteron verändert und es kam zu einer vermehrten Eryptose. Zudem zeigte die Studie, dass Progesteron die Bildung von Vollblutgerinseln erhöhte, indem es zu einer vermehrten Erythrozytenaggregation kam und zu einer spontanen Fibrinbildung.

Die Untersuchungen bestätigten den hormonellen Einfluss von Estrogen auf die Erythrozytenmorphologie und auf die Erythrozytenmembran. Da die Erythrozytenform und Membranflexibilität mit der physiologischen Funktion dieser Zellen im Kreislauf korrelierte, können die hormonellen Einflüsse, welche auf eine vermehrte Eryptose hinweisen, auch als Faktor für hämatologische Erkrankungen wahrgenommen werden (Swanepoel et al. 2017). Über nukleare Rezeptoren vermittelte hormonelle Einflüsse wurden als Risikofaktoren für Erkrankungen beschrieben, wobei zwischen den beiden Hormonen Estrogen und Progesteron differenziert werden muss. Estrogen ist im Vergleich zu Progesteron ein protektiver 


\section{Diskussion}

Faktor von kardiovaskulären Erkrankungen. Estrogen übt einen positiven Einfluss auf die Vasodilatation aus, hemmt die Inflammation, hemmt die Atherosklerose und reguliert den Blutdruck über das Renin-Aldosteron-System. Diese Funktionen von Estrogen beruhen auf die Bindung an dem sich im Zytoplasma befindlichen bzw. membranassoziierten Rezeptor ER $\alpha$ (Prabhushankar et al. 2014). Im Gegensatz zu der androgen induzierten Vasokonstriktion fördert Estrogen die Vasodilatation. Die Häufigkeit kardiovaskulärer Erkrankungen bei Frauen steigt nach der Menopause. Vor der Menopause leiden Frauen im Vergleich zu Männern weniger häufig an kardiovaskulären Erkrankungen. Dieser Unterschied beruht teilweise auf der Ebene der Gen- bzw. Proteinexpression sowie posttranslationalen Modifikation und scheint auf estrogenvermittelte Signalwege vorwiegend an Herzzellen zurückzuführen zu sein. Estrogen bindet dabei an den Rezeptoren ER $\alpha$ und ER $\beta$, die als ligandengesteuerte Transkriptionsfaktoren fungieren und mithilfe von Co-Aktivatoren und CoRepressoren mit der DNA eine Bindung eingehen, was letztendlich zu einer Veränderung der Transkription führt (Murphy und Steenbergen 2014). Damit liegt ein ligandengesteuerter Einfluss der Estrogenkomponente in den Kontrazeptiva-Präparaten über den Estrogenrezeptor $\alpha$ vor.

Am Ort der Erythropoese, dem Knochenmark, findet eine Expression des Estrogenrezeptors $\alpha$ statt. In anderen Untersuchungen beeinflusste $17-\beta$-Estradiol (E2) einige Funktionen von Vorläuferzellen, wie die der Fett- (ASC) und Knochenmarksstammzellen (BMSC). Die Stimulation mit E2 modulierte im Versuch die Vitalität und die Wachstumsrate der ASC, jedoch nicht der BMSC. Zudem beeinflusste Estrogen mesenchymale Stammzellen. Sowohl in ASC als auch BMSC konnte unter dem Estrogeneinfluss eine unterschiedliche Aktivität der alkalischen Phosphatase beobachtet werden. Der mesenchymale Vorläufer exprimierte eine $37 \mathrm{kDa}$ Variante von ER- $\alpha$, dessen Expression während der Differenzierung moduliert wurde. E2 wirkte sich positiv auf adipogene Prozesse der mesenchymalen Stammzellen aus, während es bei den Knochenmarkstammzellen nur die osteogene Induktion begünstigte (Niada et al. 2016). Neben der Hypothese des Einflusses auf die Zusammensetzung der Erythrozytenmembran und des ER $\alpha$ wurde noch weiteren Erklärungsansätzen des beschriebenen Zusammenhangs der oralen Kontrazeptiva auf hämatologische Parameter nachgegangen. Die ERK1/2- Kinase ist für Zellprozesse verantwortlich, welche die Proliferation oder auch die Apoptose regulieren (Mebratu et al. 2009). Einige extrazelluläre Stimuli, wie Hormone führen zu einer Aktivierung der ERK-Signalkaskade. Weitere Stimuli für die ERK-Aktivierung können Wachstumsfaktoren, Zytokine, Mitogene, oxidativer Stress, G-Protein-gekoppelte Rezeptoren (GPCRs) oder auch der epidermale Wachstumsfaktor (EGFR) sein. Die Aktivierung erfolgt über eine Rekrutierung des son of sevenless (SOS), was 


\section{Diskussion}

ein Faktor für die Guaninübertragung ist, welcher rat sarcoma (Ras) über das Adapterprotein growth factor receptor-bound 2 (Grb2) stimuliert und was letztendlich zu einer Umwandlung von GDP zu GTP führt. Die Stimulation von Ras initiiert weitere Interaktionen mit einer Reihe von Proteine, wie auch von Isoformen der Serin/Threonin-Kinase (Raf12). Durch das Binden von Ras an Raf, einer mitogen-activated protein kinase (MAPK)-Kinase-Kinase (MAPKKK,), verändert sich die Konformation von Raf und steigert seine Kinaseaktivität. SOS, welches durch den MAPKKK-Signalweg rekrutiert wurde, aktiviert Ras, welches Raf an der Plasmamembran über die Phosphorylierung an unterschiedlichen Stellen aktiviert. Die MAPK/ERK-Kinase (MEK) 1/2 ist infolgedessen an zwei Serinresten phosphoryliert und die Phosphorylierung von ERK1/2 an Threonin und Tyrosin wird für die volle katalytische Aktivierung benötigt. Das aktivierte ERK1/2 phosphoryliert wiederum die ribosomale Proteinkinase (RSK) und sowohl RSK als auch ERK gelangen in den Nukleus, wo sie mehrere Transkriptionsfaktoren aktivieren. Durch diesen Effekt wird die Proteinsynthese beeinflusst und die Zellproliferation verändert (Mebratu et al. 2009).

Das Ergebnis dieser Arbeit zeigte erhöhte Mittelwerte von MCH und MCV unter der Einnahme von Kontrazeptiva, was einen hormonellen Einfluss auf die Erythrozytenmorphologie vermuten lässt. Zudem konnte in der multivariaten Regressionsanalyse eine Signifikanz des Parameters MCV in Bezug auf den Kontrazeptiva-Gebrauch festgestellt werden. Es wurde bereits in früheren Laboruntersuchungen gezeigt, dass die Proliferation der Erythrozyten über den ERK-Signalweg erfolgt (Kapur et al. 2017). Dabei wurden die Konsequenzen der Kit-Aktivierung des Stammzellfaktors (SCF) beschrieben, indem ein Vergleich der unterschiedlich prozessierten Varianten aus dem membranassoziierten Stammzellfaktors (MA-SCF) und dem löslichen Stammzellfaktor (S-SCF) hergestellt wurden. Zudem wurde die membranbegrenzte (MR)-Form des SCF in Hinblick auf Überleben, Proliferation und Zellzyklusprogression der erythroiden Progenitorzellen sowie der Aktivierung der p38-, ERK- und MAP-Kinase-Signalwege untersucht. Dabei resultierte beim MR-SFC die geringste Apoptose bei der Aktivierung von Kit in erythroiden Progenitorzellen im Vergleich zu den Isoformen des Stammzellfaktors (Kapur et al. 2017). Die Proliferation und Zellzyklusprogression wurde durch die Faktoren MR-SCF und MA-SCF stimuliert, was mit einer Modulation des p38- und ERK/MAP-Kinase-Signalwegs korrelierte. Diese Versuche zeigten zusammenfassend, dass Stammzellfaktoren über Signalwege wie den ERK-Signalweg einen Einfluss auf die Proliferation von erythroiden Progenitorzellen ausüben (Kapur et al. 2017). Ebenso wäre denkbar, dass Kontrazeptiva indirekt über das Hormon Erythropoetin (Epo) auf die Erythropoese wirken. Kürzlich veröffentlichte Untersuchungen zeigten Wechselwirkungen zwischen dem extrazellulären Peptid Epo und dem von ERK1/2 unterstützten 


\section{Diskussion}

Signalweg (Haq et al. 2002). Die Ergebnisse dieser Studien bestätigen den Zusammenhang zwischen der Bildung von Erythroblasten und dem ERK-Signalweg. Zudem wurden in dieser Studie Zusammenhänge zwischen Stat5-Proteinen und der Erythropoese sowie Epo und der Erythropoese festgestellt. Das Hormon Epo stimuliert die Progenitorzellen der Erythrozyten. Signale für die Erythroblastenformation werden über die aktivierten tyrosinphosphorylierten Erythropoetinrezeptor (EpoR)-Komplexe transduziert. Um die Wirkungsweise von EpoR besser zu verstehen, wurden aus dem Knochenmark stammenden Erythroblasten von Mäusen untersucht. Die Studienergebnisse zeigten, dass Stat5 über eine bestimmte Isoform von Epo, dem Epo-H, aktiviert wurde. Die Stat1- und Stat3-Aktivierung funktionierte bei allen Epo-Formen. Der ERK-Signalweg wurde durch die Isoform EpoHM sogar hyperaktiviert (Menon et al. 2017). Die Hauptfunktion von EpoR besteht darin, erythroide Vorläuferzellen vor der Apoptose zu schützen. Der EpoR ist essentiell für die Produktion von Erythrozyten und Stat5-Proteine tragen ebenfalls eine wichtige Rolle für das Überleben von Progenitorzellen der Erythrozyten bei (Snow et al. 2002). Stat5-Proteine werden bei der EpoR-Stimulation aktiviert, allerdings ist die genaue Funktion der beiden Stat5-Proteine bei der Erythropoese bisher unklar. Die Embryonen von Stat $5 \mathrm{a}^{-/-5 b^{-/}-\text {Knock- }}$ out-Mäuse waren stark anämisch (Socolovsky et al. 1999). Ihre erythroiden Vorläuferzellen waren in ihrer Anzahl reduziert, zeigten eine höherer Apoptoserate und wurden geringer von Epo stimuliert. Dieser Versuch zeigte die entscheidende Rolle von Stat5 bei der antiapoptotischen Signalübertragung von EpoR. Stat5-Proteine binden vermutlich direkt an den Bcell lymphoma-extra large (Bcl-xL)-Promotor und vermitteln dadurch eine Induktion von Bcl$\mathrm{xL}$ in erythroiden Zellen (Socolovsky et al. 1999).

Der bereits vorgestellte ERK1/2 Signalweg kann außerdem über die in dieser Arbeit untersuchten Parameter Vitamin B 12 (Okamoto et al. 2014) und Vitamin D (Narayanan et al. 2004) vermittelt werden. Das Vitamin-B $B_{12}$-Analog Methylcobalamin fördert die Proliferation und hemmt die Apoptose von C2C12-Myoblasten bei Aktivierung des ERK1/2-Signalweges (Okamoto et al. 2014). Die aktivierte Form von Vitamin D reguliert den Kalziumstoffwechsel und den Knochenumbau und ist an der Proliferation und anderer zellulärer Prozesse beteiligt. Es bindet an dem Vitamin D-Rezeptor (VDR), welcher zu der Gruppe der Steroid/Thyroid-Rezeptoren gehört und über diese Bindung ligandengesteuert die Transkription beeinflusst. Die Aktivierung des VDRs bewirkt eine Erhöhung des ERKSignals in Knochenzellen (Narayanan et al. 2004).

Ein weiterer möglicher Mechanismus könnte die durch das Hormon Estrogen induzierte Aktivierung des Proteins Stat5 sein. Steroide stimulieren die Proliferation von steroidabhängigen Tumorzellen. ER-positives Brustkrebsgewebe enthält Tumorzellen, deren Proli- 


\section{Diskussion}

feration von E2 stimuliert wird. Bekanntermaßen sind Steroidrezeptoren ligandengesteuerte Transkriprionsfaktoren, die in die Gruppe der nuklearen Rezeptoren gehören. Steroidreaktionen sind mit intrazellulären Signalwegen verbunden, unter anderem dem Tyrosinkinase(c-Src)-Rezeptor-Signalweg. Steroide, wie das E2, aktivieren die ERK-Signalkaskade über die Bindung an zytoplasmatische und membranassoziierte Rezeptoren. Möglicherweise können Phosphoinositid-3-Kinasen (PI3K) und Stats durch E2-stimulierte Phosphorylierung aktiviert werden und so Einfluss auf die Zellproliferation nehmen. Es bestehen Wechselwirkungen zwischen dem Estrogenrezeptor und der intrazellulären c-Src sowie der zytoplasmatischen Signalfaktoren wie SH containing (Shc), PI3K und p130 Crk-associated substrate (p130Cas; Shupnik 2004). C-Src spielt eine grundlegende Rolle bei der E2stimulierten Proliferation. Wachstumsfaktoren wie EGF oder insulin-like growth factor (IGF)-1 sind für den Effekt der beschriebenen Signalfaktoren erforderlich (Takahashi et al. 2005). Die Stat5-Transkriptionsfaktoren stellen einen möglichen Weg dar, um die Signalübertragung von E2 im Nukleus zu integrieren. Ebenso wie ligandengebundene Estrogenrezeptoren translozieren phosphorylierte Stat5-Dimere zum Nukleus, um dort die Transkription ihrer Zielgene zu stimulieren. Das E2 stimuliert die Rekrutierung von Stat5 und ER an den Promotoren einiger proliferativer Gene (Stoecklin et al. 1999; Björnström et al. 2001; Faulds et al. 2001). In Brustkrebszellen hemmt der Knockout von Stat5 die E2-stimulierte Proliferation von Brustkrebszellen (Fox et al. 2009). Ebenso verhindert die Hemmung von c-Src oder dem EGFR die E2-stimulierte Proliferation in Brusttumoren, da für die Aktivierung von Stat5 der Src- und EGF-Rezeptor erforderlich ist. Das Zusammenspiel von Steroiden mit Stat5-Proteinen kann auf biologische Prozesse, wie der Zellproliferation, Einfluss nehmen (Fox et al. 2009). Aufgrund der oben erwähnten Beobachtungen auf dem Gebiet der Signaltransduktion liegt die Vermutung nahe, dass die beschriebenen Auswirkungen von Kontrazeptiva in den Daten des Kinder- und Jugendsurveys auf solche zellulären und besonders transkriptionellen Prozesse zurückzuführen sind. Diese Theorie lässt sich anhand

der vorliegenden Arbeit allerdings nicht verifizieren. Weitere Unter-suchungen sind nötig, um den genauen Wirkmechanismus zu erforschen und die auf-kommende Frage zu klären, ob Sexualhormone wie Progesteron und Estrogen direkt oder indirekt auf die Erythropoese einwirken. Mögliche Forschungsansätze für die Untersuchung des Wirkmechanismus können sein, ob es sich hierbei um eine Modulation des ERK1/2-Weges oder der Stat5-vermittelten Signaltransduktion handelt. Zudem sollte in die weitere Untersuchung die Rolle des Eisenstoffwechsels miteinbezogen werden, da die Parameter sTfR, Eisen und Vitamin $\mathrm{B}_{12}$ im Regressionsmodell signifikante Einflussgrößen auf die Erythrozyten darstellten. 


\section{Diskussion}

\subsection{Bedeutung für den klinischen Alltag}

Orale Kontrazeptiva beeinflussen hämatologische Parameter durch einen nicht erschlossenen Wirkmechanismus. Ob solche veränderten Erythrozyten ein Risiko für Herz-Kreislauf-Erkrankungen darstellen könnten, da sie in ihrer Aufgabe des Sauerstofftransports gestört sein könnten, bleibt dahingestellt. Bereits bei der Einführung von Kontrazeptiva in den 1960er Jahren wurde auf diese Risiken hingewiesen. Schon damals erkannte man ein erhöhtes Risiko für eine Venenthrombose, einen Schlaganfall oder einen Herzinfarkt durch die Einnahme von oralen Kontrazeptiva. Daraufhin wurden die Kontrazeptiva mit $35 \mu \mathrm{g}$ E und geringeren Dosierungen angeboten, um solche Risiken zu vermeiden. Allgemein wird das Risiko an kardiovaskulären Erkrankungen zu leiden bei der Anwendung von niedrigdosierten Kontrazeptiva als gering geschätzt, soweit keine weiteren Risikofaktoren wie Rauchen, Adipositas, Bluthochdruck oder andere bereits vorliegen (DGGG 2004). Bei jungen gesunden Frauen ist das Risiko für kardiovaskuläre Erkrankungen generell gering, sodass selbst unter der Einnahme von Kontrazeptiva ein geringes Risiko besteht (WHO 1998). Trotzdem liegt gegenüber den Nichtanwenderinnen von Kontrazeptiva ein zwei- bis dreifach höheres Risiko vor, eine Venenthrombose, einen Schlaganfall oder einen Herzinfarkt zu erleiden (Croft und Hannaford 1989; Gerstman et al. 1991; WHO 1996a; WHO 1996b). Ein positiver Effekt durch die Einnahme von oralen Kontrazeptiva kann bei hormonellen Schwankungen erreicht werden. Ein Beispiel ist der Einsatz von Hormonpräparaten bei Frauen mit Osteoporose in den Wechseljahren. Estrogen wirkt in dem Fall ausgleichend auf hormonelle Schwankungen in den Wechseljahren und fördert die Osteogenese (Croft und Hannaford 1989; Bloemenkamp et al. 1995; Petitti et al. 1996; WHO 1995a; WHO 1995b; WHO 1996a; WHO 1996b; WHO 1997). Einen weiteren positiven Effekt soll der Bestandteil Ethinylestradiol auf die Verhinderung der Entstehung von Atherosklerose haben. Je nach Zusammensetzung der Pille soll diese auch protektiv gegenüber kardiovaskulären Erkrankungen wirken (Diedrich et al. 2007). In jedem Fall sollte eine Risiko-Nutzen-Analyse für jede Patientin vor der Verschreibung und Einnahme eines solchen Arzneimittels geprüft werden.

\subsection{Limitationen der Studie}

Bei dem Kinder- und Jugendsurvey handelt es sich um eine für Deutschland repräsentative Studie. Es erfolgten Qualitätskontrollen in der Datenerfassung, wodurch sich auch die statistische Aussagekraft bekräftigt. Dadurch können die Ergebnisse dieser Arbeit für die in 


\section{Diskussion}

Deutschland lebenden Mädchen im Alter von 13 bis 17 Jahren verallgemeinert werden. Zudem wirkt sich die hohe Zahl der Probanden positiv auf die statistische Auswertung von Untergruppen aus. In diesem Fall handelte es sich um die Gruppe der 13- bis 17-jährigen Mädchen. Im Vergleich von Anwenderinnen und Nichtanwenderinnen von Kontrazeptiva stellte man nur geringfügige soziodemografische und gesundheitsbezogene Unterschiede der Probandinnen fest (Kamtsiuris et al. 2007b). Eine selektive Nichtbeteiligung einer der beiden Gruppen Anwenderinnen oder Nichtanwenderinnen an der Studie kann nicht ausgeschlossen werden, sondern muss als wahrscheinlich angenommen werden. Das ermittelte Ergebnis der Prävalenz der Einnahme von Kontrazeptiva gleicht den Ergebnissen anderer deutschen Studien (Schmid-Tannwald und Kluge 2003). Bei der Erfassung der Anwenderinnen von Kontrazeptiva sind Fehler denkbar. Die Anamnese der Medikamenteneinnahme deckte den Zeitraum von sieben Tagen vor der Befragung ab. Es ist daher theoretisch möglich, dass sich Anwenderinnen in der für viele Präparate üblichen siebentägigen Einnahmepause befanden und somit als Nichtanwenderinnen erfasst wurden. Dieser Fall träfe ein, wenn die Probandin am Tag der Befragung den neuen Einnahmezyklus noch nicht begonnen hätte und zuvor eine Einnahmepause von sieben Tagen hinter sich hatte. Allerdings ist davon auszugehen, dass sich eine Anwenderin von Kontrazeptiva trotz einer Einnahmepause als Anwenderin der „Pille“ in der Medikamentenanamnese vorstellen würde. Daher sind solche Fehler in der Erfassung wohl nur in Ausnahmefällen denkbar. In Anbetracht der Limitation dieser Arbeit ist von keiner Kausalität bei den beschriebenen Assoziationen auszugehen, da es sich bei dem Kinder- und Jugendsurvey um eine Querschnittsstudie handelt. Dies bedeutet, dass Zusammenhänge zwischen zwei unterschiedlichen Parametern untersucht werden können, diese allerdings keine Angaben zur Kausalität oder Direktionalität eines Zusammenhangs zulassen. Aus der Analyse geht keine sichere Aussage hervor, ob mit der Einnahme von Kontrazeptiva direkt veränderte hämatologische Parameter resultieren. Vielmehr könnte es sich auch um eine indirekte Wirkung auf die Erythropoese handeln, über die Regulation von Vitaminen, wie Vitamin $\mathrm{B}_{12}$ und Vitamin D oder auch anderen Mechanismen. Der genaue Ursache- Wirkmechanismus ist nicht geklärt. Die Ergebnisse zeigen lediglich, dass es einen Zusammenhang zwischen der Einnahme von Kontrazeptiva und den klinisch-chemischen Laborparametern gibt. Nach den Kriterien nach Hill liegt demnach keine Kausalität vor (Hill 1965). Hierfür müsste die Exposition (Anwendung von Kontrazeptiva) zeitlich dem ermittelten Effekt (klinisch-chemische Laborparameter) zuvorkommen (Rothman 1990; Rothman et al. 2008). In der Querschnittsstudie wurden die Daten allerdings gleichzeitig erfasst. Die Arbeit wird zudem durch die statistische Auswertung und die Laboranalyse limitiert. Die ermittelten Mittelwerte aus der Student-t-Test Analyse waren teilweise nur gering 


\section{Diskussion}

unterschiedlich zwischen den Gruppen. Jedoch waren die ermittelten p-Werte der Analyse nicht selten signifikant, was auf die Existenz eines Zusammenhangs hindeutete. Die Arbeit profitierte davon, dass die Bestimmung der Laborparameter aus den gewonnen Blutproben in standardisierten Verfahren unter Aufsicht der Bundesärztekammer erfolgte (Thierfelder et al. 2007). Zusätzlich erfolgte eine Qualitätskontrolle von extern. Außerdem wurden die Messungen unvoreingenommen, also ohne der Erwartung eines bestimmten Ergebnisses vorgenommen. Des Weiteren unterliegen die Untersuchungsmethoden den Empfehlungen der Deutschen Vereinten Gesellschaft für klinische Chemie und Laboratoriumsmedizin (DGKL). So wurden die Messungen der hämatologischen Parameter mit dem automatisierten Analysegerät Abott Cell-Dyn 3500 (Abott diagnostics) unterzogen. 25(OH)Vitamin D wurde quantitativ über das automatisierte Verfahren der CLIA gemessen. Mit dem Elecsys-E-2010-Gerät wurden Ferritin und Vitamin $B_{12}$ unter Verwendung eines ECLIA bestimmt. Die Messung von sTfR erfolgte mit einem verbesserten Latexagglutination Assay mit dem BNA-Nephelometer von Behring (Marburg). Die Lipide und die alkalische Phosphatase wurden mit dem Gerät Hitachi 917 der Firma Roche gemessen (Thierfelder et al. 2007). Bei der Untersuchung könnten bei den Messungen, trotz der Anwendung dieser modernen Geräte und der standardisierten Methoden, Schwankungen und Messungenauigkeiten auftreten. Der Effekt der Streuung kann unterschiedliche Ursachen haben. Um für die Mittelwertvergleiche eine Normalverteilung herzustellen, wurden einige der Parameter für die Berechnungen logarithmiert. Um Korrelationen zwischen dem 25(OH)-Vitamin D und den hämatologischen Parametern inklusive Vitamin $\mathrm{B}_{12} \mathrm{zu}$ untersuchen, wurden für die statistischen Untersuchungen die alkalische Phosphatase, Ferritin, sTfR, Vitamin $B_{12}$, Vitamin D, HDL-Cholesterin, LDL-Cholesterin, und Triglyceride logarithmiert. Bei der Korrelation nach Pearson war dieses erforderlich, um einen linearen Zusammenhang darzustellen. In der Regressionsanalyse war in den beiden vorgestellten, verschieden adjustierten Modellen der Parameter sTfR signifikant unterschiedlich zwischen den beiden Gruppen. In dem ersten vorgestellten Regressionsmodel konnte zusätzlich zu dem sTfR für die weiteren Parameter Eisen und MCV eine Signifikanz festgestellt werden. Die Adjustierung erfolgte mit konfundierenden Variablen, welche zuvor in der univariaten Analyse eine Signifikanz aufwiesen. Die anderen hämatologischen Variablen, wie RBC, HB, Hkt, MCH und MCHC, waren in beiden multivariaten Regressionsmodellen allerdings nicht mehr signifikante Prädiktoren. Der Eisenstoffwechsel scheint eine wichtige Rolle zu spielen, da die Variablen sTfR, Eisen und zudem MCV sich in den Modellen als signifikante Prädiktoren erwiesen. Trotz der insgesamt eher schwachen Assoziationen mancher hämatologischer Para-

meter können diese statistischen Ergebnisse mögliche Zusammenhänge zwischen der 


\section{Diskussion}

Sexualhormone und der Erythropoese aufdecken, da es sich um eine insgesamt hohe Stichprobenzahl handelt. Eine Vergleichbarkeit der Studienergebnisse ist kaum gegeben. Es wurden in älteren Studien eine Veränderung von einzelnen Parametern wie etwa dem erniedrigten Vitamin- $B_{12}$-Spiegel unter der Einnahme von Kontrazeptiva ermittelt, was sich mit den Ergebnissen dieser Arbeit deckt (Anderson et al. 1976; Berenson und Rahman 2012; McArthur et al. 2013; Mountifield 1986). Des Weiteren wurde bereits in einer Analyse der KiGGS-Daten der Einfluss von Kontrazeptiva auf kardiovaskuläre Risikofaktoren, insbesondere der Lipide festgestellt (Rosner 2008). Bisher liegen keine Ergebnisse eines Einflusses der Kontrazeptiva auf die Erythrozyten über die Erythropoese vor und dieser Zusammenhang muss in Zukunft erst genauer untersucht werden.

\subsection{Schlussfolgerung}

Mädchen in Deutschland verwenden Kontrazeptiva ab einem Alter von 13 Jahren. Bei Anwenderinnen oraler Kontrazeptiva fanden sich bei der statistischen Untersuchung der Daten aus der KiGGS-Studie signifikante Unterschiede bei hämatologischen Parametern gegenüber Nichtanwenderinnen. Trotz der teilweise geringen Korrelation kann man aufgrund der großen Fallzahl in dieser Studie eine vorläufige Aussage zu einem bestehenden Zusammenhang zwischen der Einnahme weiblicher Sexualhormone in Kontrazeptiva-Präparate und der Erythropoese treffen. Die Aussagekraft der Analyse wird zudem durch die Unvoreingenommenheit der Datenaufnahme und die Repräsentativität der bundesweiten Stichproben bestärkt. Des Weiteren hat die Studie eine hohe Qualität, da die Aufnahme der Laborparameter mit einem standardisierten Verfahren und die Unter-suchungen durch ausgebildete Ärzte mit pädiatrischem Hintergrund erfolgten. Weitere Untersuchungen sind notwendig, um die Ergebnisse aus dieser Arbeit zu bestätigen und den genauen Wirkmechanismus zu beschreiben. Die gefundenen Unterschiede der hämatologischen Parameter bei Anwenderinnen und Nichtanwenderinnen sind zwar teilweise gering, aber nicht selten signifikant. Zudem finden sich Unterschiede der Parameter des Eisenstoffwechsels und des Knochenstoffwechsels. Insbesondere scheint die Morphologie bzw. der Durchmesser der Erythrozyten bei Anwenderinnen verändert zu sein, was sich in dieser Arbeit durch das signifikant erhöhte MCV in den Blutproben äußerte. Die enorme Größe des Kollektivs spricht für einen realen Zusammenhang der Einnahme von Kontrazeptiva auf die Erythropoese und den dadurch veränderten Parametern. Zudem ist das untersuchte Kollektiv wohl weitgehend gesund und leidet nicht unter Erkrankungen, welche solche Veränderungen der Para- 


\section{Diskussion}

meter hervorrufen könnten. Dies begünstigt die Aussagekraft des Ergebnisses. Eine mögliche Erklärung für die Assoziation zwischen oralen Kontrazeptiva und den veränderten hämatologischen Parametern der Anwenderinnen ist das Zusammenspiel von Hormonrezeptoren und den dadurch stimulierten Signalwegen. Anhand früherer Studien in der Literatur konnten hypothetische Wirkungswege erarbeitet werden. Es bleibt unklar, ob es sich um einen direkten Einfluss über Estrogen oder einen anderen indirekten Einflussweg auf die Erythropoese handelt. Es wurde bereits ein indirekter Einfluss auf die Zellproliferation über Vitamin D und Vitamin B 12 festgestellt (Narayanan et al. 2004; Okamoto et al. 2014). Ein Zusammenhang zwischen dem 25(OH)-Vitamin D und der Erythrozyten wurde bereits in früheren Untersuchungen festgestellt (Doudin et al. 2018). 


\section{Zusammenfassung}

\section{$5 \quad$ Zusammenfassung}

In dieser Post-hoc-Analyse wurde der Einfluss oraler Kontrazeptiva auf hämatologische Parameter bei $\mathrm{n}=2775$ weiblichen Adoleszenten im Alter zwischen 13 und 17 Jahren in Deutschland untersucht. Es wurden die Daten aus dem bundesweit repräsentativen Kinderund Jugendgesundheitssurvey (KiGGS) des Robert Koch-Instituts in den Jahren 2003 bis 2006 herangezogen. In der KiGGS-Querschnittstudie wurden standardisierte und gut validierte Verfahren verwendet und es lag ein großer, unvoreingenommener Datensatz aus den Ergebnissen von Selbst- und Fremdbeurteilungsfragebögen vor. Zudem wurden Werte von labor-klinischen Parametern aufgenommen, welche aus Blutproben erhoben wurden. In der deskriptiven Untersuchung konnte festgestellt werden, dass Mädchen im Alter von 13 bis 17 Jahren mit zunehmendem Alter stetig häufiger Kontrazeptiva nutzten, bis hin zu 45\% im letzten Altersjahr. Zudem wendeten Mädchen ohne Migrationshintergrund häufiger Kontrazeptiva an als Migrantinnen $(22,0 \%$ versus 7,5\%; $<<0,001)$. Unabhängig von der Einnahme oraler Kontrazeptiva bestand eine positive Korrelation zwischen dem Serum25(OH)-Vitamin D und MCV ( $\mathrm{r}=0,136 ; \mathrm{p}<0,001)$ bzw. MCH ( $\mathrm{r}=0,047 ; \mathrm{p}=0,043)$. Negativ korrelierte das 25(OH)-Vitamin D hingegen mit den folgenden Parametern: Erythrozytenzahl $(\mathrm{RBC} ; \mathrm{r}=-0,072 ; \mathrm{p}=0,002), \operatorname{MCHC}(\mathrm{r}=-0,111 ; \mathrm{p}<0,001)$, löslicher Transferrinrezeptor (sTfR; $r=-0,123 ; p<0,001)$ und Vitamin $B_{12}(r=-0,058 ; p=0,014)$. In der multivariaten Regressionsanalyse waren die Parameter Eisen $(\beta=0,022 ; 95 \%$ - CI $=1,001-$ $1,045 ; \mathrm{p}=0,043), \mathrm{sTfR}(\beta=-3,472 ; 95 \%-\mathrm{CI}=0,003-0,282 ; \mathrm{p}=0,002)$ und MCV $(\beta=-$ 0,053; 95\%-CI $=0,907-0,992 ; \mathrm{p}=0,022)$ signifikante Prädiktoren für die Vorhersage der Anwendung von Kontrazeptiva. In einem weiteren Regressionsmodell, welches additiv mit den Lipiden als konfundierende Variablen adjustiert war, konnte ein signifikanter Unterschied des Parameters sTfR $(\beta=-3,397 ; 95 \%-C I=0,003--0,324 ; \mathrm{p}=0,003)$ bei Anwenderinnen und Nichtanwenderinnen festgestellt werden. Die Ergebnisse dieser Analyse könnten auf einen hormonellen Einfluss durch den Gebrauch von oralen Antikonzeptiva auf die Erythropoese hindeuten. Weitere epidemiologische Untersuchungen in unabhängigen Kohorten und zusätzliche experimentelle Studien mit biochemischer Methodik sind nötig, um die genannten Beobachtungen zu bestätigen und vermutete Wirkmechanismus zu identifizieren. 


\section{Summary}

\section{Summary}

In this post-hoc analysis, the influence of oral contraceptives on haematological parameters in $\mathrm{n}=2775$ female German adolescents aged between 13 and 17 years was examined. Data from the nationwide representative Child and Youth Health Survey (KiGGS) of the Robert Koch institute in the years 2003 to 2006 were used. The cross-sectional KiGGS study used standardized and well-validated procedures and provided a large, unbiased data including self- and parents-rated assessment questionnaires. In addition, values of clinical laboratory parameters were recorded, which were collected from blood samples. In the descriptive analysis, it was found that girls aged 13 to 17 increasingly used contraceptives with age, up to $45 \%$ in the last birth year. In addition, girls without a migrant background showed a higher frequency of contraceptive use compared to migrants $(22.0 \%$ versus $7.5 \%, \mathrm{p}<0.001)$. Regardless of oral contraceptive use, there was a positive correlation between serum $25(\mathrm{OH})$ vitamin D and MCV ( $\mathrm{r}=0.136, \mathrm{p}<0.001)$ and $\mathrm{MCH}(\mathrm{r}=0.047, \mathrm{p}=0.043)$, respectively. In contrast, serum $25(\mathrm{OH})$ vitamin D correlated negatively with the following parameters: RBC $(\mathrm{r}=-0.072, \mathrm{p}=0.002), \operatorname{MCHC}(\mathrm{r}=-0.111, \mathrm{p}<0.001), \mathrm{sTfR}(\mathrm{r}=-0.123, \mathrm{p}<0.001)$ and vitamin $\mathrm{B}_{12}(\mathrm{r}=-0.058, \mathrm{p}=0.014)$. In multivariate regression analysis, iron $(\beta=0.022 ; 95 \%$ $\mathrm{CI}=1.001-1.045 ; \mathrm{p}=0.043)$, soluble transferrin receptor $(\mathrm{sTfR} ; \beta=-3.472 ; 95 \%-\mathrm{CI}=$ $0.003-0.282 ; \mathrm{p}=0.002)$ and $\mathrm{MCV}(\beta=-0.053 ; 95 \%-\mathrm{CI}=0.907-0.992 ; \mathrm{p}=0.022)$ were all significant predictors of contraceptive use in separate models. In another regression model, which was additively adjusted with the lipids as confounders, a significant difference in the parameter soluble transferrin receptor (sTfR; $\beta=-3.397 ; 95 \%-C I=0.003--0.324 ; p$ $=0.003)$ was detected. The results of this work suggest a hormonal influence of the use of oral contraceptives on erythropoiesis. Further epidemiological studies in independent cohorts and additional experimental studies with biochemical methodology are needed to confirm the above observations and to identify the suspected mechanism of action. 


\section{Literaturverzeichnis}

\section{$7 \quad$ Literaturverzeichnis}

Abdel-Hafiz H, Takimoto GS, Tung L, Horwitz KB (2002): The inhibitory function in human progesterone receptor $\mathrm{N}$ termini binds SUMO-1 protein to regulate autoinhibition and transrepression. J Biol Chem 277, 33950-6

Anderson KE, Bodansky O, Kappas A (1976): Effects of oral contraceptives on vitamin metabolism. Adv Clin Chem 18, 247-87

Arias-Loza PA, Kreissl MC, Kneitz S, Kaiser FR, Israel I, Hu K, Frantz S, Bayer B, Fritzemeier KH, Korach KS, Pelzer T (2012): The estrogen receptor- $\alpha$ is required and sufficient to maintain physiological glucose uptake in the mouse heart. Hypertension 60, 1070-7

Bain DL, Franden MA, McManaman JL, Takimoto GS, Horwitz KB (2000): The N-terminal region of the human progesterone A-receptor. Structural analysis and the influence of the DNA binding domain. J Biol Chem $\underline{275}, 7313-20$

Bain DL, Franden MA, McManaman JL, Takimoto GS, Horwitz KB (2001): The N-terminal region of human progesterone B-receptors: biophysical and biochemical comparison to A-receptors. J Biol Chem $\underline{276}$, 23825-31

Barros RP, Machado UF, Warner M, Gustafsson JA (2006): Muscle GLUT4 regulation by estrogen receptors ER $\beta$ and ER $\alpha$. Proc Natl Acad Sci USA $\underline{103}, 1605-8$

Berenson AB, Rahman M (2012): Effect of hormonal contraceptives on vitamin $B_{12}$ level and the association of the latter with bone mineral density. Contraception $\underline{86}, 481-7$

Björnström L, Kilic E, Norman M, Parker MG, Sjöberg M (2001): Cross-talk between Stat5b and estrogen receptor- $\alpha$ and $-\beta$ in mammary epithelial cells. J Mol Endocrinol 27, 93-106

Bland R (2000): Steroid hormone receptor expression and action in bone. Clin Sci (Lond) $\underline{98}, 217-40$

Bloemenkamp KWM, Rosendaal FR, Helmerhorst FM, Büller HR, Vandenbroucke JP (1995): Enhancement by factor $\mathrm{V}$ Leiden mutation of risk of deep-vein thrombosis associated with oral contraceptives containing a third-generation progestogen. Lancet $\underline{346}, 1592-6$

Bopassa JC, Eghbali M, Toro L, Stefani E (2010): A novel estrogen receptor GPER inhibits mitochondria permeability transition pore opening and protects the heart against ischemia-reperfusion injury. Am J Physiol Heart Circ Physiol 298, 16-23

BZgA (Hrsg.): Jugendsexualität. Repräsentative Wiederholungsbefragung von 14- bis 17-Jährigen und ihren Eltern. Rangfolge der 10 am häufigsten angewendeten Arzneimittelgruppen in den letzten 7 Tagen vor der Befragung. BZgA, 2006 Köln 


\section{Literaturverzeichnis}

Chambliss KL, Wu Q, Oltmann S, Konaniah ES, Umetani M, Korach KS, Thomas GD, Mineo C, Yuhanna IS, Kim SH et al. (2010): Non-nuclear estrogen receptor $\alpha$ signaling promotes cardiovascular protection but not uterine or breast cancer growth in mice. J Clin Invest $\underline{120}$, 2319-30

Chung TH, Wang SM, Wu JC (2004): 17ß-estradiol reduces the effect of metabolic inhibition on gap junction intercellular communication in rat cardiomyocytes via the estrogen receptor. J Mol Cell Cardiol 37, 1013-22

Croft P, Hannaford PC (1989): Risk factors for acute myocardial infarction in women: evidence from the Royal College of General Practitioners' oral contraception study. BMJ 298, 165-8

Daniel AR, Qiu M, Faivre EJ, Ostrander JH, Skildum A, Lange CA (2007): Linkage of progestin and epidermal growth factor signaling: phosphorylation of progesterone receptors mediates transcriptional hypersensitivity and increased ligand-independent breast cancer cell growth. Steroids $\underline{72}, 188-201$

DGGG (2004): Empfängnisverhütung; Familienplanung in Deutschland. Arbeitsgemeinschaft der wissenschaftlichen medizinischen Fachgesellschaften. AWMF-Leitlinien Register Nr. 015/015

Deschamps AM, Murphy E (2009): Activation of a novel estrogen receptor, GPER, is cardioprotective in male and female rats. Am J Physiol Heart Circ Physiol 297, 1806-13

Dortschy R, Schaffrath Rosario A, Scheidt-Nave C, Thierfelder W, Thamm M, Gutsche J, Markert A: Beiträge zur Gesundheitsberichterstattung des Bundes: Bevölkerungsbezogene Verteilungswerte ausgewählter Laborparameter aus der Studie zur Gesundheit von Kindern und Jugendlichen in Deutschland (KiGGS). Robert Koch-Institut, Berlin 2009

Doudin A, Becker A, Rothenberger A, Meyer T (2018): Relationship between serum 25-hydroxyvitamin D and red blood cell indices in German adolescents. Eur J Pediatr 177, 583-91

Du Y, Rosner BM, Knopf H, Schwarz S, Dören M, Scheidt-Nave C (2011): Hormonal contraceptive use among adolescent girls in Germany in relation to health behavior and biological cardiovascular risk factors. J Adolesc Health $\underline{48}, 331-7$

Faulds MH, Pettersson K, Gustafsson JA, Haldosén LA (2001): Cross-talk between ERs and signal transducer and activator of transcription 5 is E2 dependent and involves two functionally separate mechanisms. Mol Endocrinol 15, 1929-40

Fehily AM, Dickerson JW, Meade BW, Ellis FR, (1982): Plasma and erythrocyte membrane fatty acids in oral contraceptive users. Clin Chim Acta $\underline{120}, 41-7$ 


\section{Literaturverzeichnis}

Fejes-Toth G, Pearce D, Naray-Fejes-Toth A (1998): Subcellular localization of mineralocorticoid receptors in living cells: effects of receptor agonists and antagonists. Proc Natl Acad Sci USA $\underline{95}, 2973-8$

Fox EM, Andrade J, Shupnik MA (2009): Novel actions of estrogen to promote proliferation: integration of cytoplasmic and nuclear pathways. Steroids $\underline{74}, 622-7$

Gerstman B, Piper J, Tornita D, Ferguson W, Stadel B, Lundin F (1991): Oral contraceptive estrogen dose and the risk of deep venous thromboembolic disease. Am J Epidemiol 133, 32-7

Giangrande PH, Kimbrel EA, Edwards DP, McDonnell DP (2000): The opposing transcriptional activities of the two isoforms of the human progesterone receptor are due to differential cofactor binding. Mol Cell Biol 20, 3102-15

Goodman R (1997): The Strengths and Difficulties Questionnaire: a research note. J Child Psychol Psychiatry $\underline{38}, 581-6$

Goodman R, Meltzer H, Bailey V (1998): The Strengths and Difficulties Questionnaire: A pilot study on the validity of the self-report version. Eur Child Adolesc Psychiatry $\mathbf{7}, 125-30$

Goodman R, Ford T, Simmons H, Gatward R, Meltzer H (2000): Using the Strengths and Difficulties Questionnaire (SDQ) to screen for child psychiatric disorders in a community sample. Br J Psychiatry $\underline{177}, 534-9$

Gorres BK, Bomhoff GL, Morris JK, Geiger PC (2011): In vivo stimulation of oestrogen receptor $\alpha$ increases insulin-stimulated skeletal muscle glucose uptake. J Physiol $\underline{589}$, 2041-54

Grace E, Emans SJ, Drum DE (1982): Hematological abnormalities in adolescence who take oral contraceptive pills. J Pediatr $\underline{101}, 771-4$

Graham JD, Clarke CL (1997): Physiological action of progesterone in target tissues. Endocr Rev $\underline{18}$, 502-19

Graham JD, Clarke CL (2002): Expression and transcriptional activity of progesterone receptor A and progesterone receptor B in mammalian cells. Breast Cancer Res $\underline{4}, 187-90$

Gronemeyer H (1991): Transcription activation by estrogen and progesterone receptors. Annu Rev Genet $\underline{25}, 89-123$

Gronemeyer H, Meyer ME, Bocquel MT, Kastner P, Turcotte B, Chambon P (1991): Progestin receptors: isoforms and antihormone action. J Steroid Biochem Mol Biol $\underline{40}$, 271-8

Grüne B, Gröger S: Kontrazeption. In: Diedrich K, Holzgreve W, Jonat W, Schultze-Mosgau A, Schneider KTM, Weiss JM (Hrsg.): Gynäkologie und Geburtshilfe. 2. Auflage; Springer, Heidelberg 2007, 123-62 


\section{Literaturverzeichnis}

Han Y, Feng HL, Sandlow JI, Haines CJ (2009): Comparing expression of progesterone and estrogen receptors in testicular tissue from men with obstructive and nonobstructive azoospermia. J Androl $\underline{30}, 127-33$

Haq R, Halupa A, Beattie BK, Mason JM, Zanke BW, Barber DL (2002): Regulation of erythropoietin-induced STAT serine phosphorylation by distinct mitogen-activated protein kinases. J Biol Chem 277, 17359-66

Hart GR, Furniss JL, Laurie D, Durham SK (2006): Measurement of vitamin D status: background, clinical use, and methodologies. Clin Lab $\underline{52}, 335-43$

Heßling A, Bode H (2013): Sexual- und Verhütungsverhalten Jugendlicher und junger Erwachsener, Ausgewählte Ergebnisse von Befragungen der Bundeszentrale für gesundheitliche Aufklärung $(\mathrm{BZgA})$. Bundesgesundheitsblatt Gesundheitsforschung Gesundheitsschutz $\underline{56}$, 184-91

Heneghan AF, Connaghan-Jones KD, Miura MT, Bain DL (2007): Coactivator assembly at the promoter: efficient recruitment of SRC2 is coupled to cooperative DNA binding by the progesterone receptor. Biochemistry $\underline{46}, 11023-32$

Hill AB (1965): The environment and disease: association or causation? Proc R Soc Med $\underline{58}, 295-300$

Hölling H, Kamtsiuris P, Lange M, Thierfelder W, Thamm M, Schlack R (2007): Der Kinder- und Jugendgesundheitssurvey (KiGGS): Studienmanagement und Durchführung der Feldarbeit. Bundesgesundheitsblatt Gesundheitsforschung Gesundheitsschutz 무, 557-66

Hölling H, Schlack R, Kamtsiuris P, Butschalowsky H, Schlaud M, Kurth BM (2012): Die KiGGSStudie. Bundesweit repräsentative Längs- und Querschnittstudie zur Gesundheit von Kindern und Jugendlichen im Rahmen des Gesundheitsmonitorings am Robert Koch-Institut. Bundesgesundheitsblatt Gesundheitsforschung Gesundheitsschutz $\underline{55}$, 836-42

Hsieh YC, Yang S, Choudhry MA, Yu HP, Rue LW III, Bland KI, Chaudry IH (2005): PGC-1 upregulation via estrogen receptors: a common mechanism of salutary effects of estrogen and flutamide on heart function after trauma-hemorrhage. Am J Physiol Heart Circ Physiol 289, $2665-72$

Htun H, Barsony J, Renyi I, Gould DL, Hager GL (1996): Visualization of glucocorticoid receptor translocation and intranuclear organization in living cells with a green fluorescent protein chimera. Proc Natl Acad Sci USA 르, 4845-50

Htun H, Holth LT, Walker D, Davie JR, Hager GL (1999): Direct visualization of the human estrogen receptor $\alpha$ reveals a role for ligand in the nuclear distribution of the receptor. Mol Biol Cell $\underline{10}, 471-86$ 


\section{Literaturverzeichnis}

Jacobsen BM, Schittone SA, Richer JK, Horwitz KB (2005): Progesterone-independent effects of human progesterone receptors (PRs) in estrogen receptor-positive breast cancer: PR isoform-specific gene regulation and tumor biology. Mol Endocrinol $\underline{19}, 574-87$

Kapur R, Chandra S, Cooper R, McCarthy J, Williams DA (2017): Role of p38 and ERK MAP kinase in proliferation of erythroid progenitors in response to stimulation by soluble and membrane isoforms of stem cell factor. Blood $\underline{100}, 1287-93$

Kamtsiuris P, Lange M, Schaffrath-Rosario A (2007a): Der Kinder- und Jugendgesundheitssurvey (KiGGS): Stichprobendesign, Response und Nonresponse- Analyse. Bundesgesundheitsblatt Gesundheitsforschung Gesundheitsschutz $\underline{50}, 547-56$

Kamtsiuris P, Bergmann E, Rattay P, Schlaud M (2007b): Inanspruchnahme medizinischer Leistungen. Ergebnisse des Kinder- und Jugendgesundheitssurveys (KiGGS). Bundesgesundheitsblatt Gesundheitsforschung Gesundheitsschutz 50, 836-50

Kararigas G, Bito V, Tinel H, Becher E, Baczko I, Knosalla C, Albrecht-Kupper B, Sipido KR, RegitzZagrosek V (2012): Transcriptome characterization of estrogen-treated human myocardium identifies myosin regulatory light chain interacting protein as a sex-specific element influencing contractile function. J Am Coll Cardiol $\underline{59}$, 410-7

Kastner P, Krust A, Turcotte B, Stropp U, Tora L, Gronemeyer H, Chambon P (1990): Two distinct estrogen-regulated promoters generate transcripts encoding the two functionally different human progesterone receptor forms A and B. EMBO J $\underline{9}, 1603-14$

Kaya H, Saito T (1985): Effect of progesterone and its $17 \alpha$-hydroxyl derivative on human erythrocyte membrane. Jpn J Pharmacol 모, 299-306

Klasen H, Woerner W, Wolke D, Meyer R, Overmeyer S, Kaschnitz W, Rothenberger A, Goodman R (2000): Comparing the German Versions of the Strengths and Difficulties Questionnaire (SDQ) and the Child Behavior Checklist. Eur Child Adolesc Psychiatry 9, 271-6

Keck C, Tempfer C: Hormonale Kontrazeption. UNI-MED Verlag, Bremen 2003

Knopf H (2007): Arzneimittelanwendung bei Kindern und Jugendlichen. Erfassung und erste Ergebnisse beim Kinder- und Jugendgesundheitssurvey (KiGGS). Bundesgesundheitsblatt Gesundheitsforschung Gesundheitsschutz $\underline{50}, 863-70$

Kuhl H, Taubert HD: Hormonelle Kontrazeption. In: Schneider HPG (Hrsg.): Empfängnisverhütung. Urban \& Schwarzenberg, München 1996, 3-64

Kurth BM (2007): Der Kinder- und Jugendgesundheitssurvey (KiGGS): Ein Überblick über Planung, Durchführung und Ergebnisse unter Berücksichtigung von Aspekten eines Qualitätsmanagements. Bundesgesundheitsblatt Gesundheitsforschung Gesundheitsschutz $\underline{50}$, 533-46 


\section{Literaturverzeichnis}

Lange CA, Richer JK, Shen T, Horwitz KB (1998): Convergence of progesterone and epidermal growth factor signaling in breast cancer. Potentiation of mitogen-activated protein kinase pathways. J Biol Chem $\underline{273}$, 31308-16

Lange M, Kamtsiuris P, Lange C, Schaffrath Rosario A, Stolzenberg H, Lampert T (2007): Messung soziodemographischer Merkmale im Kinder- und Jugendgesundheitssurvey (KiGGS) und ihre Bedeutung am Beispiel der Einschätzung des allgemeinen Gesundheitszustands. Bundesgesundheitsblatt Gesundheitsforschung Gesundheitsschutz 무, 578-89

Larsson G, Milsom I, Lindstedt G, Rybo G (1992): The influence of a low-dose combined oral contraceptive on menstrual blood loss and iron status. Contraception $\underline{46}$, 327-34

Lehmann R, Peek R, Gansfus R: Aspekte der Lernausgangslage von Schülerinnen und Schülern der fünften Klassen an Hamburger Schulen. Behörde für Schule, Jugend und Berufsbildung, Amt für Schule, Hamburg 1997

Leonhardt SA, Boonyaratanakornkit V, Edwards DP (2003): Progesterone receptor transcription and non-transcription signaling mechanisms. Steroids $\underline{68}, 761-70$

Lindberg MK, Moverare S, Skrtic S, Gao H, Dahlman-Wright K, Gustafsson JA, Ohlsson C (2003): Estrogen receptor (ER)- $\beta$ reduces ER $\alpha$-regulated gene transcription, supporting a "ying yang" relationship between ER $\alpha$ and ER $\beta$ in mice. Mol Endocrinol 17, 203-8

Li X, Lonard DM, O'Malley BW (2004): A contemporary understanding of progesterone receptor function. Mech Ageing Dev 125, 669-78

Lonard DM, O'Malley BW (2007): Nuclear receptor coregulators: judges, juries and executioners of cellular regulation. Mol Cell 27, 691-700

Lonard DM, Lanz RB, O'Malley BW (2007): Nuclear receptor coregulators and human disease. Endocr Rev $\underline{28}, 575-87$

Lyons MR, Peterson LR, McGill JB, Herrero P, Coggan AR, Saeed IM, Recklein C, Schechtman KB, Gropler RJ (2013): Impact of sex on the heart's metabolic and functional responses to diabetic therapies. Am J Physiol Heart Circ Physiol 305, 1584-91

Macaigne M, Amouyel P, Isorez-Decocq D, Sinn MC (1995): Biological status of adolescent girls using estrogen-progestins. Contracept Fertil Sex $\underline{9}, 541-4$

Margolis KL, Bonds DE, Rodabough RJ, Tinker L, Phillips LS, Allen C, Bassford T, Burke G, Torrens J, Howard BV, WHI Investigators (2004): Effect of oestrogen plus progestin on the incidence of diabetes in postmenopausal women: results from the Women's Health Initiative Hormone Trial. Diabetologia 47, 1175-87 


\section{Literaturverzeichnis}

McArthur JO, Tang H, Petocz P, Samman S (2013): Biological variability and impact of oral contraceptives on vitamins $\mathrm{B}_{6}, \mathrm{~B}_{12}$ and folate status in women of reproductive age. Nutrients $\underline{5}$, $3634-45$

McDonnell DP, Goldman ME (1994): RU486 exerts antiestrogenic activities through a novel progesterone receptor A form-mediated mechanism. J Biol Chem $\underline{269}$, 11945-9

Menon MP, Fang J, Wojchowski DM (2006): Core erythropoietin receptor signals for late erythroblast development. Blood 107, 2662-72

Mebratu, Y, Tesfaigzi, Y (2009): How ERK1/2 activation controls cell proliferation and cell death: Is subcellular localization the answer? Cell Cycle $\underline{8}, 1168-75$

Mountifield JA (1986): Serum vitamin $B_{12}$ and folate levels in women taking oral contraceptives. Can Fam Physician $\underline{32}, 862-5$

Molenda-Figueira, HA, Murphy SD, Shea KL, Siegal NK, Zhao Y, Chadwick JG Jr, Denner LA, Tetel MJ (2008): Steroid receptor coactivator-1 from brain physically interacts differentially with steroid receptor subtypes. Endocrinology 149, 5272-9

Mote PA, Balleine RL, McGowan EM, Clarke CL (1999): Colocalization of progesterone receptors $\mathrm{A}$ and $\mathrm{B}$ by dual immunofluorescent histochemistry in human endometrium during the menstrual cycle. J Clin Endocrinol Metab 또, 2963-71

Mote PA, Bartow S, Tran N, Clarke CL (2002): Loss of co-ordinate expression of progesterone receptors A and B is an early event in breast carcinogenesis. Breast Cancer Res Treat $\underline{72}, 163-$ 72

Mote PA, Graham JD, Clarke CL (2007): Progesterone receptor isoforms in normal and malignant breast. Ernst Schering Found Symp Proc 1, 77-107

Mulac-Jericevic B, Mullinax RA, DeMayo FJ, Lydon JP, Conneely OM (2000): Subgroup of reproductive functions of progesterone mediated by progesterone receptor-B isoform. Science $\underline{289}, 1751-4$

Mulac-Jericevic B, Lydon JP, DeMayo FJ, Conneely OM (2003): Defective mammary gland morphogenesis in mice lacking the progesterone receptor B isoform. Proc Natl Acad Sci USA 100, 9744-9

Murphy E, Steenbergen C (2014): Estrogen regulation of protein expression and signaling pathways in the heart. Biol Sex Differ $\underline{5}, 6$

Narayanan R, Tovar Sepulveda VA, Falzon M, Weigel NL (2004): The functional consequences of cross-talk between the vitamin D receptor and ERK signaling pathways are cell-specific. J Biol Chem 279, 47298-310 


\section{Literaturverzeichnis}

Naz F, Jyoti S, Akhtar N, Afzal M, Siddique YH (2012): Lipid profile of women using oral contraceptive pills. Pak J Biol Sci $\underline{15}, 947-50$

Neuhauser H, Thamm M (2007): Blutdruckmessung im Kinder- und Jugendgesundheitssurvey (KiGGS). Methodik und erste Ergebnisse. Bundesgesundheitsblatt Gesundheitsforschung Gesundheitsschutz $\underline{50}, 728-35$

Niada S, Giannasi C, Ferreira LM, Milani A, Arrigoni E, Brini AT (2016): 17ß-estradiol differently affects osteogenic differentiation of mesenchymal stem/stromal cells from adipose tissue

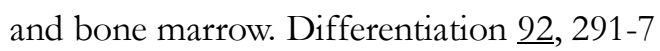

Nilsen J, Brinton RD (2002): Impact of progestins on estrogen-induced neuroprotection: synergy by progesterone and 19-norprogesterone and antagonism by medroxyprogesterone acetate. Endocrinology 143, 205-12

Nilsen J, Brinton RD (2003): Divergent impact of progesterone and medroxyprogesterone acetate (Provera) on nuclear mitogen-activated protein kinase signaling. Proc Natl Acad Sci USA $\underline{100}, 10506-11$

Okamoto M, Tanaka H, Okada K, Kuroda Y, Nishimoto S, Murase T, Yoshikawa H (2014): Methylcobalamin promotes proliferation and migration and inhibits apoptosis of $\mathrm{C} 2 \mathrm{C} 12$ cells via the ERK1/2 signaling pathway. Biochem Biophys Res Com $\underline{443}, 871-5$

Ozawa H (2005): Steroid hormones, their receptors and neuroendocrine system. J Nippon Med Sch $\underline{72}, 316-25$

Pare G, Krust A, Karas RH, Dupont S, Aronovitz M, Chambon P, Mendelsohn ME (2002): Estrogen receptor- $\alpha$ mediates the protective effects of estrogen against vascular injury. Circ Res $\underline{90}$, $1087-92$

Pedram A, Razandi M, Lubahn D, Liu J, Vannan M, Levin ER (2008): Estrogen inhibits cardiac hypertrophy: role of estrogen receptor- $\beta$ to inhibit calcineurin. Endocrinol $\underline{149}, 3361-9$

Petitti DB, Sidney S, Bernstein A, Wolf S, Quesenberry C, Ziel HK (1996): Stroke in users of lowdose oral contraceptives. N Eng J Med $\underline{335}, 8-15$

Prabhushankar R, Krueger C, Manrique C (2014): Membrane estrogen receptors: their role in blood pressure regulation and cardiovascular disease. Curr Hypertens Rep 16, 408

Ravens-Sieberer U (2000): Verfahren zur Erfassung der gesundheitsbezogenen Lebensqualität bei Kindern und Jugendlichen Ein Überblick. Bundesgesundheitsblatt Gesundheitsforschung Gesundheitsschutz 43, 198-209

Ravens-Sieberer U, Bullinger M (1998): Assessing health-related quality of life in chronically ill children with the German KINDL: first psychometric and content analytical results. Qual Life Res 7, 399-407 


\section{Literaturverzeichnis}

Ravens-Sieberer U, Ellert U, Erhart M (2007): Gesundheitsbezogene Lebensqualität von Kindern und Jugendlichen in Deutschland. Eine Normstichprobe für Deutschland aus dem Kinder- und Jugendgesundheitssurvey (KIGGS). Bundesgesundheitsblatt Gesundheitsforschung Gesundheitsschutz $\underline{50}, 810-8$

Revankar CM, Cimino DF, Sklar LA, Arterburn JB, Prossnitz ER (2005): A transmembrane intracellular estrogen receptor mediates rapid cell signaling. Science $\underline{307}, 1625-30$

Rosner B: Einfluss von oralen Kontrazeptiva auf kardiovaskuläre Risikofaktoren bei 14- bis 17-jährigen Mädchen in Deutschland. Med. Mag.-Arb. Hannover 2008

Rothman KJ (1990): No adjustments are needed for multiple comparisons. Epidemiology 1 , 43-6

Rothman KJ, Greenland S, Lash TL: Modern epidemiology. 3. Auflage; Lippincott Williams \& Wilkins, Philadelphia 2008

Samalecos A, Gellersen B (2008): Systematic expression analysis and antibody screening do not support the existence of naturally occurring progesterone receptor (PR)-C, PR-M, or other truncated PR isoforms. Endocrinology 149, 5872-87

Scarpin KM, Graham JD, Mote PA, Clarke CL (2009): Progesterone action in human tissues: regulation by progesterone receptor (PR) isoform expression, nuclear positioning and coregulator expression. Nucl Recept Signal 31, e009

Schenk L, Ellert U, Neuhauser H (2007): Kinder und Jugendliche mit Migrationshintergrund in Deutschland. Bundesgesundheitsblatt Gesundheitsforschung Gesundheitsschutz $\underline{50}, 590-9$

Schmid-Tannwald I, Kluge N: Sexualität und Kontrazeption aus der Sicht der Jugendlichen und ihrer Eltern. BZgA, Köln 2003

Simoncini T, Hafezi-Moghadam A, Brazil DP, Ley K, Chin WW, Liao JK (2000): Interaction of oestrogen receptor with the regulatory subunit of phosphatidylinositol-3-OH kinase. Nature $\underline{407}, 538-41$

Shupnik MA (2004): Crosstalk between steroid receptors and the c-Src-receptor tyrosine kinase pathways: implications for cell proliferation. Oncogene 23, 7979-89

Snow JW, Abraham N, Ma MC, Abbey NW, Herndier B, Goldsmith MA (2002): STAT5 promotes multilineage hematolymphoid development in vivo through effects on early hematopoietic progenitor cells. Blood 99, 95-101

Socolovsky M, Fallon AE, Wang S, Brugnara C, Lodish HF (1999): Fetal anemia and apoptosis of red cell progenitors in Stat5a-/-5b-/- mice: a direct role for Stat5 in Bcl-X(L) induction. Cell $\underline{98}, 181-91$ 


\section{Literaturverzeichnis}

Souberbielle JC, Fayol V, Sault C, Lawson-Body E, Kahan A, Cormier C (2005): Assay-specific decision limits for two new automated parathyroid hormone and 25-hydroxyvitamin D assays. Clin Chem $\underline{51}, 395-400$

Stoecklin E, Wissler M, Schaetzle D, Pfitzner E, Groner B (1999): Interactions in the transcriptional regulation exerted by Stat 5 and by members of the steroid hormone receptor family. J Steroid Biochem Mol Biol 우, 195-204

Stolzenberg H, Kahl H, Bergmann KE (2007): Körpermaße bei Kindern und Jugendlichen in Deutschland. Bundesgesundheitsblatt Gesundheitsforschung Gesundheitsschutz 므, 659-69

Swanepoel AC, Emmerson O, Pretorius E (2017): Effect of progesterone and synthetic progestins on whole blood clot formation and erythrocyte structure. Microsc Microanal 23, 607-17

Takahashi T, Ohmichi M, Kawagoe J, Ohshima C, Doshida M, Ohta T, Saitoh M, Mori-Abe A, Du B, Igarashi H et al. (2005): Growth factors change nuclear distribution of estrogen receptor$\alpha$ via mitogen-activated protein kinase or phosphatidylinositol 3-kinase cascade in a human breast cancer cell line. Endocrinology 146, 4082-9

Tetel MJ, Giangrande PH, Leonhardt SA, McDonnell DP, Edwards DP (1999): Hormone-dependent interaction between the amino- and carboxyl-terminal domains of progesterone receptor in vitro and in vivo. Mol Endocrinol 13, 910-24

Thierfelder W, Bergmann KE, Hellenbrand W, Seher C, Tischer A, Thefeld W (2002): Laboruntersuchungen im Kinder- und Jugendgesundheitssurvey. Gesundheitswesen 64, 23-9

Thierfelder W, Dortschy R, Hinzpeter B, Kahl H, Scheidt-Nave C (2007): Biochemische Messparameter im Kinder- und Jugendgesundheitssurvey (KiGGS). Bundesgesundheitsblatt Gesundheitsforschung Gesundheitsschutz $\underline{50}, 757-70$

Thierfelder W, Dortschy R, Hinzpeter B, Kahl H, Scheidt-Nave C (2008): Verteilung klinisch-chemischer Kenngrößen in der deutschen Bevölkerung im Alter von 0 bis 18 Jahren: Erste Ergebnisse des Kinder- und Jugendgesundheitssurvey (KiGGS). J Lab Med 32, 92-106

Tincello DG, Taylor AH, Spurling SM, Bell SC (2009): Receptor isoforms that mediate estrogen and progestagen action in the female lower urinary tract. J Urol 181, 1474-82

Too CK, Giles A, Wilkinson M (1999): Estrogen stimulates expression of adenine nucleotide translocator ANT1 messenger RNA in female rat hearts. Mol Cell Endocrinol 150, 161-7

Tsuda K, Kinoshita Y, Nishio I (2002): Synergistic role of progesterone and nitric oxide in the regulation of membrane fluidity of erythrocytes in humans: an electron paramagnetic resonance investigation. Am J Hypertens $\underline{15}$, 702-8 


\section{Literaturverzeichnis}

Tsutsumi S, Zhang X, Takata K, Takahashi K, Karas RH, Kurachi H, Mendelsohn ME (2008): Differential regulation of the inducible nitric oxide synthase gene by estrogen receptors 1 and 2. J Endocrinol 199, 267-73

Tung L, Mohamed MK, Hoeffler, JP, Takimoto GS, Horwitz KB (1993): Antagonist-occupied human progesterone B-receptors activate transcription without binding to progesterone response elements and are dominantly inhibited by A-receptors. Mol Endocrinol ㄱ, 1256-65

Tung L, Abdel-Hafiz H, Shen, T, Harvell DM, Nitao LK, Richer JK, Sartorius CA, Takimoto GS, Horwitz KB (2006): Progesterone receptors (PR)-B and -A regulate transcription by different mechanisms: AF-3 exerts regulatory control over coactivator binding to PR-B. Mol Endocrinol 20, 2656-70

Tyagi RK, Lavrovsky Y, Ahn SC, Song CS, Chatterjee B, Roy AK (2000): Dynamics of intracellular movement and nucleocytoplasmic recycling of the ligand-activated androgen receptor in living cells. Mol Endocrinol 14, 1162-74

van Steensel B, Brink M, van der Meulen K, van Binnendijk EP, Wansink DG, de Jong L, de Kloet ER, van Driel R (1995): Localization of the glucocorticoid receptor in discrete clusters in the cell nucleus. J Cell Sci $\underline{108}, 3003-11$

Voss MR, Stallone JN, Li M, Cornelussen RN, Knuefermann P, Knowlton AA (2003): Gender differences in the expression of heat shock proteins: the effect of estrogen. Am J Physiol Heart Circ Physiol 285, 687-92

Vegeto E, Shahbaz MM, Wen DX, Goldman ME, O'Malley BW, McDonnell DP (1993): Human progesterone receptor A form is a cell- and promoter-specific repressor of human progesterone receptor B function. Mol Endocrinol 7, 1244-55

Wallace AM, Gibson S, de la Hunty A, Lamberg-Allardt C, Ashwell M (2010): Measurement of 25hydroxyvitamin D in the clinical laboratory: current procedures, performance characteristics and limitations. Steroids $\underline{75}, 477-88$

Wei LL, Gonzalez-Aller C, Wood WM, Miller LA, Horwitz KB (1990): 5'-Heterogeneity in human progesterone receptor transcripts predicts a new amino-terminal truncated "C"-receptor and unique A-receptor messages. Mol Endocrinol 4, 1833-40

Wei LL, Hawkins P, Baker C, Norris B, Sheridan PL, Quinn PG (1996): An amino-terminal truncated progesterone receptor isoform, PRc, enhances progestin-induced transcriptional activity. Mol Endocrinol 10, 1379-87

Wertalik LF, Metz EN, LoBuglio AF, Balcerzak SP (1972): Decreased serum B 12 levels with oral contraceptive use. JAMA $\underline{221}, 1371-4$ 


\section{Literaturverzeichnis}

WHO Collaborative Study of Cardiovascular Disease and Steroid Hormone Contraception (1995a): Venous thromboembolic disease and combined oral contraceptives: results of international multicentre case-control study. Lancet $\underline{346}, 1575-82$

WHO Collaborative Study of Cardiovascular Disease and Steroid Hormone Contraception (1995b): Effect of different progestagens in low oestrogen oral contraceptives on venous thromboembolic disease. Lancet $\underline{346}, 1582-8$

WHO Collaborative Study of Cardiovascular Disease and Steroid Hormone Contraception (1996a): Ischemic stroke and combined oral contraceptives: results of an international, multicentre, case-control study. Lancet $\underline{348}, 498-505$

WHO Collaborative Study of Cardiovascular Disease and Steroid Hormone Contraception (1996b): Hemorrhagic stroke, overall stroke, and combined oral contraceptives: results of an international, multicentre, case-control study. Lancet $\underline{348}, 505-10$

WHO Collaborative Study of Cardiovascular Disease and Steroid Hormone Contraception (1997): Acute myocardial infarction and combined oral contraceptives: results of an international, multicentre, case-control study. Lancet $\underline{349}, 1202-9$

WHO (1998): Cardiovascular Disease and Steroid Hormone Contraception: report of a WHO Scientific Group. World Health Organ Tech Rep Ser 국, 1-89

Winkler J, Stolzenberg H (1999): Der Sozialschichtindex im Bundes-Gesundheitssurvey. Gesundheitswesen $\underline{61 \text { Suppl 2 }}, 178-83$

Wen DX, Xu YF, Mais DE, Goldman ME, McDonnell DP (1994): The A and B isoforms of the human progesterone receptor operate through distinct signaling pathways within target cells. Mol Cell Biol 14, 8356-64

Yan L, Ge H, Li H, Lieber SC, Natividad F, Resuello RR, Kim SJ, Akeju S, Sun A, Loo K et al. (2004): Gender-specific proteomic alterations in glycolytic and mitochondrial pathways in aging monkey hearts. J Mol Cell Cardiol $\underline{37}, 921-9$

Yu W, Dahl G, Werner R (1994): The connexin43 gene is responsive to oestrogen. Proc Biol Sci 255, $125-32$

Zhao J, Imbrie GA, Baur WE, Iyer LK, Aronovitz MJ, Kershaw TB, Haselmann GM, Lu Q, Karas RH (2012): Estrogen receptor-mediated regulation of microRNA inhibits proliferation of vascular smooth muscle cells. Arterioscler Thromb Vasc Biol $\underline{33}$, 257-65

Zhu Y, Bian Z, Lu P, Karas RH, Bao L, Cox D, Hodgin J, Shaul PW, Thoren P, Smithies O, Gustafsson JA, Mendelsohn ME (2002): Abnormal vascular function and hypertension in mice deficient in estrogen receptor $\beta$. Science $\underline{295}$, 505-8 


\section{Teilpublikation}

Teile dieser Dissertation wurden bereits im Journal für Quality of Life Research des Springer Verlags publiziert.

Lewandowski SK, Duttge G, Meyer T (2020): Quality of life and mental health in adolescent users of oral contraceptives. Results from the nationwide, representative German Health Interview and Examination Survey for Children and Adolescents (KiGGS). Qual Life Res

https://doi.org/10.1007/s11136-020-02456-y 


\section{Danksagung}

Mein besonderer Dank gilt Prof. Dr. mult. Thomas Meyer für die Überlassung des Dissertationsthemas. Den Erfolg dieser Arbeit verdanke ich vor allem seinem Interesse an meiner Arbeit, den wissenschaftlichen Anregungen seinerseits sowie seiner geduldigen Ausdauer und seiner ständigen Bereitschaft zum Diskurs. Weiterhin möchte ich meinen Dank für das mir entgegengebrachte Vertrauen sowie die hervorragende wissenschaftliche Betreuung aussprechen.

Überdies bedanke ich mich bei Herrn Prof. Dr. Nicolai Miosge für die wissenschaftliche Unterstützung und sein Interesse an meiner Arbeit.

Darüber hinaus gilt mein Dank der Universitätsmedizin Göttingen und dem Forschungsteam von Prof. Dr. mult. Thomas Meyer und insbesondere Louisa Habich. 